NBER WORKING PAPER SERIES

\title{
INTERNATIONAL EVIDENCE ON LONG RUN MONEY DEMAND
}

\author{
Luca Benati \\ Robert E. Lucas, Jr. \\ Juan Pablo Nicolini \\ Warren Weber \\ Working Paper 22475 \\ http://www.nber.org/papers/w22475 \\ NATIONAL BUREAU OF ECONOMIC RESEARCH \\ 1050 Massachusetts Avenue \\ Cambridge, MA 02138 \\ July 2016
}

We wish to thank Jesus Fernandez-Villaverde, Helmut Luetkepohl, Albert Marcet, Ed Nelson and Pedro Teles for useful discussions. Special thanks to Joao Ayres, and Nicole Gorton, Eva Werner and Junji Yano for invaluable help with the data. Usual disclaimers apply.

At least one co-author has disclosed a financial relationship of potential relevance for this research. Further information is available online at http://www.nber.org/papers/w22475.ack

NBER working papers are circulated for discussion and comment purposes. They have not been peer-reviewed or been subject to the review by the NBER Board of Directors that accompanies official NBER publications.

(C) 2016 by Luca Benati, Robert E. Lucas, Jr., Juan Pablo Nicolini, and Warren Weber. All rights reserved. Short sections of text, not to exceed two paragraphs, may be quoted without explicit permission provided that full credit, including ()$^{\text {notice, }}$ is given to the source. 
International Evidence on Long Run Money Demand

Luca Benati, Robert E. Lucas, Jr., Juan Pablo Nicolini, and Warren Weber

NBER Working Paper No. 22475

July 2016

JEL No. E4,E41

\section{ABSTRACT}

We explore the long-run demand for M1 based on a dataset comprising 31 countries since 1851. In many cases cointegration tests identify a long-run equilibrium relationship between either velocity and the short rate, or M1, GDP, and the short rate. Evidence is especially strong for the United States and the United Kingdom over the entire period since World War I, and for highinflation countries such as Israel. For low-inflation countries the data often prefer the specification in the levels of velocity and the short rate originally estimated by Selden (1956) and Latané (1960) to either the log-log, or the semi-log ones. This is especially clear for the United States.

Luca Benati

Department of Economics

University of Bern

Schanzeneckstrasse 1

CH-3001 Bern, SWITZERLAND

luca.benati@vwi.unibe.ch

Robert E. Lucas, Jr.

Department of Economics

The University of Chicago

1126 East 59th Street

Chicago, IL 60637

and NBER

relucas@midway.uchicago.edu
Juan Pablo Nicolini

FRB Minneapolis

and Universidad Di Tella

juanpa@minneapolisfed.org

Warren Weber

Federal Reserve Bank of Atlanta

wew@webereconomics.com

A online appendix is available at http://www.nber.org/data-appendix/w22475 


\section{Introduction}

The idea that the quantity of money in an economy can be measured and analyzed with some accuracy, and that changes in this quantity can be related in systematic ways to changes in interest rates, output and prices has had a long but checkered history. The postwar work of Friedman, Schwartz, Brunner, Meltzer, and others led to a common vocabulary for different definitions of money, and well-documented data sets covering many countries over long time periods. Theoretical models proposed by Baumol, Tobin and others described well how changes in the money supply affect other variables, and their predictions conformed well to evidence, at least at the low frequencies. Yet, over recent decades many economists have come to the view that monetary aggregates convey no useful information, and have turned to macroeconomic models in which measures of money do not appear at all. One driver of this change was the alleged instability of the relationship between these macroeconomic series.

Our own conclusions in this paper are almost an exact opposite of this widespread view. We review the evidence on empirical money demand functions, using annual data on money ( $M_{1}$, for us), nominal GDP, and short term interest rates from 31 countries over periods that range in some cases to over 100 years. We find remarkable stability in long run money demand behavior in many countries, and an equally surprising sameness across different countries. In some cases of instability, anomalies have straightforward explanations. We describe these cases, and others that are less easy to dismiss, in some detail below.

In Section 2 we develop a generalized version of the Baumol-Tobin model that will guide our empirical investigation. We set up the model and then work out its main predictions. We draw the conclusions described above in two steps. The first is described in Section 3, where we simply plot the implied predictions of a particular case of the model against the data for all countries we have. We find this informal visual evidence quite remarkable. The second is described in Sections 4 to 8, were we describe the econometric analysis of this evidence, based on cointegration methods, and we provide formal statistical tests that forcefully support the hypothesis of a stable long run money demand.

\section{A Model of Money Demand}

We begin by developing a simple model that will guide our empirical investigation. We study a labor-only, representative agent economy with uncertainty in which making transactions is costly. We let $s_{t}$ be the state at time $t$, and let $s^{t}=\left\{s_{0}, s_{1}, \ldots, s_{t}\right\}$. The preferences of the representative agent are

$$
E_{0} \sum_{t=0}^{\infty} \beta^{t} U\left(x\left(s^{t}\right)\right)
$$


where $x\left(s^{t}\right)$ is his consumption given history up through date $t$, and the function $U$ is differentiable, increasing and concave. The goods production technology is given by

$$
y\left(s^{t}\right)=x\left(s^{t}\right)=z\left(s^{t}\right) l\left(s^{t}\right),
$$

where $l\left(s^{t}\right)$ is time devoted to the production of the consumption good and $z\left(s^{t}\right)$ is an exogenous stochastic process. The agent is endowed in each period with a unit of time, with $l\left(s^{t}\right)$ allocated to goods production and $1-l\left(s^{t}\right)$ used to carry out transactions.

We assume that households choose the number $n$ of 'trips to the bank' in the manner of the classic Baumol-Tobin (BT) model. At the beginning of a period, a household begins with some nominal wealth that can be allocated to the transactional asset $M\left(s^{t}\right)$, or to non-transactional assets, risk-free government bonds or other statecontingent assets $Q\left(s^{t}, s_{t+1}\right)$. During the first of the $n$ subperiods, one member of the household uses money to buy consumption goods. During this same initial sub-period another member of the household produces and sells goods in exchange for money. At the end of the subperiod, producers transfer to the bank the proceeds from their transactions. The situation at the beginning of the second subperiod thus replicates exactly the situation at the beginning of the first. This process is repeated $n$ times during the period. The choice of this variable $n$ will be the only economically relevant decision made by households. Purchases over a period are then subject to a cash in advance constraint

$$
P\left(s^{t}\right) x\left(s^{t}\right) \leq M\left(s^{t}\right) n\left(s^{t}\right) .
$$

BT assumed that the cost of carrying out these transactions increases linearly in the number of trips. We will consider this case here, and also allow for other forms for this cost function. Specifically, we describe the total cost of making transactions, measured in units of time, by a non-negative, increasing and smooth function $\theta\left(n\left(s^{t}\right), \nu\left(s^{t}\right)\right)$, where $\nu\left(s^{t}\right)$ is an exogenous stochastic process. The variable $\nu\left(s^{t}\right)$ thus introduces some unobserved randomness into the model. This is essential to motivate the econometric analysis that is the core of the paper. It can be interpreted as changes over time in the technology to adjust portfolios available to households. We assume that $\theta\left(0, \nu\left(s^{t}\right)\right)=0$, so the time involved in no trips to the banks is zero.

Equilibrium in the labor market then implies that

$$
1=l\left(s^{t}\right)+\theta\left(n\left(s^{t}\right), \nu\left(s^{t}\right)\right)
$$

and the equality of production and consumption implies

$$
x\left(s^{t}\right)=z\left(s^{t}\right)\left(1-\theta\left(n\left(s^{t}\right), \nu\left(s^{t}\right)\right)\right) .
$$

The real wage is equal to $z\left(s^{t}\right)$ and the nominal wage is $z\left(s^{t}\right) P\left(s^{t}\right)$.

Note that the only resources not used for production are the ones described by the function $\theta\left(n\left(s^{t}\right), \nu\left(s^{t}\right)\right){ }^{1}$ Thus $\theta\left(n\left(s^{t}\right), \nu\left(s^{t}\right)\right)$ amounts to time taken away from the

\footnotetext{
${ }^{1}$ We have referred to 'banks', but we are implicitly assuming that their operations do not require the use of labor. This assumption is inessential and made for simplicity.
} 
production of final goods, the only relevant component of utility. Optimal monetary policy would try to minimize the term $\theta\left(n\left(s^{t}\right), \nu\left(s^{t}\right)\right)$, ideally, setting $n\left(s^{t}\right)$ as close to zero as possible. The term $\theta\left(n\left(s^{t}\right), \nu\left(s^{t}\right)\right)$ is thus directly associated with the welfare cost of transactions, which will clearly depend on monetary policy.

At the beginning of each period, an agent starts with nominal wealth $W\left(s^{t}\right)$, which can be allocated to $M\left(s^{t}\right)$, interest bearing bonds, $B\left(s^{t}\right)$, or state-contingent assets $Q\left(s^{t}, s_{t+1}\right)$. Let $P^{Q}\left(s^{t}, s_{t+1}\right)$ be the price of an Arrow-Debreu security, bought at $t$ in state $s^{t}$, which pays off one unit of money in state $s_{t+1}$. The agent's allocation of these assets is then restricted by

$$
M\left(s^{t}\right)+B\left(s^{t}\right)+\sum_{s_{t+1}} Q\left(s^{t}, s_{t+1}\right) P^{Q}\left(s^{t}, s_{t+1}\right) \leq W\left(s^{t}\right) .
$$

It will be convenient to divide both sides by $P\left(s^{t}\right)$, writing

$$
\frac{M\left(s^{t}\right)}{P\left(s^{t}\right)}+\frac{B\left(s^{t}\right)}{P\left(s^{t}\right)}+\sum_{s_{t+1}} \frac{Q\left(s^{t}, s_{t+1}\right)}{P\left(s^{t+1}\right)} \frac{P\left(s^{t+1}\right)}{P\left(s^{t}\right)} P^{Q}\left(s^{t}, s_{t+1}\right) \leq \frac{W\left(s^{t}\right)}{P\left(s^{t}\right)}
$$

which restates agents' choices in units of consumption. If we let $\widetilde{P}^{Q}\left(s^{t}, s_{t+1}\right)$ denote the price of the state contingent asset divided by the probability of the state, we can write this constraint as

$$
m\left(s^{t}\right)+b\left(s^{t}\right)+E\left[q\left(s^{t}, s_{t+1}\right) \pi\left(s^{t}, s_{t+1}\right) \widetilde{P}^{Q}\left(s^{t}, s_{t+1}\right)\right] \leq \omega\left(s^{t}\right),
$$

where lower case letters are real values and where $\pi\left(s^{t}, s_{t+1}\right) \equiv P\left(s^{t+1}\right) / P\left(s^{t}\right)$ denotes the gross inflation rate between period $t$ in sate $s^{t}$ and period $t+1$ in state $\left(s^{t}, s_{t+1}\right)$.

We treat the gross nominal return on short term bonds, $R\left(s^{t}\right)$, as an exogenous process determined by monetary policy. ${ }^{2}$ The assumption that the short-term interest rate is determined by policy implies restrictions on the behavior of the growth rate of the money supply, as is well known and as we show in Appendix A.

So far, we have been silent with respect to what our measure of money, $M\left(s^{t}\right)$, accounts for. For the theoretical analysis, we allow for money to pay a nominal return, lower than the one paid by bonds, which we call $R^{m}\left(s^{t}\right)$. As we will show, this is an important aspect of the theory. We explain our choices for both the particular monetary aggregate and its return in detail below, when discussing the empirical analysis.

We can now determine the agent's wealth next period, contingent on the actions taken in the current period and the realization of the exogenous shock $s_{t+1}$. In nominal units, this is

\footnotetext{
${ }^{2}$ When policy is described as a sequence of interest rates, there may be indeterminacy of the price level. Real money balances will however be unique. In this paper we ignore issues regarding the determination of the price level.
} 


$$
\begin{aligned}
W\left(s^{t}, s_{t+1}\right) \leq & M\left(s^{t}\right) R^{m}\left(s^{t}\right)+B\left(s^{t}\right) R\left(s^{t}\right)+Q\left(s^{t}, s_{t+1}\right) \\
& +\left[1-\theta\left(n\left(s^{t}\right), \nu\left(s^{t}\right)\right)\right] z\left(s^{t}\right) P\left(s^{t}\right)+\tau\left(s^{t}, s_{t+1}\right) P\left(s^{t+1}\right)-P\left(s^{t}\right) x\left(s^{t}\right),
\end{aligned}
$$

where $\tau\left(s^{t}, s_{t+1}\right)$ is the real value of the monetary transfer the government makes to the representative agent. Dividing by the price level $P\left(s^{t+1}\right)$, we obtain

$$
\begin{aligned}
\omega\left(s^{t}, s_{t+1}\right) \leq & \frac{m\left(s^{t}\right) R^{m}\left(s^{t}\right)+b\left(s^{t}\right) R\left(s^{t}\right)}{\pi\left(s^{t}, s_{t+1}\right)}+q\left(s^{t}, s_{t+1}\right) \\
& +\frac{\left[1-\theta\left(n\left(s^{t}\right), \nu\left(s^{t}\right)\right)\right] z\left(s^{t}\right)-x\left(s^{t}\right)}{\pi\left(s^{t}, s_{t+1}\right)}+\tau\left(s^{t}, s_{t+1}\right) .
\end{aligned}
$$

Finally, the cash in advance constraint can be written in real terms as

$$
x\left(s^{t}\right) \leq m\left(s^{t}\right) n\left(s^{t}\right) .
$$

We now consider the decision problem of a single, atomistic agent who takes as given the prices $\widetilde{P}^{Q}\left(s^{t}, s_{t+1}\right)$, the inflation rate $\pi\left(s^{t}, s_{t+1}\right)$, the interest rate $R\left(s^{t}\right)$, the real wage $z\left(s^{t}\right)$ and the shock $\nu\left(s^{t}\right)$. Given the initial wealth $\omega\left(s^{t}\right)$, this agent chooses his consumption $x\left(s^{t}\right)$, the number of bank trips $n\left(s^{t}\right)$, and the assets $m\left(s^{t}\right), b\left(s^{t}\right)$, and $q\left(s^{t}, s_{t+1}\right)$ that he chooses to hold. These choices then determine the wealth $\omega\left(s^{t}, s_{t+1}\right)$ that he carries into the next period conditional on $s_{t+1}$. These choices are restricted by equations (1), (2a), and (3).

The Bellman equation describing the decision problem is

$$
\begin{aligned}
V(\omega)= & \max _{x, n, m, b, q\left(s^{\prime}\right)} U(x)-\varepsilon\left[m+b+E\left[q\left(s^{\prime}\right) \pi\left(s^{\prime}\right) \widetilde{P}^{Q}\left(s^{\prime}\right)\right]-\omega\right]-\delta[x-m n] \\
& +\beta E\left[V\left(\frac{m R^{m}+b R+[1-\theta(n)] z-x}{\pi\left(s^{\prime}\right)}+\tau\left(s^{\prime}\right)+q\left(s^{\prime}\right)\right)\right]
\end{aligned}
$$

where, for simplicity, we omitted the dependence of current variables on the state, and where $s^{\prime}$ denotes the future state.

The first order conditions are

$$
\begin{gathered}
x: \quad U^{\prime}(x)=\beta E\left[\frac{V^{\prime}\left(\omega^{\prime}\right)}{\pi\left(s^{\prime}\right)}\right]+\delta \\
n: \quad \delta m=\beta E\left[\frac{V^{\prime}\left(\omega^{\prime}\right)}{\pi\left(s^{\prime}\right)}\right] \theta_{n}(n) z \\
m: \quad \delta n+\beta E\left[\frac{V^{\prime}\left(\omega^{\prime}\right)}{\pi\left(s^{\prime}\right)}\right] R^{m}=\varepsilon \\
b: \quad \beta E\left[\frac{V^{\prime}\left(\omega^{\prime}\right)}{\pi\left(s^{\prime}\right)}\right] R=\varepsilon
\end{gathered}
$$




$$
q\left(s^{\prime}\right): \quad \beta V^{\prime}\left(\omega^{\prime}\right)=\varepsilon \pi\left(s^{\prime}\right) P^{Q}\left(s^{\prime}\right)
$$

and the envelope condition is

$$
V^{\prime}(\omega)=\varepsilon
$$

Note that (6) and (7) imply

$$
\beta E\left[\frac{V^{\prime}\left(\omega^{\prime}\right)}{\pi\left(s^{\prime}\right)}\right]\left(R-R^{m}\right)=\delta n
$$

which combined with (5) yields

$$
\frac{m}{\theta_{n}(n) z}\left(R-R^{m}\right)=n \text {. }
$$

In equilibrium

$$
m=\frac{x}{n}=\frac{z(1-\theta(n))}{n}
$$

so, if we replace the value of $m$ in the previous equation and let $r^{*} \equiv\left(R-R^{m}\right)$, we obtain

$$
r^{*} \equiv\left(R-R^{m}\right)=n^{2} \frac{\theta_{n}(n)}{1-\theta(n)}
$$

which gives an extended squared root formula for the equilibrium value of $n .{ }^{3}$

Note first that, using just sub-indexes to indicate the dependency on the state, the solution for real money balances relative to output is

$$
m\left(r_{t}, \nu_{t}\right)=\frac{M\left(r_{t}^{*}, \nu_{t}\right)}{x\left(r_{t}^{*}, \nu_{t}\right) P\left(r_{t}^{*}, \nu_{t}\right)}=\frac{1}{n\left(r_{t}^{*}, \nu_{t}\right)},
$$

which does not depend on $z_{t}$.

There are several empirical implications of this solution which do not depend on the particular functional form assumed for the function $\theta(n)$ we would like to discuss now. First, the theory implies an income elasticity equal to one. This is the specification we will study for much of the paper. In Appendix G, we allow for a more general specification which does not restrict the income elasticity to be one, and where we are able to test this unitary income elasticity implication. Second, as $\theta\left(n_{t}, \nu_{t}\right)$ is differentiable with a strictly positive derivative, some of its properties are inherited by the function $m\left(r_{t}^{*}, \nu_{t}\right)$. In particular, up to a linear approximation the stochastic properties of $m_{t}$ are inherited from the stochastic properties of $r_{t}^{*}$ and $\nu_{t}$. This has testable implications, as long as $\nu_{t}$ is stationary as we will assume throughout the paper. Specifically, if $r_{t}^{*}$ is stationary, so should be $m_{t}$, while if it is the case that $r_{t}^{*}$ has a unit root, $m_{t}$ should have a unit root too. As it turns out, for the specifications of the function $\theta\left(n_{t}, \nu_{t}\right)$ that we explore in the theory and on the empirical section these properties hold exactly, not only in a linear approximation.

\footnotetext{
${ }^{3}$ The squared root formula is the by now classic solution of the Baumol-Tobin formulation.
} 


\subsection{Analysis of the solution}

As equation (10) makes clear, the equilibrium relationship between real money demand (the inverse of $n$ ) and the spread between the return on bonds and the return on money $\left(r^{*}\right)$ critically depends on the characteristics of the cost function $\theta\left(n_{t}, \nu_{t}\right)$. We now consider three cases that deliver approximations to functional forms which have been used in empirical work, and which we will explore in the following Sections.

The exponential case Consider first the following function

$$
\theta\left(n_{t}, v_{t}\right)=\gamma \nu_{t} n_{t}^{\sigma}
$$

In this case, equation (10) becomes

$$
n_{t}^{\sigma+1} \frac{\sigma \gamma \nu_{t}}{1-\gamma \nu_{t} n_{t}^{\sigma}}=r_{t}^{*}
$$

Note that $\gamma \nu_{t} n_{t}^{\sigma}$ is the cost of inflation in units of time and that $1-\nu_{t} n_{t}$ is time devoted to GDP, so the ratio can be interpreted as the welfare cost of inflation on output. When the interest rate $r_{t}^{*}$ is arbitrarily close to zero, so is the number of trips to the bank $n_{t}$, so the term $\gamma \nu_{t} n_{t}^{\sigma}$ is arbitrarily close to zero, and the denominator in the expression above is equal to one.

For moderate interest rates, the welfare cost is negligible. Still, even for relatively high interest rates, estimates of the welfare cost of inflation are hardly above $4 \%$. Thus, the denominator in the expression above would range from 1 to 0.96 . It therefore seems reasonable to use the approximation $1-\gamma \nu_{t} n_{t}^{\sigma} \simeq 1$ and write the solution as

$$
n_{t}^{\sigma+1} \sigma \gamma \nu_{t} \simeq r_{t}^{*}
$$

Taking logs we then obtain

$$
\ln \sigma \gamma+\ln \nu_{t}+(\sigma+1) \ln n_{t}=\ln r_{t}^{*}
$$

which is the log-log function typically used in the literature. The BT case is the one obtained by assuming that the function $\theta\left(n\left(r_{t}^{*}\right)\right)$ is linear, or $\sigma=1$, which implies an interest rate elasticity of $1 / 2$.

The Selden-Latané specification A less well know specification is obtained for the following cost function

$$
\theta\left(n_{t}, \nu_{t}\right)=b \ln \left(\varepsilon+n_{t}\right)+\frac{e \varepsilon+\nu_{t}}{n_{t}+\varepsilon}-\left(b \ln \varepsilon+\frac{e \varepsilon+\nu_{t}}{\varepsilon}\right)
$$

where the term $\left(b \ln \varepsilon+\frac{e \varepsilon+\nu_{t}}{\varepsilon}\right)$ guarantees that $\theta(0,0)=0$, and $b>e$ so the function is increasing. The function is concave, so it means that the marginal cost of making 
transactions is decreasing with the number of transactions (or, what is the same, decreasing with the nominal interest rate).

In this case the solution is given by

$$
n_{t}^{2} \frac{\frac{1}{\left(n_{t}+\varepsilon\right)^{2}}\left[\left(\varepsilon+n_{t}\right) b-\varepsilon e-\nu_{t}\right]}{1-\theta\left(n_{t}, \nu_{t}\right)}=r_{t}^{*}
$$

If, as before, we proceed with the approximation $1-\theta\left(n, \nu_{t}\right) \simeq 1$, we obtain

$$
\frac{n_{t}^{2}}{\left(n_{t}+\varepsilon\right)^{2}}\left[\left(\varepsilon+n_{t}\right) b-\varepsilon e-\nu_{t}\right] \simeq r_{t}^{*}
$$

Thus, for small values of $\varepsilon$, the solution can be approximated by

$$
n_{t} b-\nu_{t} \simeq r_{t}^{*}
$$

which implies a linear relationship between velocity and the interest rate.

This empirical specification was used by Richard Selden (1956) over half a century ago, and, to the very best of our knowledge, it has been used again in the literature only once, by Henry Allen Latané (1960). The main reason for considering this longforgotten specification is that, as we will discuss in Section 8, for several low-inflation countries - first and foremost, the United States - the data seem to quite clearly prefer it over the traditional log-log one discussed above and the semi-log specification that we discuss next.

The semi-log Finally, consider the following specification

$$
\theta\left(n_{t}, \nu_{t}\right)=-b \frac{\ln \left(\varepsilon+n_{t}\right)}{n_{t}+\varepsilon}-\frac{k+\nu_{t}}{n_{t}+\varepsilon}+\left(b \frac{\ln \varepsilon}{\varepsilon}+\frac{k+\nu_{t}}{\varepsilon}\right)
$$

where again the term in the right-hand side implies $\theta\left(0, \nu_{t}\right)=0$.

In addition, we assume

$$
k+\nu_{t}>b(1-\ln \varepsilon)
$$

so that the function is always increasing in $n_{t}$. This function is also concave as the one before. The main difference between this function and the two studied above is that it asymptotes a constant (the term in parenthesis on the right hand side) as the number of trips grow arbitrarily large.

In this case, the solution is given by

$$
\frac{n_{t}^{2}}{\left(n_{t}+\varepsilon\right)^{2}} \frac{\left[b\left(\ln \left(\varepsilon+n_{t}\right)-1\right)+k+\nu_{t}\right]}{1-\theta\left(n_{t}, \nu_{t}\right)}=r^{*}
$$

If, as before, we ignore the term $1-\theta\left(n, \nu_{t}\right)$, and also consider relatively low values for $\varepsilon$,we obtain a linear relationship between the log of velocity and the interest rate, which corresponds to the well known semi-log specification. 

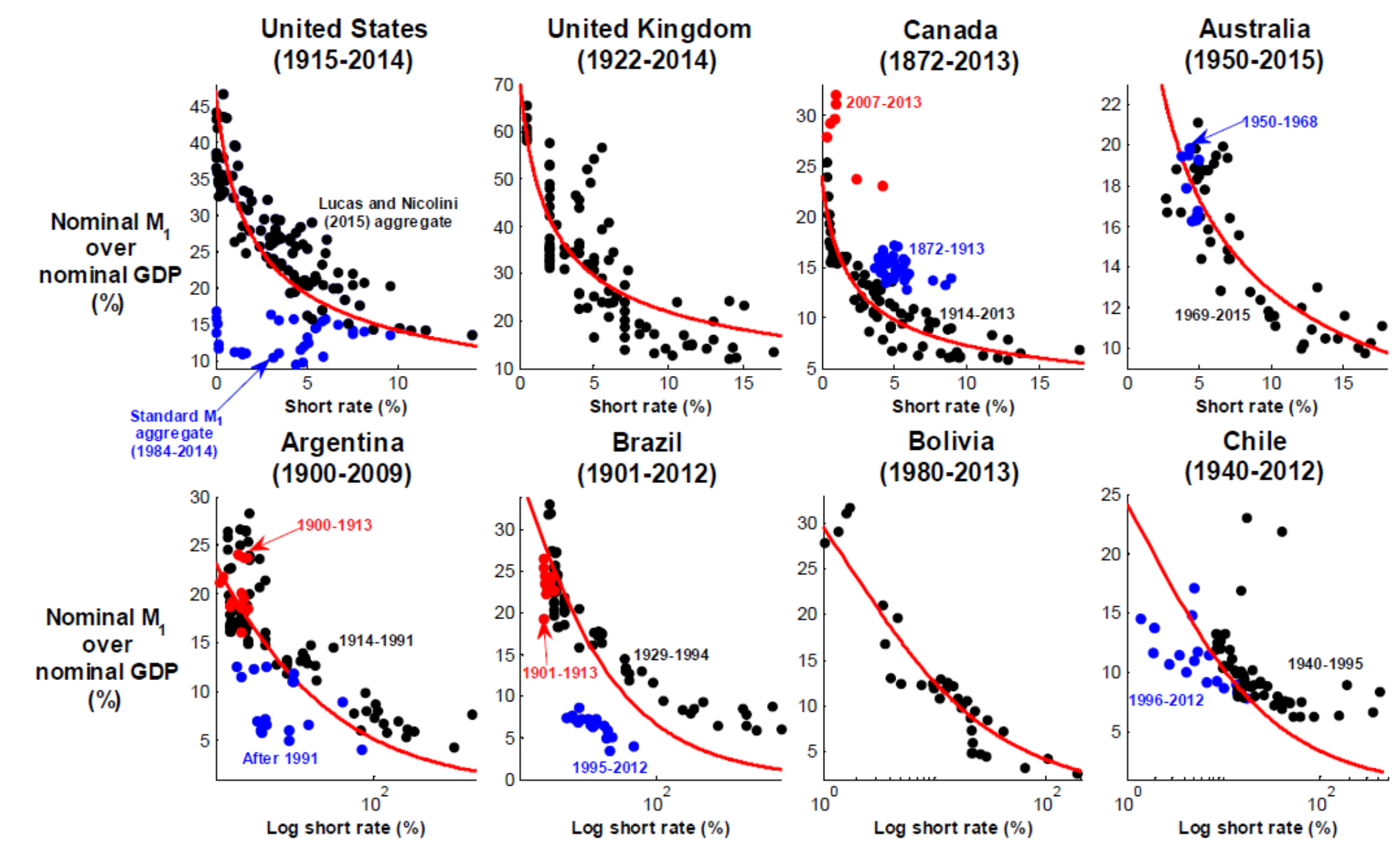

New Zealand

(1934-2004)
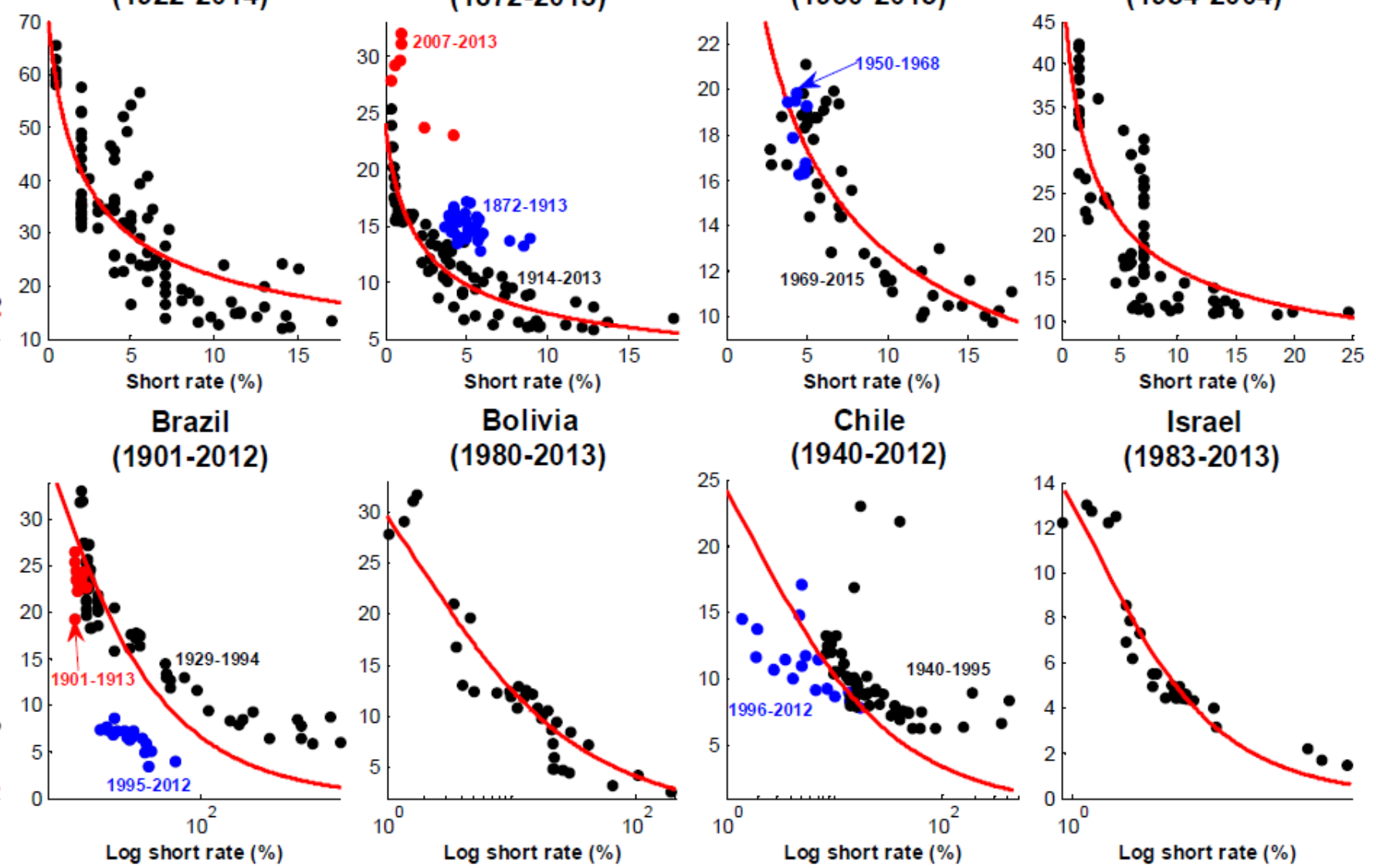

Figure 1 The raw data: short rate, ratio between nominal $\mathrm{M}_{1}$ and nominal GDP, and fitted Baumol-Tobin specification 


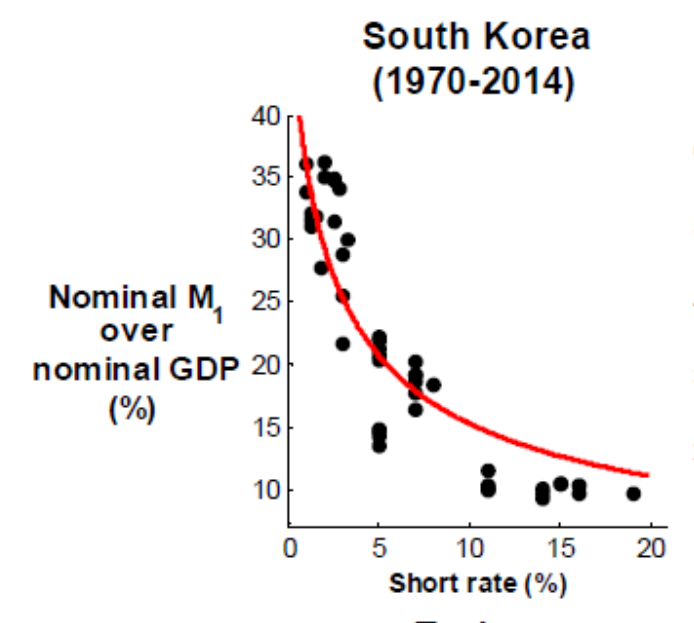

Turkey

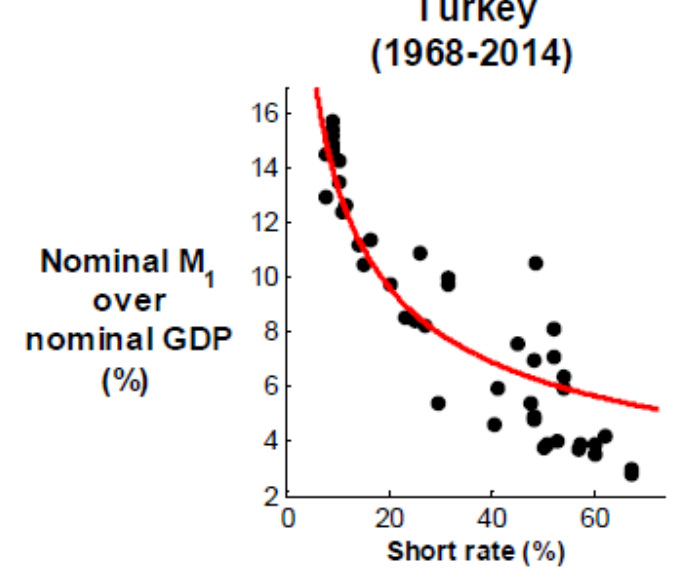

Hong Kong

(1985-2012)

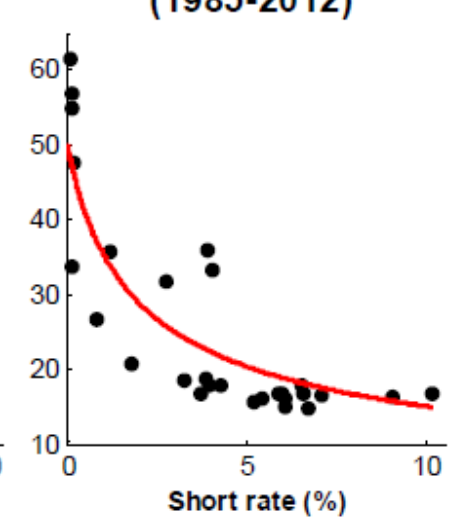

Colombia

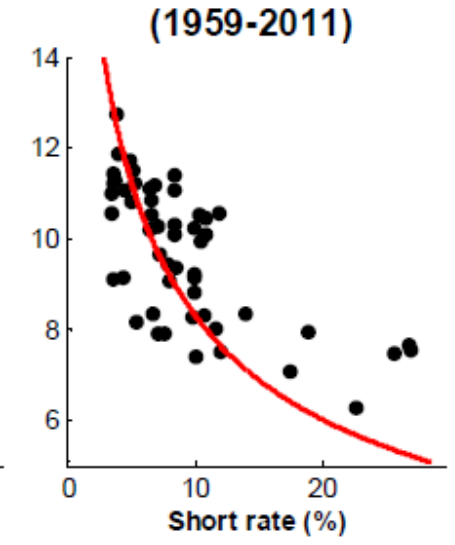

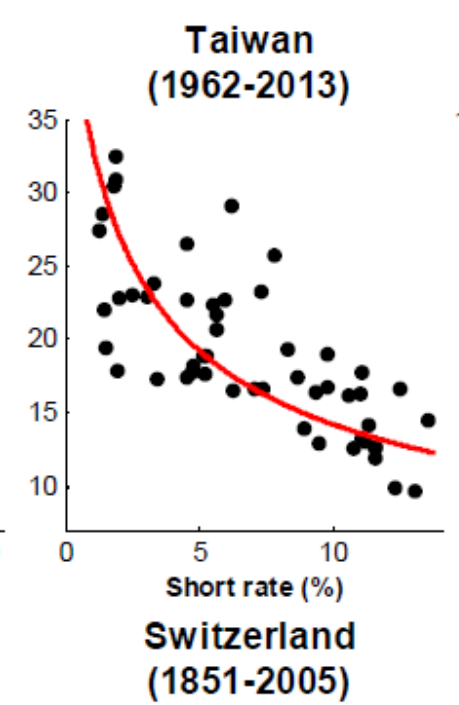
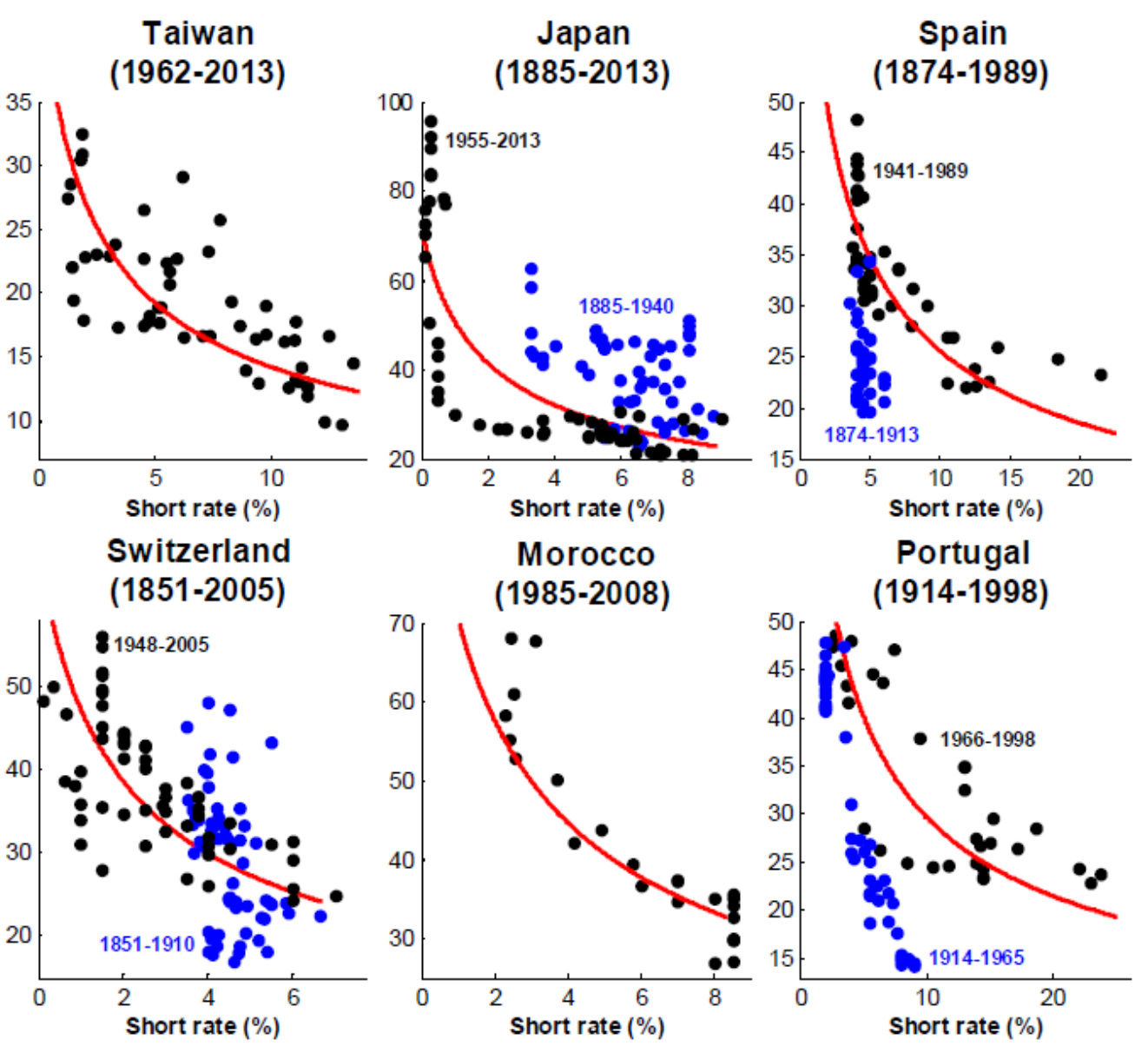

Morocco

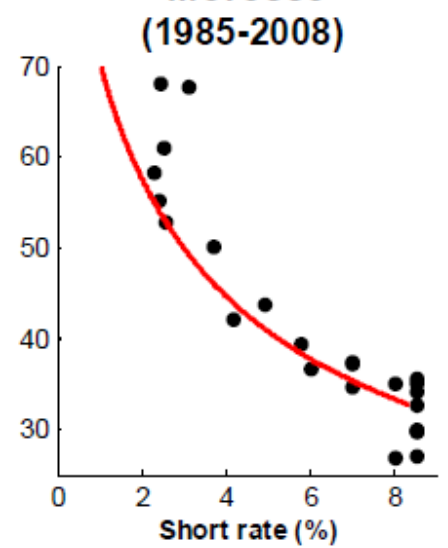

Portugal

(1914-1998)

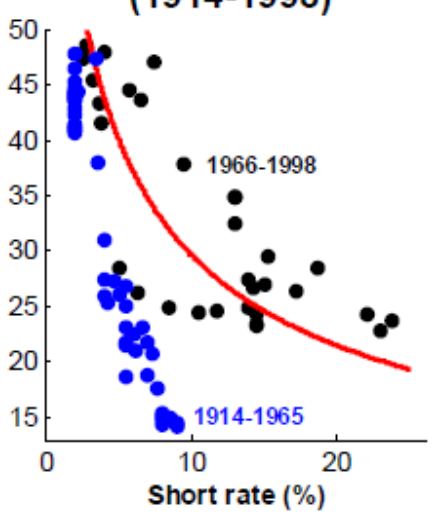

Figure 2 The raw data: short rate, ratio between nominal $\mathrm{M}_{1}$ and nominal GDP, and fitted Baumol-Tobin specification 


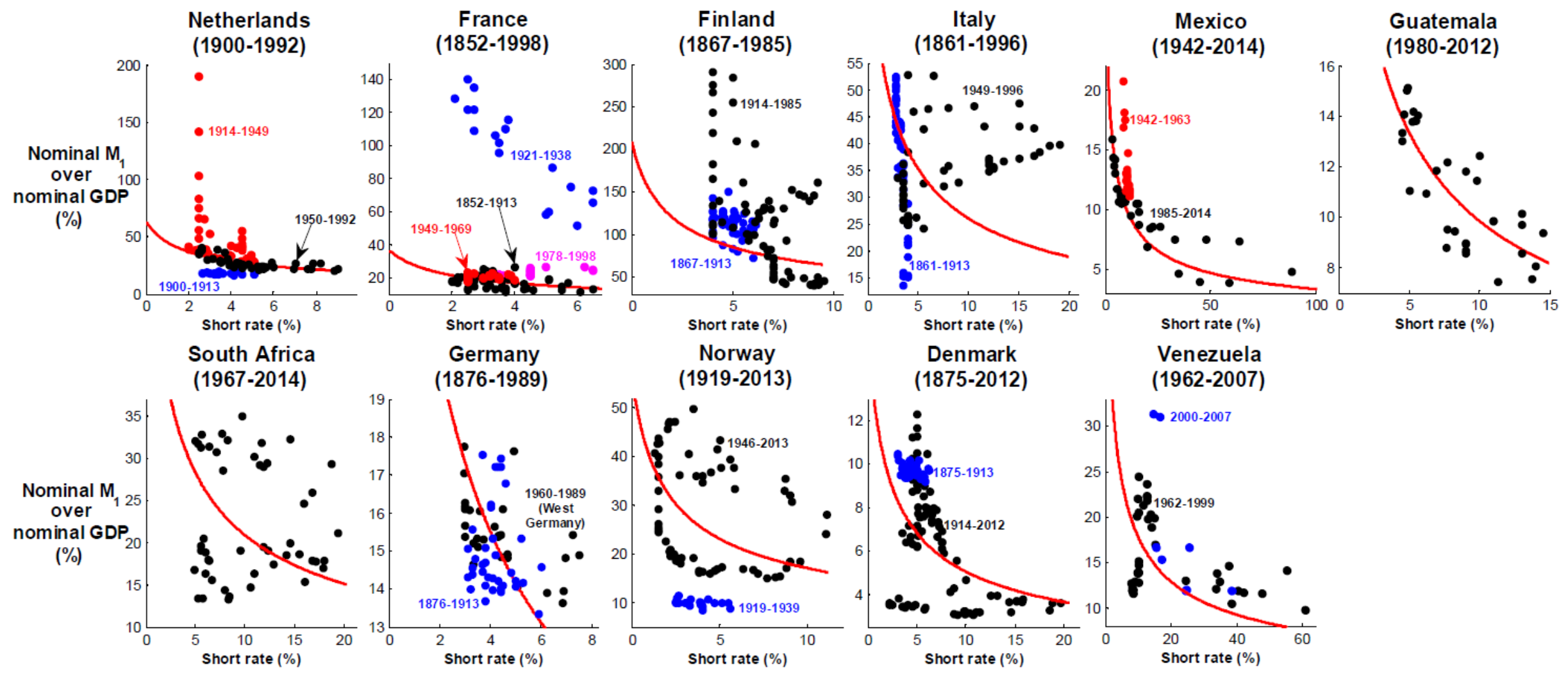

Figure 3 The raw data: short rate, ratio between nominal $\mathrm{M}_{1}$ and nominal GDP, and fitted Baumol-Tobin specification 


\section{A First Look at the Data}

The functional forms considered in the previous Section deliver expressions that can be suitably taken to the data. The formal econometric analysis is presented in the following Sections.

As a first step, in this Section we present the data and compare them to the theory. In order to do so, we will focus on the particular case in which the function $\theta$ is linear in $n$, which corresponds to the $\mathrm{BT}$ case of the log-log specification in which the elasticity is constant and equal to $1 / 2$.

Before doing that, we need to address the issue of how we map our theoretical construct $M_{t}$ to the data. As the model makes clear, the choice of the natural aggregate comes associated to the discussion of the nominal return of that particular aggregate $R^{m}$, since real money balances in the model depend not on the interest rate on bonds, but rather on the spread between that rate and the rate paid by money. Since we do not have data on the interest rate paid by deposits, we choose to work with $M_{1}$, which in most countries includes cash and checking accounts. We will proceed under the assumption that, in the countries we study, checking accounts do not pay interest. Although this is a questionable assumption, it is certainly more appropriate for $M_{1}$ that for broader aggregates, which typically include interest-paying deposits. ${ }^{4}$ As for cash, we follow Alvarez and Lippi (2009) and assume that it entails a negative return, associated with the risk of being lost or stolen. Alvarez and Lippi (2009) estimate the cost of holding cash to be close to $2 \%$ using detailed individual data from Italy. In addition, and to simplify, we assume that cash is about half of total money so that $R^{m}=0.99$.

This is a very important assumption when considering the log-log specification, since it implies that real money balances have a satiation point when the interest rate on bonds is zero, as is the case for some countries in the sample. Indeed, if on the contrary we assume that $R^{m}=0$, the log-log curve goes to infinity as $R \rightarrow 1$. As it can be seen in the evidence we show in this Section, this does not seem to be the case for countries that did experience several periods of almost zero interest rates, like the U.S. and Japan. This assumption also plays an important role in the formal econometric tests, as it often improves the performance of the empirical version of the log-log model. ${ }^{5}$

A caveat must be made explicit. Payments in this model are for household purchases of final goods, so they ignore other transactions where cash and deposits are used, as paying employees and suppliers of intermediate goods and to clear asset ex-

\footnotetext{
${ }^{4}$ It is the case, for instance, that deposits did pay interest in the U.S. after Regulation Q was modified in the early 1980s. It is also the case that some deposits included in $M_{1}$ did pay interest in very high-inflation countries as Argentina and Brazil.

${ }^{5}$ For example, as we will see, for Switzerland for the period 1851-1906, the bootstrapped $p$-values for Johansen's trace and maximum eigenvalue tests of no cointegration between the logarithm of $M_{1}$ velocity and the short rate are 0.160 and 0.113 without the Alvarez-Lippi $1 \%$ correction to the short rate, but they fall to 0.094 and 0.057 with the correction.
} 
changes. We are implicitly treating all these payments - way larger than final goods payments - as proportional to final goods payments. This will require introducing a constant of proportionality as another free parameter in the model, that will be country specific.

In other words, the theory we developed is not aimed at matching levels of $M_{1}$ over GDP, but rather changes on this ratio as the interest rate changes. One way to see our descriptive exercise therefore is as using one free parameter per country, to allow for a country-specific intercept, while the slope will be given by the BT assumption of a linear technology, so that the elasticity is equal to 0.5.

Figures 1 to 3 show scatterplots of the short rate and of the ratio between nominal $M_{1}$ and nominal GDP (that is: the inverse of $M_{1}$ velocity), together with the theoretical curve which corresponds to an approximation of equation (11), namely, the BT case so

$$
\frac{M_{t}^{j}}{Y_{t}^{j}}=\frac{A^{j}}{\left(r_{t}^{j}+1\right)^{1 / 2}}
$$

where $Y_{t}^{j}$ is nominal income at time $t$ in country $j$ and $A^{j}$ is a country-specific constant. As mentioned above, we let $r_{t, j}^{*}=R_{t}^{j}-0.99$, where $R_{t}^{j}$ is the gross short term interest rate at time $t$ in country $j$. In three cases in which we could not find a (sufficiently long) interest rate series, ${ }^{6}$ we use inflation as a proxy for the opportunity cost of money. For a detailed description of the data and the sources for each country, see Appendix B.

The grouping of countries has been largely arbitrary. The first row of Figure 1 contains countries which belonged, at some point, to the Commonwealth. The second row contains countries which experienced very high inflation rates, and the interest rate (i.e., the horizontal) axis, is in a logarithmic scale, due to the magnitudes reached by inflation and interest rates in these countries. In the second row of Figure 1 there are two countries, Argentina and Brazil, for which we highlight the most recent period (since 1991, and since 1995, respectively). These are the two countries in our sample which experienced recurrent periods of very high inflation that lasted over a decade. The blue points correspond to the periods which followed the successful stabilization years, 1991 for Argentina and 1995 for Brazil. These points are highlighted since in both cases, the points following a successful stabilization lie below the theoretical curve that matches the previous period.

Figure 2 reports countries for which the theoretical curve is visually a still decent approximation to the data. The first row of Figure 3 shows countries for which the fit gets worse, ${ }^{7}$ but still there seems to be some relationship between the theory and the data, while the second row of Figure 3 shows countries for which there seems to be no connection between theory and data.

\footnotetext{
${ }^{6}$ Specifically, Mexico, Chile (for the period 1941-2012), and Brazil (for the period 1934-2012).

${ }^{7}$ For the Netherlands, the two World Wars and their aftermaths had been characterized by an anomalous behaviour of velocity, which in some cases reached values ranging between 50 and almost 200. Because of this, in our econometric analysis we will uniquely focus on the period 1950-1992.
} 
In all of these figures, the data are shown with different colors under four circumstances: $(i)$ data for the Gold Standard, up until $1913,{ }^{8}$ are always shown with a different color than that used for subsequent years; $(i i)$ when we have data for non-consecutive sub-periods (this is the case, e.g., for France); (iii) when we have different series for the short rate which cannot be linked (this is the case, e.g., for Venezuela); and (iv) when we want to highlight drastic changes in the relationship between velocity and the short rate (this is the case, e.g., for the Netherlands and Portugal). Finally, for the United States we show with a different color the 'standard' $M_{1}$ aggregate for the period since 1984, in order to highlight how failure to correct $M_{1}$ as in Lucas and Nicolini (2015) leads to the apparent breakdown of the relationship between velocity and the short rate documented by several authors. ${ }^{9}$ In our view, it is remarkable how well this simple theory performs in this first inspection for a large set of countries, in spite of a few apparent failures.

When presenting plots, difficult trade-offs arise. In the main text we opted for these scatterplots. In Figures 1 to 7 of the online appendix we provide an alternative set of plots showing the time series for $M_{1}$ velocity and the short rate, which we have been standardized by dividing the demeaned observations by its standard deviation, in order to better highlight the relationship between them. We find that alternative way of looking at the data equally interesting.

Despite the attractiveness of looking at simple plots, however, the previous analysis has severe limitations. One would like to formally test if, as some of our simple technologies imply, the ratio between real money balances and output inherit a unit root when the short term interest rate exhibits a unit root. We also want to formally test if, indeed, the estimated elasticities are equal to $1 / 2$, as the simple BT specification suggests, when using the log-log specification. In addition, we would also like to let the data indicate which of the three specifications appear to provide a better fit, and therefore learn something regarding the shape of the function $\theta\left(n_{t}, \nu_{t}\right)$. To the extent that the interest rate and velocity exhibit a unit root-which, as we discuss in Section 5, appears to be overwhelmingly the case - we can use cointegration techniques to test whether there is a statistical long-run relationship between the two series, and therefore between the interest rate and the ratio of money balances to GDP. This is a particularly important question, since the distinction between shortrun and long-run has always been at the center of the discussion in empirical studies of the money demand. Cointegration techniques are particularly suited to address this distinction formally, with the advantage that the cointegration residual provides a measure of the short-run deviations.

\footnotetext{
${ }^{8}$ Although we take the Gold Standard to have ended in August 1914, with the outbreak of WWI, in fact, marking the exact date of its end is all but impossible, as Richard Nixon's closing of the 'gold window' in August 1971 was the culmination of a decades-long unravelling process which had started with WWI. (For a fascinating discussion of such progressive unravelling, see e.g. Barro (1982).) We take August 1914 as the date marking the end of the Gold Standard mostly because we regard WWI as the single most important shock to the system.

${ }^{9}$ See, first and foremost, Friedman and Kuttner (1992).
} 
The remainder of the paper contain the formal econometric analysis of our data set.

\section{Main Features of Our Approach}

In this paper we explore the long-run demand for $M_{1}$ via cointegration methods. The main reason is that, as we will show, the hypothesis that the short term interest rate (in levels or in logs) exhibits a unit root is clearly supported by the data for most countries. At the same time, the debate over the stability of the money demand has long made the distinction between the short and the long run. This distinction is totally absent in our model, but a large theoretical literature developed to try to understand the large and sustained deviations of observed real money balances from their theoretical counterparts: the 'short-run' deviations of money demand. ${ }^{10}$

The entire notion of cointegration boils down to the existence of a long-run relationship between series driven by permanent shocks. And those permanent shocks are the main source of identification of the relationship between the short term interest rate and real money balances to output that we will discuss in what follows. The existence of the cointegration relationship implies that, in the long-run, any permanent increase in the interest rate maps into a corresponding permanent decrease in real money balances: the exact amount will be described by the estimated cointegrating vector. In addition, any deviation of the two series from their long-run relationshipi.e., what is technically known as the cointegration residual-is transitory, and it is bound to disappear in the long-run. Accordingly, the persistence of this cointegration residual become an explicit measure of the 'short-run' deviations. This is why, since the early 1990s, cointegration has become the standard approach for searching for a long-run money demand. ${ }^{11}$

It is important to highlight two aspects of our empirical strategy. First, we will perform tests which take either cointegration, or no cointegration, as the null hypothesis (specifically, Shin's, and Johansen's). Although the overwhelming majority of the papers in the literature have been based on Johansen's procedure, there is no reason why - especially within the present context - no cointegration should be regarded as the 'natural null hypothesis'. Rather, it might reasonably be argued that, since we are here searching for the presence of a long-run money demand for transaction purposes, cointegration should be regarded as the natural null, ${ }^{12}$ so that tests should just be based on Shin's (1994) procedure. A key reason for not eschewing Johansen's

\footnotetext{
${ }^{10}$ See Grossman and Weiss (1983) or Rotemberg (1984) for early contributions or Alvarez and Lippi (2015) for a recent one.

${ }^{11}$ See in particular Friedman and Kuttner (1992), Stock and Watson (1993), and Ball (2001).

${ }^{12}$ The reason why, when dealing with a money demand for transaction purposes, cointegration should be regarded as the 'natural null hypothesis' is that basic economic logic suggests that - up to fluctuations in the opportunity cost of money - the nominal quantity of money demanded should be proportional to the nominal volume of transactions (i.e., to nominal GDP).
} 
approach altogether, however, is that, as we document via Monte Carlo simulations, Johansen's procedure exhibits an overall better performance, and it produces more informative results. This is why, in the end, we decided to use both approaches.

Second, we perform our analysis separately for the Gold Standard and for the subsequent period. As it has been extensively documented, ${ }^{13}$ the stochastic properties of inflation in the former period had been radically different from the latter, with inflation being most of the times statistically indistinguishable from white noise. By the Fisher equation, this implies that, unless the natural rate of interest had contained a sizeable permanent component (due, e.g., to permanent shifts in trend productivity growth), nominal interest rates should be expected to have been stationary, too, which would preclude them from being entered in any cointegrated system, or cointegrating regression. ${ }^{14}$ The integration properties of nominal interest rates during the Gold Standard period ought therefore be separately checked, or otherwise we would run the risk of performing cointegration analysis based on a series which had been stationary for a significant portion of the sample period.

In the next section, we study the integration properties of the data, where we show that the presence of unit roots seems very robust. The following one discusses the boostraping procedures that are involved in the cointegration tests and in the estimations procedures. We then discuss the Monte Carlo evidence, that provides measures of the performance of the tests. Finally, we discuss how to interpret the outcome of the tests, in view of the Monte Carlo evidence, before analyzing the results.

\section{$5 \quad$ Integration Properties of the Data}

As previously mentioned, a necessary condition for using cointegration methods is that all series feature a unit root. In this section we therefore briefly summarize the main results from the extensive investigation of the integration properties of the data reported in the online Appendix A.

Although in the main text we will only study bivariate systems with $M_{1}$ velocity and the short-term interest rate, we now discuss the integration properties of all variables, since in the online Appendix E we report estimates of systems including money balances and GDP separately, in order to test the hypothesis of unitary income elasticity.

Tables A.1a-A.1b in the online appendix report, for the series in our dataset, bootstrapped $p$-values for Elliot, Rothenberg, and Stock (1996) tests. ${ }^{15}$ For nominal

\footnotetext{
${ }^{13}$ See Barsky (1987) and Benati (2008).

${ }^{14}$ A key assumption underlying both Johansen's and Shin's cointegration tests is that all of the variables entering either the multivariate system (in the former case), or the single-equation cointegrating regression (in the latter case) are integrated of order one. See Hamilton (1994, very first sentence of p. 636) and Shin (1994, p. 92).

${ }^{15}$ For either series, $p$-values have been computed by bootstrapping 10,000 times estimated
} 
GDP and nominal $M_{1}$, which exhibit obvious trends, the tests are based on models including an intercept and a time trend. ${ }^{16}$ For the short rate and velocity, on the other hand, they are based on models including an intercept, but no time trend. For the short rate, the rationale for not including a time trend is obvious: The notion that nominal interest rates may follow an upward path, ${ }^{17}$ in which they grow over time, is manifestly absurd. ${ }^{18}$ For $M_{1}$ velocity, on the other hand, things are, at first sight, less obvious. The reason for not including a time trend originates from the fact that what we are here focusing on is a demand for money for transaction purposes (so this argument holds for $M_{1}$, but it would not hold for broader aggregates). The resulting natural assumption of unitary income elasticity logically implies that, if the demand for $M_{1}$ is stable, $M_{1}$ velocity should inherit the stochastic properties of the opportunity cost of money. In turn, this implies that the type of unit root tests we run for $M_{1}$ velocity should be the same as those we run for the nominal rate.

For both velocity and the short rate we report results for either the levels or the logarithms of the series. For GDP and $M_{1}$, on the other hand, we only consider tests based on the logarithms of the series. The reason for this is that the level of either series is manifestly characterized by exponential-type growth, which is why these series are never considered in levels, and they are rather always considered in logarithms. For our purposes, this would not be a problem if Elliot et al.'s unit root tests allowed for the alternative of stationarity around an exponential time trend, rather than a linear one. Since this is not the case, for both GDP and $M_{1}$ we are necessarily compelled to only consider tests based on their logarithms.

Finally, for the short-term rate we report results based on both the simple series (either in levels, or in logarithms), and the simple series corrected along the lines of Alvarez and Lippi (2009), by adding to it a 1\% cost of either losing cash, or having it stolen.

\section{1 $\quad M_{1}$ velocity and the short rate}

Evidence of a unit root in $M_{1}$ velocity and the short rate is typically strong, with the bootstrapped $p$-values being almost uniformly greater than the 10 per cent significance level we take as our benchmark throughout the entire paper, and often

$\operatorname{ARIMA}(p, 1,0)$ processes. In all cases, the bootstrapped processes are of length equal to the series under investigation. As for the lag order, $p$, since, as it is well known, results from unit root tests may be sensitive to the specific lag order which is being used, for reasons of robustness we consider two alternative lag orders, either 1 or 2 years.

${ }^{16}$ The reason for including a time trend is that, as discussed e.g. by Hamilton (1994, pp. 501), the model used for unit root tests should be a meaningful one also under the alternative.

${ }^{17}$ The possibility of a downward path is ruled out by the zero lower bound.

${ }^{18}$ This does not rule out the possibility that, over specific sample periods in which inflation exhibits permanent variation (such as post-WWII samples dominated by the Great Inflation episode), nominal interest rates are I(1), too. Rather, by the Fisher effect, we should expect this to be the case. Historically, however, a unit root in inflation has been the exception, rather than the rule - see Benati (2008). 
significantly so. The following exceptions ought to be briefly discussed:

First, in a few cases results based on the two alternative lag orders we consider produce contrasting evidence. ${ }^{19}$ In these cases we regard the null of a unit root as not having been convincingly rejected, and in what follows we therefore proceed under the assumption that these series are I(1).

Second, under the Gold Standard a unit root is rejected for both the level and the logarithm of the short rate (either with, or without the $1 \%$ correction) for Canada, Finland, France, and Spain, and it is rejected for Switzerland based on the logarithm of the short rate with the $1 \%$ correction. In all of these cases, stationarity of the short rate precludes it from being entered in any cointegrated system, or cointegrating regression. ${ }^{20}$ By the same token, a unit root in the level of the short rate is rejected for Argentina, Brazil for the period 1934-2012, and Chile for the period 1941-2012, whereas in neither case it is rejected based on the logarithms. For all these three cases we will therefore eschew the Selden-Latané specification. Under the Gold Standard a unit root in either the level or the logarithm of velocity is rejected for Italy: In this case we will therefore uniquely consider unrestricted specifications for GDP, $M_{1}$, and the short rate.

Third, for Taiwan a unit root in velocity is rejected based on the level, but not based on the logarithm. In this case we will eschew the Selden-Latané specification.

\subsection{GDP and $M_{1}$}

Evidence of a unit root in the logarithms of nominal GDP and nominal $M_{1}$ is, likewise, typically strong. ${ }^{21}$ For GDP, a unit root is rejected only for Bolivia, and for France under the Gold Standard (the latter rejection is ultimately irrelevant, since, as previously mentioned, for France the interest rate is stationary, so that it is not possible to analyze cointegrated systems). As for $M_{1}$, it is rejected only for Israel, Canada (1967-2013), and Finland (1914-1985). For Bolivia, Israel, Canada (1967-2013), and Finland (1914-1985) we will therefore eschew unrestricted specifications for GDP, $M_{1}$, and the short rate, and we will uniquely focus on bivariate systems with velocity and the short rate.

\subsection{Are the series under investigation $\mathrm{I}(2)$ ?}

A necessary condition for performing either Johansen's or Shin's cointegration tests is that the series under investigation contain a unit root, and that their order of integration is not greater than one. Tables A.2a-A.2b in the online appendix report

\footnotetext{
${ }^{19}$ This is the case, e.g., for the logarithms of velocity and the short rate for Israel; for log velocity for Chile for the period 1940-1995; and for the short rate for West Germany.

${ }^{20}$ See footnote 12 .

${ }^{21}$ Again, in those few cases in which results based on the two alternative lag orders produce contrasting evidence, we regard the null of a unit root as not having been convincingly rejected, and we proceed under the assumption that the series is $\mathrm{I}(1)$.
} 
bootstrapped $p$-values for Elliot et al.'s (1996) unit root tests with an intercept, but no time trend, for either the log- or the first-differences of $M_{1}$ velocity and the short rate, and for the log-differences of nominal $M_{1}$ and nominal GDP.

For Morocco, and for Portugal under the Gold Standard, it is not possible to reject the null of a unit root in either the log-differences or the first-differences of $M_{1}$ velocity and the short rate. By the same token, for Hong Kong a unit root can be rejected only for either the log- or the first-difference of the short rate. This implies that for these three cases it is not possible to run any cointegration test, and in what follows we will therefore ignore them.

For Italy over the post-WWII period, and for Turkey, a unit root can be rejected only for the first-differences of $M_{1}$ velocity and the short rate, and for the log-difference of velocity. In these two cases we will therefore only run cointegration tests based on the semi-log and the Selden-Latané specifications. On the other hand, for West Germany we cannot run cointegration tests based on the Selden-Latané specification, as the null of a unit root cannot be rejected for the level of $M_{1}$ velocity.

Finally, there are several countries for which it is not possible to reject the null of a unit root in the log-differences of nominal GDP and/or nominal $M_{1}$. In all of these cases we will eschew unrestricted specifications for GDP, $M_{1}$, and the short rate, and we will uniquely focus on bivariate systems featuring (the logarithms of) velocity and the short rate.

We now turn to a brief discussion of methodological issues pertaining bootstrapping cointegrated processes.

\section{Issues Pertaining Bootstrapping}

Everything in this paper is bootstrapped ${ }^{22}$ - specifically, both the $p$-values for the cointegration tests, and, more generally, all of the objects of interest, such as the coefficients on the short rate in the estimated long-run money demand functions. In this section we therefore briefly discuss $(i)$ details of the bootstrapping procedures we use, and $(i i)$ how such procedures perform, in particular in terms of comparative performance. In our discussion we will extensively refer to Appendices $\mathrm{B}$ and $\mathrm{C}$ in the online appendix, which contain the Monte Carlo evidence motivating both some of our choices, and the way we will interpret the empirical evidence.

\footnotetext{
${ }^{22}$ As for Johansen's tests, the rationale for bootstrapping critical and $p$-values was provided by Johansen (2002) himself, who showed how, in small samples, trace and maximum eigenvalue tests based on asymptotic critical values typically tend to perform poorly. Since this is a small-sample issue, as a matter of logic we should expect Shin's (1994) tests to suffer from an analogous poor performance, thus justifiying the use of a bootstrapping procedure. Appendix B in the online appendix provides an additional rationale for bootstrapping Shin's tests: As we show there, even in very large samples the distributions of Shin's test statistics coincide with the asymptotic distribution reported in Shin's (1994) Table 1 only if the cointegration residual has no persistence.
} 


\subsection{Details of the bootstrapping procedures}

We bootstrap Johansen's tests via the procedure proposed by Cavaliere et al. (2012; henceforth, CRT). In a nutshell, CRT's procedure is based on the notion of computing critical and $p$-values by bootstrapping the model which is relevant under the null hypothesis. ${ }^{23}$ All of the technical details can be found in CRT, which the reader is referred to. We select the VAR lag order as the maximum ${ }^{24}$ between the lag orders chosen by the Schwartz and the Hannan-Quinn criteria ${ }^{25}$ for the VAR in levels.

As for Shin's tests, to the very best of our knowledge nobody has yet provided anything comparable to what CRT did for Johansen's procedure (in fact, we were not even able to find a single paper discussing how to bootstrap Shin's test statistic). The bootstrap procedure we propose in Appendix $\mathrm{C}$ in the online appendix is based on exactly the same idea underlying CRT, that is: Computing critical and $p$-values by bootstrapping the process which is relevant under the null hypothesis. Within the present context, this implies that the process to be bootstrapped is the VECM estimated under the null of one cointegration vector. Apart from this, and with the exception of two comparatively less important technical issues we discuss in Section C.2.1 of Appendix $\mathrm{C}$ in the online appendix, the procedure we are proposing for Shin's tests is very similar to the one proposed by CRT for Johansen's ones.

\subsection{Monte Carlo evidence}

Tables 1 and 2 report Monte Carlo evidence on the performance of the two bootstrapping procedures, which is discussed in detail in Sections C.3.1 and C.3.2 of Appendix $\mathrm{C}$ in the online appendix, respectively. In either case, we perform the Monte Carlo simulations based on two types of DGPs, featuring no cointegration and cointegration, respectively. For either DGP, we consider five alternative sample lengths, $T=$ 50, 100, 200, 500, and 1,000.

\subsubsection{Cavaliere et al.'s (2012) procedure for Johansen's tests}

The main findings emerging from Table 1 can be summarized as follows:

\footnotetext{
${ }^{23}$ This means that for tests of the null of no cointegration against the alternative of one or more cointegrating vectors the model which is being bootstrapped is a simple, non-cointegrated VAR in differences. For the maximum eigenvalue tests of $h$ versus $h+1$ cointegrating vectors, on the other hand, the model which ought to be bootstrapped is the VECM estimated under the null of $h$ cointegrating vectors.

${ }^{24}$ We consider the maximum between the lag orders chosen by the SIC and HQ criteria because the risk associated with selecting a lag order smaller than the true one (model mis-specification) is more serious than the one resulting from choosing a lag order greater than the true one (over-fitting).

${ }^{25}$ On the other hand, we do not consider the Akaike Information Criterion since, as discussed (e.g.) by Luetkepohl (1991), for systems featuring I(1) series the AIC is an inconsistent lag selection criterion, in the sense of not choosing the correct lag order asymptotically.
} 
If the true DGP features no cointegration, CRT's procedure performs very well irrespective of the sample size, with empirical rejection frequencies (henceforth, ERFs) very close to the 10 per cent significance level. This is in line with the Monte Carlo evidence reported in CRT's Tables I, p. 1731, and with the analogous evidence reported in Benati (2015).

\begin{tabular}{|c|c|c|c|c|c|}
\hline \multirow{2}{*}{\multicolumn{6}{|c|}{ 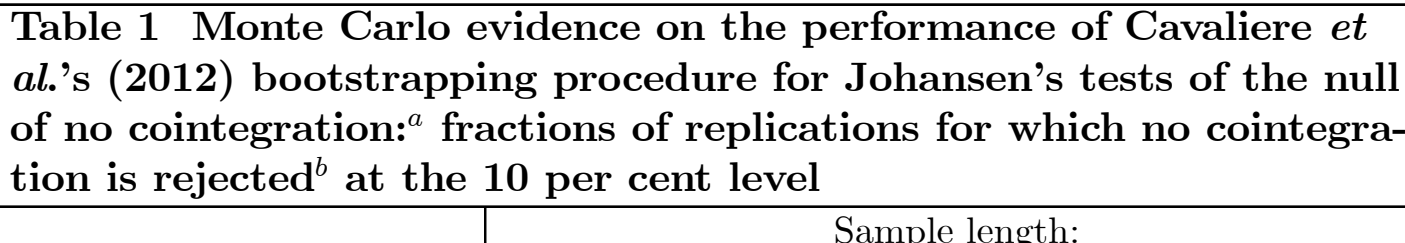 }} \\
\hline & & & & & \\
\hline & $T=50$ & $T=100$ & $T=20$ & $T=50$ & $T=1000$ \\
\hline & \multicolumn{5}{|c|}{ True data-generation process: no cointegration } \\
\hline & 0.116 & 0.098 & 0.105 & 0.107 & 0.119 \\
\hline $\begin{array}{c}\text { Persistence of the } \\
\text { cointegration residual: }\end{array}$ & \multicolumn{5}{|c|}{ True data-generation process: cointegration } \\
\hline$\rho=0$ & 0.774 & 1.000 & 1.000 & 1.000 & 1.000 \\
\hline$\rho=0.25$ & 0.584 & 0.993 & 1.000 & 1.000 & 1.000 \\
\hline$\rho=0.5$ & 0.350 & 0.882 & 1.000 & 1.000 & 1.000 \\
\hline$\rho=0.75$ & 0.184 & 0.433 & 0.937 & 1.000 & 1.000 \\
\hline$\rho=0.9$ & 0.117 & 0.167 & 0.328 & 0.958 & 1.000 \\
\hline$\rho=0.95$ & 0.114 & 0.120 & 0.164 & 0.533 & 0.966 \\
\hline \multicolumn{6}{|c|}{$\begin{array}{l}{ }^{a} \text { Based on the trace test of the null of no cointegration against the alternative of } \\
1 \text { or more cointegrating vectors. }{ }^{b} \text { Based on } 1,000 \text { Monte Carlo replications, and, } \\
\text { for each of them, on } 5,000 \text { bootstrap replications. }\end{array}$} \\
\hline
\end{tabular}

If, however, the true DGP does feature cointegration, the procedure performs well only if the persistence of the cointegration residual is sufficiently low, and/or the sample size is sufficiently large. (It is to be noticed that CRT did not explore how the persistence of the cointegration residual affects the performance of their procedure.) If however the cointegration residual is persistent, and the sample size is small, the procedure fails to detect cointegration a non-negligible fraction of the times. ${ }^{26}$ This is conceptually in line with some of the evidence reported by Engle and Granger (1987), and it has a straightforward explanation: As the cointegration residual becomes more and more persistent, it gets closer and closer to a random walk (in which case there would be no cointegration), and the procedure needs therefore larger and larger samples to detect the truth (i.e.: that the residual is highly persistent, but ultimately stationary).

\footnotetext{
${ }^{26}$ For example, with $T=100$, cointegration will be detected, at the 10 per cent level, 43.3 per cent of the times if $\rho=0.75$, and just 12.0 per cent of the times if $\rho=0.95$.
} 


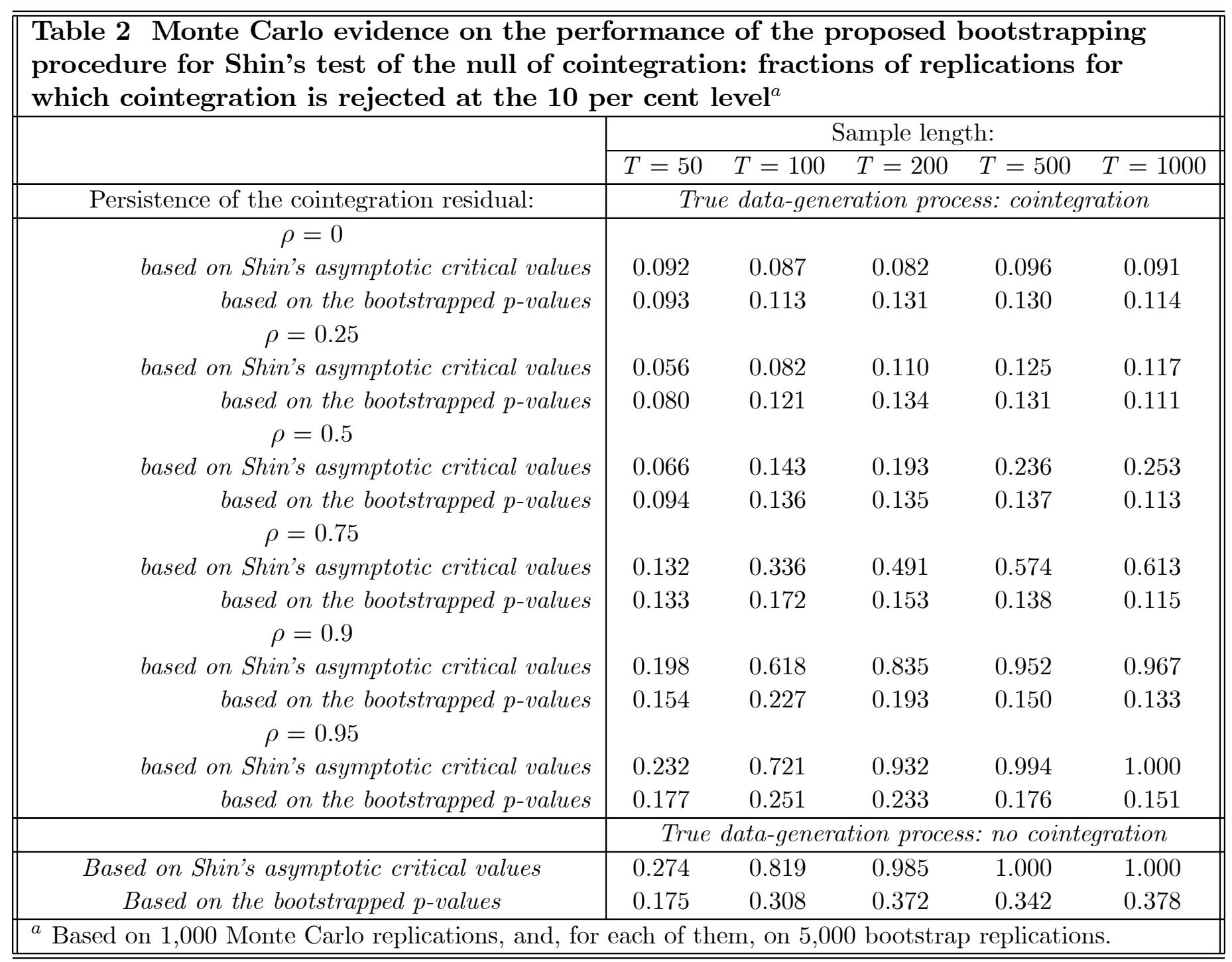




\subsubsection{Our proposed procedure for Shin's tests}

Turning to Shin's tests, the main findings emerging from Table 2 can be summarized as follows:

If the true DGP features cointegration, then, the greater the persistence of the cointegration residual, the more the proposed bootstrap procedure improves upon Shin's asymptotic critical values. ${ }^{27}$

If the DGP features no cointegration, however, even in large samples the proposed bootstrapped procedure produces ERFs far from the ideal of 100 per cent. For $T=$ 1000, for example, cointegration is rejected only about 38 per cent of the times, and based on smaller sample lengths, much less than that.

\subsubsection{Summing up}

What precedes can be summarized as follows:

If Johansen's tests do detect cointegration, we should have a reasonable presumption that cointegration is indeed there. If, on the other hand, they do not detect it, a possible explanation is that the sample period is too short, and/or the cointegration residual is highly persistent.

Lack of rejection of the null of cointegration based on Shin's tests and our bootstrapping procedure does not represent strong evidence that cointegration truly is there. Further, rejection of the null of cointegration does not appear to be especially informative about the true nature of the DGP, as the ERFs are not significantly different conditional on the two possible states of the world. Another way to put all this is that results from Shin's tests appear, overall, as less informative than the corresponding results produced by Johansen's tests bootstrapped as in CRT.

We now turn to the issue of what we should expect to obtain from cointegration tests before running them, based on $(i)$ the persistence of the cointegration residuals, and $(i i)$ the just-discussed Monte Carlo evidence on how such persistence affects the performance of the tests for a given sample length.

\section{What Should We Expect from Cointegration Tests?}

In Section 8 we will perform cointegration tests based on about three dozen samples. Performing such a large number of tests implies that, even if cointegration truly is there in all samples, and ever under ideal conditions (e.g., Shin's tests incorrectly rejecting the null of cointegration $x$ per cent of the times at the $x$ per cent level), a certain number of fluke results is to be expected. Further, the Monte Carlo evidence we discussed in the previous section suggests that - in line with Engle and Granger

\footnotetext{
${ }^{27}$ For example, for $T=100$, if $\rho=0.95$, tests based on asymptotic critical values would lead a researcher to reject the null of cointegration at the 10 per cent level 72.1 per cent of the times, whereas the bootstrap-based procedure only rejects 25.1 per cent of the times.
} 
(1987) - detecting a cointegration relationship can be extremely difficult when the sample period is comparatively short, and/or the cointegration residual is highly persistent. In this section we therefore start by exploring how persistent 'candidate cointegration residuals' (defined below) actually are. Based on this, and on the series' actual sample lengths, we then discuss what we should reasonably expect to obtain from cointegration tests before running them.

\subsection{How persistent are the 'candidate cointegration residu- als'?}

Table 3 reports Hansen (1999) 'grid bootstrap' median-unbiased (henceforth, MUB) estimates of the sum of the AR coefficients in $\mathrm{AR}(2)$ representations for the "candidate cointegration residuals' in our dataset. ${ }^{28}$ By 'candidate cointegration residual' (henceforth, CCR) we mean the linear combination of the I(1) variables in the system which will indeed be regarded as a cointegration residual if cointegration is detected. The reason why we label it as 'candidate' is because, as the Monte Carlo evidence in the previous section has shown, if a cointegration residual is highly persistent, cointegration might well not be detected even if it is there, which would prevent the candidate from being identified as a true cointegration residual. For reasons of robustness, we report results based on two alternative estimators of the cointegration vector, Johansen's, and Stock and Watson's (1993). The results reported in Table 3 are based on the log-log specification (with Alvarez and Lippi's (2009) 1\% correction for the short rate) for the six high-inflation countries, and on the Selden-Latané specification for all other countries. The full set of results based on either specification for all countries is reported in Tables SELA.1, SL.1, LL.1, and LLCO.1 of the online appendix.

Results based on either estimator, and either specification, are qualitatively similar, and point towards a non-negligible extent of persistence of the CCRs. At the same time, our dataset exhibits a wide extent of heterogeneity in terms of the estimated persistence, with the MUB estimate - let's label it as $\hat{\rho}_{M U B}$-ranging (based on Johansen's estimator of the cointegration vector) from a minimum of 0.30 for Australia, to a maximum of 1.00 for Portugal for the period 1966-1998. By classifying the $\hat{\rho}_{M U B}$ 's, in an admittedly quite arbitrary fashion, as 'highly persistent' $\left(\hat{\rho}_{M U B} \geq 0.8\right)$; 'moderately persistent' $\left(0.4<\hat{\rho}_{M U B}<0.8\right)$; and 'not very persistent' $\left(\hat{\rho}_{M U B} \leq 0.4\right)$, we end up with sixteen $\hat{\rho}_{M U B}$ 's in the first group, fifteen in the second, and three in the third. Results based on Stock and Watson's estimator point towards an even greater extent of persistence, with the number of MUB estimates in the three groups being equal to twenty-one, ten, and three, respectively.

\footnotetext{
${ }^{28}$ Results are based on 2,000 bootstrap replications for each possible value of the sum of the AR coefficients in the grid. Bootstrapping has been performed as in Diebold and Chen (1996).
} 


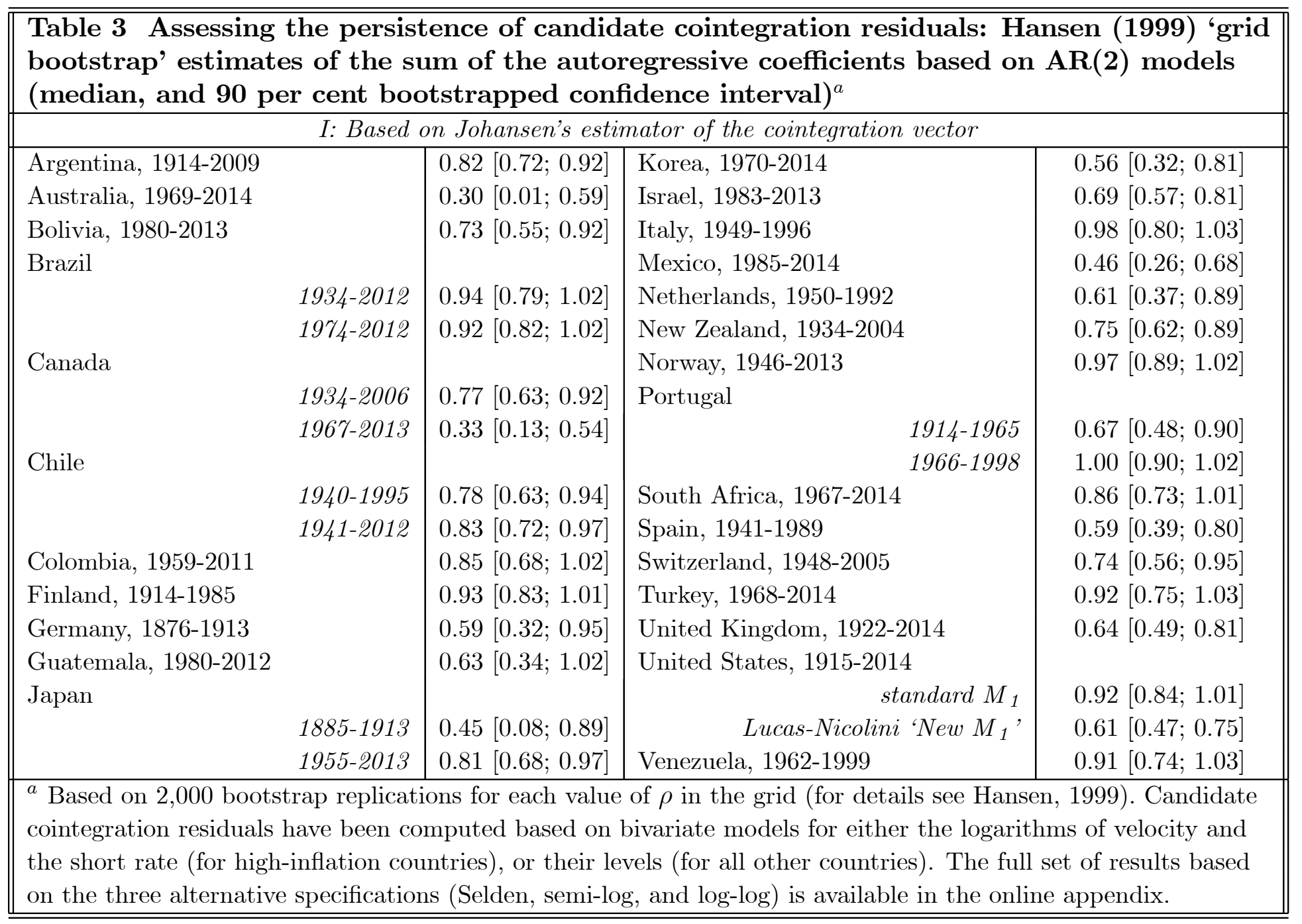




\begin{tabular}{|c|c|c|c|}
\hline \multicolumn{4}{|c|}{$\begin{array}{l}\text { Table } 3 \text { (continued) Assessing the persistence of candidate cointegration residuals: Hansen } \\
\text { (1999) 'gridbootstrap' estimates of the sum of the autoregressive coefficients based on } \operatorname{AR}(2) \\
\text { models (median, and } 90 \text { per cent bootstrapped confidence interval) }{ }^{a}\end{array}$} \\
\hline \multicolumn{4}{|c|}{ II: Based on Stock and Watson's estimator of the cointegration vector } \\
\hline Argentina, 1914-2009 & $0.86[0.77 ; 0.99]$ & Korea, 1970-2014 & $0.57[0.34 ; 0.82]$ \\
\hline Australia, 1969-2014 & $0.31[0.03 ; 0.61]$ & Israel, 1983-2013 & $0.65[0.46 ; 0.84]$ \\
\hline Bolivia, 1980-2013 & $0.72[0.55 ; 0.91]$ & Italy, 1949-1996 & $0.98[0.85 ; 1.03]$ \\
\hline Brazil & & Mexico, 1985-2014 & $0.52[0.31 ; 0.72]$ \\
\hline 1934-2012 & $0.91[0.77 ; 1.02]$ & Netherlands, 1950-1992 & $0.71[0.48 ; 1.01]$ \\
\hline $1974-2012$ & $1.00[0.93 ; 1.03]$ & New Zealand, 1934-2004 & $0.81[0.68 ; 0.95]$ \\
\hline \multirow[t]{2}{*}{ Canada } & & Norway, 1946-2013 & $1.00[0.96 ; 1.02]$ \\
\hline & $0.81[0.69 ; 0.96]$ & Portugal & \\
\hline $1967-2013$ & $0.34[0.13 ; 0.56]$ & $1914-1965$ & $0.67[0.47 ; 0.91]$ \\
\hline \multirow[t]{3}{*}{ Chile } & & 1966-1998 & $1.02[0.99 ; 1.10]$ \\
\hline & $0.80[0.66 ; 1.00]$ & South Africa, 1967-2014 & $1.01[0.96 ; 1.03]$ \\
\hline & $0.83[0.71 ; 0.98]$ & Spain, 1941-1989 & $0.61[0.41 ; 0.82]$ \\
\hline Colombia, 1959-2011 & $0.87[0.70 ; 1.02]$ & Switzerland, 1948-2005 & $0.84[0.67 ; 1.02]$ \\
\hline Finland, 1914-1985 & $0.97[0.91 ; 1.01]$ & Turkey, 1968-2014 & $0.94[0.76 ; 1.03]$ \\
\hline Germany, 1876-1913 & $0.99[0.87 ; 1.03]$ & United Kingdom, 1922-2014 & $0.69[0.54 ; 0.84]$ \\
\hline Guatemala, 1980-2012 & $0.65[0.34 ; 1.02]$ & United States, 1915-2014 & \\
\hline \multirow[t]{3}{*}{ Japan } & & standard $M_{1}$ & $1.00[0.96 ; 1.02]$ \\
\hline & $1.01[0.87 ; 1.06]$ & Lucas-Nicolini 'New $M_{1}$ ' & $0.64[0.51 ; 0.79]$ \\
\hline & $0.87[0.74 ; 1.01]$ & Venezuela, 1962-1999 & $0.89[0.69 ; 1.03]$ \\
\hline \multicolumn{4}{|c|}{$\begin{array}{l}{ }^{a} \text { Based on 2,000 bootstrap replications for each value of } \rho \text { in the grid (for details see Hansen, 1999). Candidate } \\
\text { cointegration residuals have been computed based on bivariate models for either the logarithms of velocity and } \\
\text { the short rate (for high-inflation countries), or their levels (for all other countries). The full set of results based } \\
\text { on the three alternative specifications (Selden, semi-log, and log-log) is available in the online appendix. }\end{array}$} \\
\hline
\end{tabular}




\subsection{Implications}

Under these circumstances, statistical tests will often have a hard time in detecting cointegration even if it truly is there. This will be especially so in those cases in which $\hat{\rho}_{M U B}$ is high and the sample period is comparatively short, such as Turkey. As we discuss in the next Section, based on neither of the three specifications (SeldenLatané, semi-log, and log-log) do Johansen's tests detect any evidence of cointegration between velocity and the short rate for this country (on the other hand, based on either specification Shin's tests do not reject the null of cointegration). Such a failure of Johansen's tests to detect evidence of cointegration is especially startling in the light of the the evidence reported either Figure 2, or Figure 7 of the online appendix, highlighting very strongly correlated fluctuations in velocity and the short rate, and it has a straightforward explanation: Given the comparatively short sample period (46 years), and the high persistence of the CCR (with $\hat{\rho}_{M U B}$ in Table 3 equal to either 0.92 or 0.94 ), it is not surprising that Johansen's procedure does not reject the null of no cointegration. Rather, based on the evidence reported in Table 1, this is to be expected: When the true DGP features cointegration, with $T=50$ and $\rho=0.9$ Cavaliere et al.'s (2012) bootstrapping procedure for Johansen's tests correctly rejects the null of no cointegration only 11.7 per cent of the times. This is qualitatively and even quantitatively in line with the Monte Carlo evidence reported by Engle and Granger (1987) for cointegration tests based on the Dickey-Fuller test statistic. This means that if cointegration were truly there in Turkish data, given the sample length we are working with, and the specific characteristics of the DGP, we would have a nearly 90 per cent chance of not detecting it.

So what a reader should take away from all this is that the results from cointegration tests we are going to discuss in the next section should not be taken strictly at face value: Rather, they ought to be interpreted in the light of the Monte Carlo evidence on the performance of cointegration tests reported in Tables 1 and 2, and of the evidence on the persistence of the CCRs reported in Table $3{ }^{29}$

Let us now turn to the results from cointegration tests.

\section{Searching for a Long-Run Money Demand}

Tables 4. $a$ to 4.c report results from either Johansen or Shin tests for cointegration between log velocity (the inverse of the ratio of real money balances to output) and the log of the short rate, which corresponds to the basic Baumol-Tobin constantelasticity specification. As mentioned above, following Alvarez and Lippi (2009), the short rate has been corrected by adding to it the expected cost of either losing cash, or having it stolen, which we calibrate to 1 per cent. In Tables $5 a-5 b$ we report the

\footnotetext{
${ }^{29}$ This is very much in the spirit of Lucas' (1988) interpretation of econometric results which, taken at face value, appeared to contradict the findings of Meltzer (1963).
} 
results for the Selden-Latané specification, which corresponds to an elasticity that is increasing over time.

The corresponding set of results based on the semi-log specification for all countries are reported in Tables SL2a-SL.2 $b$ in the online appendix, and they are discussed in Appendix $\mathrm{E}$ in the online appendix. We do not discuss them here because they are typically weaker than those based on either the log-log or the Selden-Latané specifications: In a nutshell, as we will see, the data seem to prefer the Selden-Latané specification at comparatively low interest rates (i.e., those associated with countries such as the United States, or the United Kingdom), and the log-log specification at high, or very high interest rates (e.g., for countries such as Argentina, or Israel), whereas evidence based on the semi-log specification is never strong.

Figures 4 to 9 report the estimation results for the log-log specification..$^{30}$ In the top rows, we report the candidate cointegration residuals produced by either Johansen's or Stock and Watson's (1993) estimators, and in the bottom rows the bias-corrected bootstrapped distributions ${ }^{31}$ of the corresponding estimates of the coefficient on the $\log$ of the short rate (i.e., the interest rate elasticity of money demand). For each bootstrapped distribution we also report the mean, the median, and the 5th and 95th percentiles. Figures 10 to 15 report the corresponding set of results based on the Selden-Latané specification, whereas Figures SL.1 to SL.6 of the online appendix report results for the semi-log specification. For the reasons discussed above, in all cases we report both candidate cointegration residuals, and estimates of the coefficients on the short rate, for all countries, rather than only for those for which statistical tests detect evidence of cointegration.

\subsection{Evidence from cointegration tests}

\subsubsection{Unrestricted tests of the null of cointegration}

Although this paper mostly focuses on the results produced by bivariate systems, we want to briefly discuss those produced by Shin's tests of the null of cointegration applied to unrestricted specifications featuring (the logarithm of) the short rate, and the logarithms of nominal GDP and $M_{1}$. The reason for doing so is that they represent one 'extreme end' of the spectrum within the full set of results: As we discuss in Appendix E.1 in the online appendix, based on unrestricted three-variables systems

\footnotetext{
${ }^{30}$ Again: These results are based on the 'corrected' short rate, incorporating the expected cost of either losing cash, or having it stolen.

${ }^{31}$ Bootstrapping has been implemented as in Cavaliere et al. (2012) based on the estimated VECM conditonal on one cointegration vector. The bias-correction has been implemented as in Kilian (1998). The only difference between what Kilian did, and what we are doing here, is that whereas he applied his proposed methodology to bias-correcting impulse-response functions, we are here using it to bias-correct the elements of the cointegration vector (this is conceptually in line with Cavaliere, Taylor, and Trenkler (2015)). In general, however, the extent of the bias was small (the non-bias-corrected estimates are available upon request), so that bias-correcting does not make any material difference to the results.
} 
it is almost impossible to reject the null of cointegration. ${ }^{32}$ For the reasons discussed in Sections 6.2.2 and 6.2.3, ${ }^{33}$ however, these results should be downplayed: As we stressed there, lack of rejection of the null of cointegration based on Shin's tests and our bootstrapping procedure does not represent strong evidence that cointegration truly is there ${ }^{34}$

Let's now turn to bivariate systems for velocity and the short rate.

\subsubsection{Evidence from bivariate systems for velocity and the short rate}

The log-log specification Based on the log-log specification, evidence of cointegration is uniformly very strong for all of the high-inflation countries with the single exception of Bolivia, as well as for Canada (1967-2012), Guatemala, New Zealand, Norway, Portugal and Switzerland: In all of these cases, $p$-values for Johansen's tests are below $10 \%$, and $p$-values for Shin's tests are above $10 \% .^{35}$

On the other hand, in four cases - Finland, Venezuela, West Germany, and Japan under the Gold Standard - the opposite is true, with Johansen's tests not rejecting the null of no cointegration, and Shin's tests instead rejecting cointegration.

Finally, in almost all of the other cases neither Johansen's nor Shin's tests do reject the null, thus producing contradictory evidence (this is the case, e.g., for both the United States and the United Kingdom). Under this respect, and based on our previous discussion in Sections 6 and 7, two things ought to be stressed: on the one hand, as we showed via Monte Carlo, Johansen's procedure exhibits an overall better performance, and it produces more informative results; on the other hand, however, even bootstrapping critical and p-values as in CRT (2012), Johansen's tests still suffer, in small samples, from the problem highlighted by Engle and Granger (1987). The former issue suggests to give more weight to the results from Johansen's testspointing towards no cointegration - whereas the latter one suggests that this result might well be the figment of a comparatively short sample period, and/or of a highly persistent cointegration residual. ${ }^{36}$ So, in the end, evidence for this group of countries is not clear-cut. Based on the discussion in Sections 6 and 7; on the respective sample

\footnotetext{
${ }^{32}$ Specifically, at the 10 per cent level we obtain just four rejections of the null out of 33 tests based on the semi-log specification, whereas based on the log-log specification with the $1 \%$ correction to the short rate we obtain only one rejection.

${ }^{33}$ See also Section E.3.2 in Appendix E.

${ }^{34}$ There is no need to remind the reader that using the asymptotic critical values reported in Shin's (1994) Table 1 is a non-starter. On this, see the extended discussion in Appendix B in the online appendix.

${ }^{35}$ To be precise, for Portugal (1966-1998) the $p$-value for the maximum eigenvalue tests is 0.125. The overall picture for this country, however, clearly points towards cointegration. For Switzerland, the $p$-value for Shin's test for the period 1948-2005 is 0.064 , but once again, overall evidence clearly points towards cointegration.

${ }^{36}$ E.g., for the United States (based on the Lucas-Nicolini aggregate) $\hat{\rho}_{M U B}$ in Table LLCO.1 in the online appendix is equal to either 0.77 or 0.79 , whereas the corresponding figures for the United Kingdom are 0.81 and 0.83 .
} 


\begin{tabular}{|c|c|c|c|}
\hline \multicolumn{4}{|c|}{$\begin{array}{l}\text { Table 4a Results from cointegration tests between the logarithms of } M_{1} \\
\text { velocity and of a short-term rate for very high inflation countries }{ }^{b}\end{array}$} \\
\hline & \multicolumn{2}{|c|}{ I: Johansen's tests of the null of no cointegration } & \multirow[b]{2}{*}{$\begin{array}{l}\text { II: Shin's tests } \\
\text { of the null of } \\
\text { cointegration }\end{array}$} \\
\hline & $\begin{array}{l}\text { Trace tests of the null of no } \\
\text { cointegration against the } \\
\text { alternative of } 1 \text { or more } \\
\text { cointegrating vectors: }\end{array}$ & $\begin{array}{l}\text { Maximum eigenvalue } \\
\text { tests of } 0 \text { versus } 1 \\
\text { cointegrating vectors: }\end{array}$ & \\
\hline Argentina, 1914-2009 & $21.303(0.032)$ & $18.866(0.023)$ & $0.567(0.288)$ \\
\hline Bolivia, 1980-2013 & $15.480(0.255)$ & $15.134(0.154)$ & $0.156(0.249)$ \\
\hline \multicolumn{4}{|l|}{ Brazil } \\
\hline 1974-2012 & $20.904(0.049)$ & $15.221(0.093)$ & $0.325(0.104)$ \\
\hline 1934-2012 & $20.270(0.034)$ & $16.842(0.037)$ & $2.043(0.011)$ \\
\hline \multicolumn{4}{|l|}{ Chile } \\
\hline $1940-1995$ & $26.453(0.013)$ & $18.953(0.033)$ & $0.178(0.244)$ \\
\hline 1941-2012 & $18.541(0.059)$ & $13.224(0.119)$ & $0.127(0.725)$ \\
\hline Israel, 1983-2013 & $41.66(0.001)$ & $40.773(0.000)$ & $0.135(0.350)$ \\
\hline Mexico, 1985-2014 & $15.569(0.230)$ & $14.027(0.205)$ & $0.132(0.285)$ \\
\hline
\end{tabular}




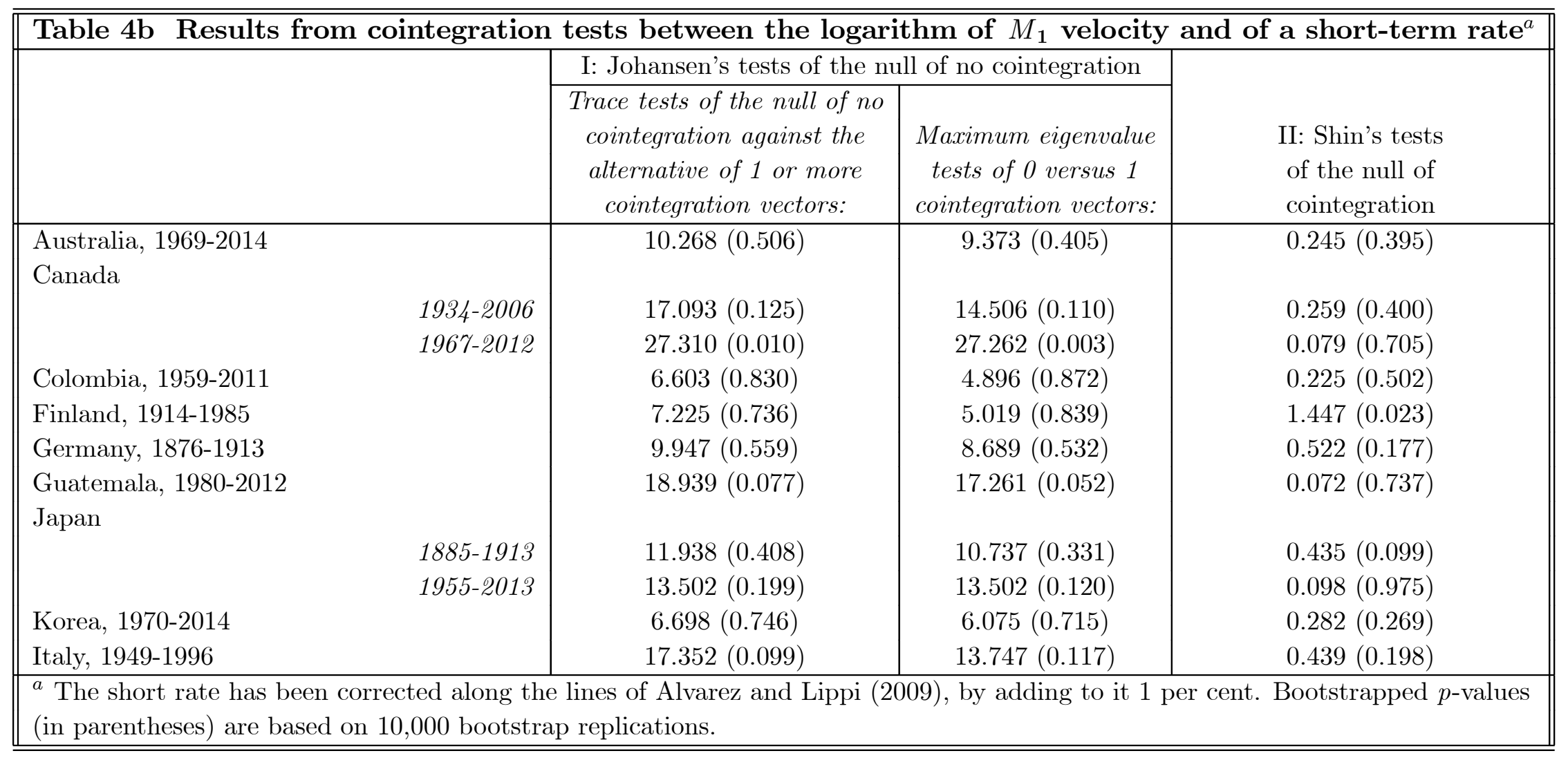




\begin{tabular}{|c|c|c|c|}
\hline \multicolumn{4}{|c|}{ 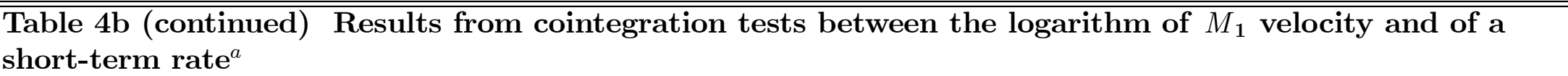 } \\
\hline & \multicolumn{2}{|c|}{ I: Johansen's tests of the null of no cointegration } & \multirow[b]{2}{*}{$\begin{array}{l}\text { II: Shin's tests } \\
\text { of the null of } \\
\text { cointegration }\end{array}$} \\
\hline & $\begin{array}{l}\text { Trace tests of the null of no } \\
\text { cointegration against the } \\
\text { alternative of } 1 \text { or more } \\
\text { cointegration vectors: }\end{array}$ & $\begin{array}{l}\text { Maximum eigenvalue } \\
\text { tests of } 0 \text { versus } 1 \\
\text { cointegration vectors: }\end{array}$ & \\
\hline Netherlands, 1950-1992 & $15.054(0.166)$ & $9.309(0.401)$ & $0.216(0.413)$ \\
\hline New Zealand, 1934-2004 & $17.535(0.087)$ & $16.340(0.049)$ & $0.500(0.327)$ \\
\hline Norway, 1946-2013 & $24.004(0.016)$ & $20.698(0.015)$ & $0.736(0.157)$ \\
\hline \multicolumn{4}{|l|}{ Portugal } \\
\hline $1914-1965$ & $20.699(0.061)$ & $19.887(0.032)$ & $0.120(0.360)$ \\
\hline $1966-1998$ & $19.392(0.086)$ & $14.975(0.125)$ & $0.074(0.546)$ \\
\hline South Africa, 1967-2014 & $16.776(0.131)$ & $15.686(0.080)$ & $0.336(0.160)$ \\
\hline Spain, 1941-1989 & $7.850(0.642)$ & $7.632(0.537)$ & $0.261(0.256)$ \\
\hline \multicolumn{4}{|l|}{ Switzerland } \\
\hline $1851-1906$ & $15.520(0.094)$ & $15.377(0.057)$ & $0.780(0.192)$ \\
\hline $1948-2005$ & $31.284(0.001)$ & $27.586(0.001)$ & $0.975(0.064)$ \\
\hline Taiwan, 1962-2013 & $6.108(0.816)$ & $5.508(0.794)$ & $0.387(0.131)$ \\
\hline Turkey, 1968-2014 & $8.010(0.721)$ & $5.829(0.792)$ & $0.172(0.521)$ \\
\hline United Kingdom, 1922-2014 & $15.684(0.159)$ & $15.361(0.077)$ & $0.951(0.058)$ \\
\hline \multicolumn{4}{|l|}{ United States, 1915-2014 } \\
\hline based on the standard $M_{1}$ aggregate & $11.224(0.342)$ & $9.563(0.320)$ & $3.021(0.015)$ \\
\hline based on Lucas and Nicolini's 'New $M_{1}$ ' aggregate & $14.623(0.187)$ & $13.107(0.137)$ & $0.369(0.290)$ \\
\hline Venezuela, 1962-1999 & $6.616(0.771)$ & $4.389(0.888)$ & $0.364(0.094)$ \\
\hline West Germany, 1960-1989 & $12.243(0.419)$ & $12.194(0.261)$ & $0.442(0.076)$ \\
\hline
\end{tabular}




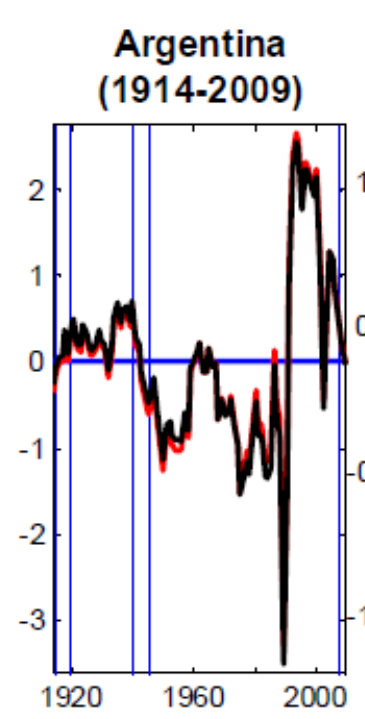

Candidate cointegration residuals, de-meaned and standardized
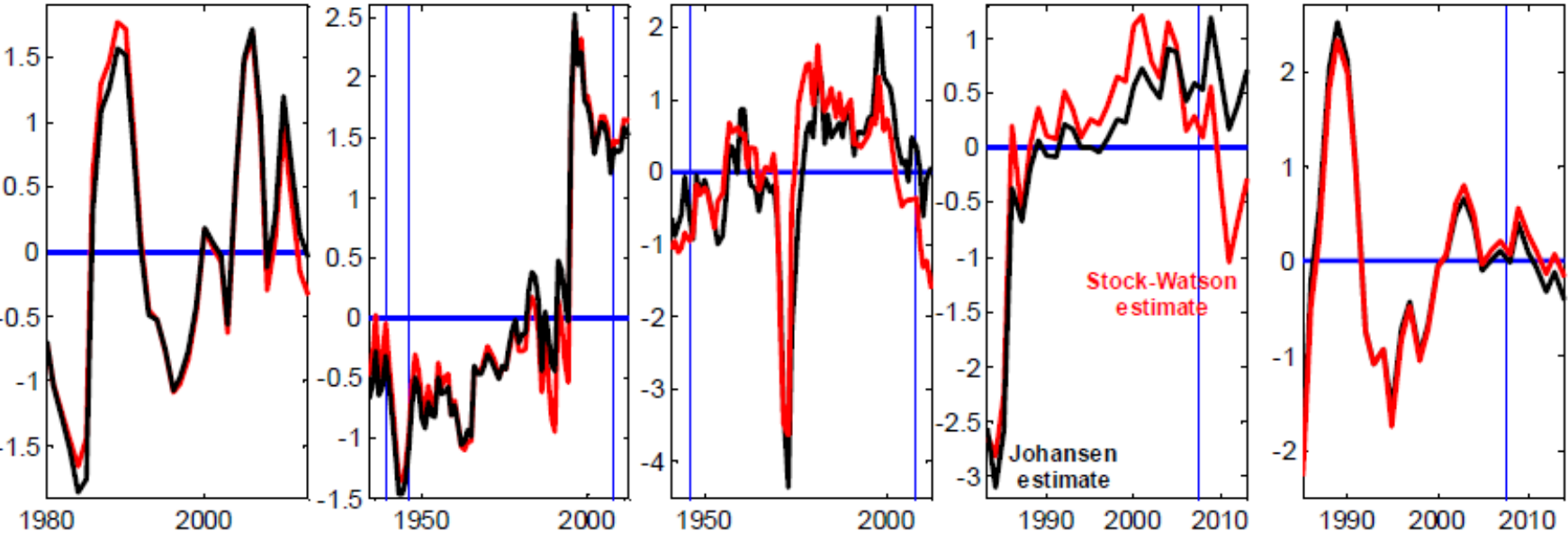

Bootstrapped distributions of the estimated elasticity
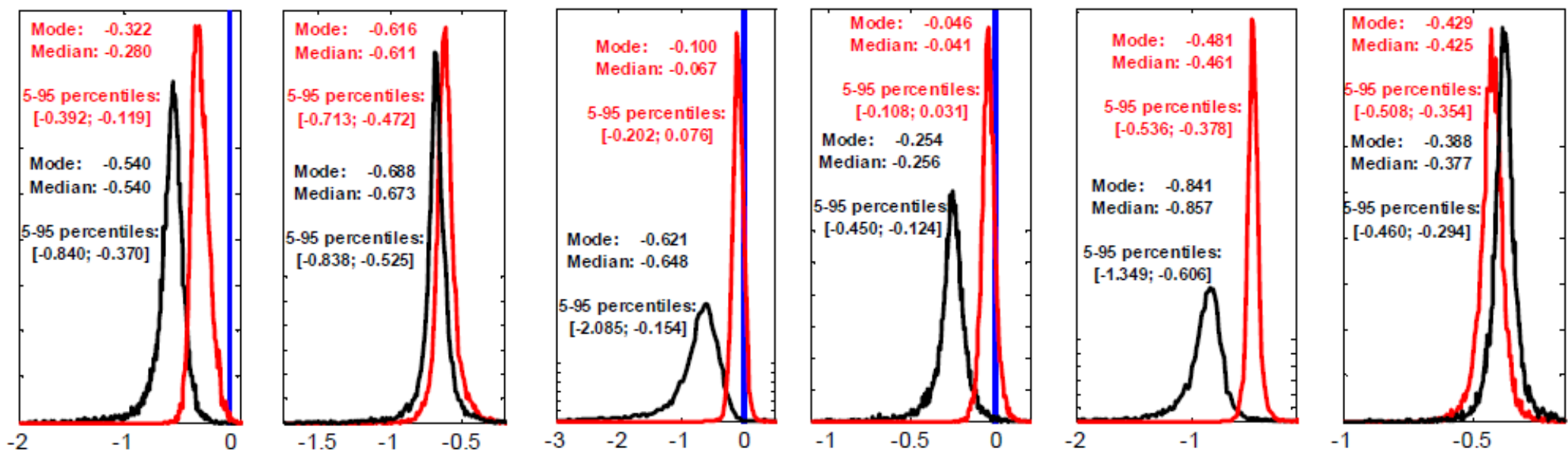

Figure 4 Log-log specification with the $1 \%$ correction to the short rate, imposing unitary income elasticity: cointegration residuals and bootstrapped distributions of the coefficients on the log of the short rate 
Candidate cointegration residuals, de-meaned and standardized
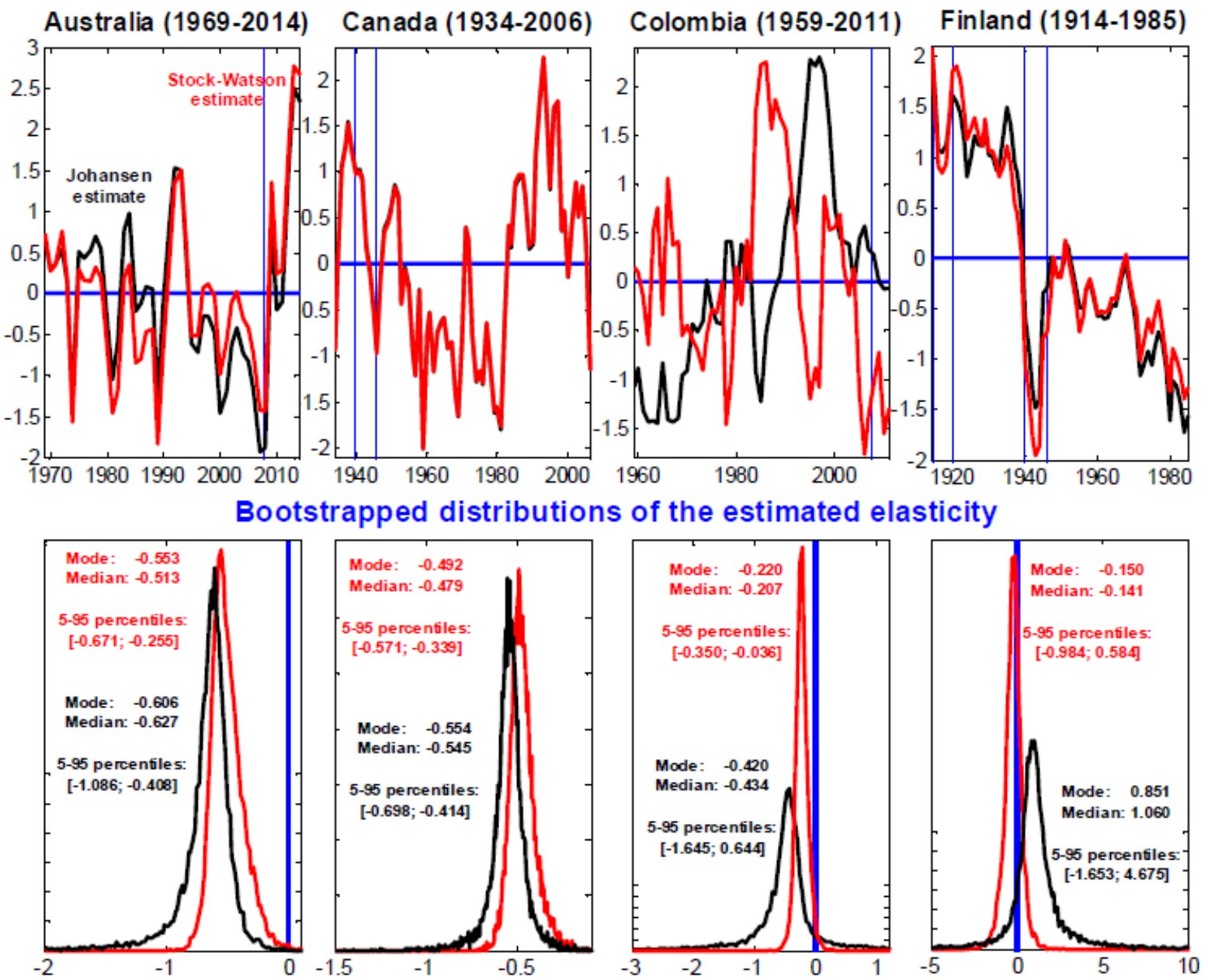

Figure 5 Log-log specification with the $1 \%$ correction to the short rate, imposing unitary income elasticity: cointegration residuals and bootstrapped distributions of the coefficients on the log of the short rate 
Candidate cointegration residuals, de-meaned and standardized
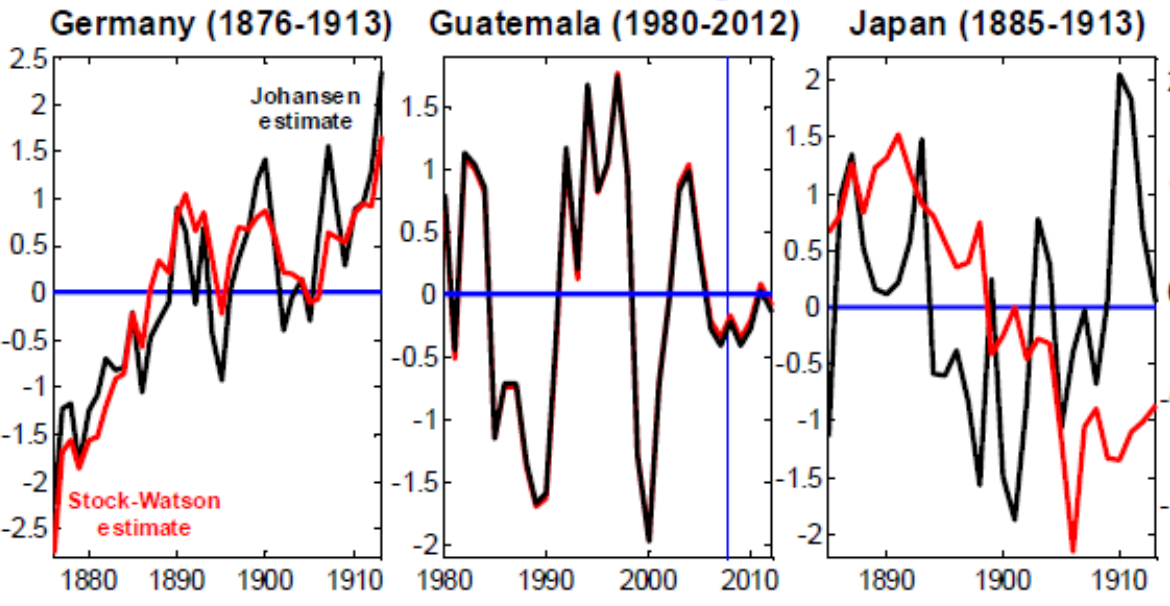

Japan (1955-2013)

Korea (1970-2014)

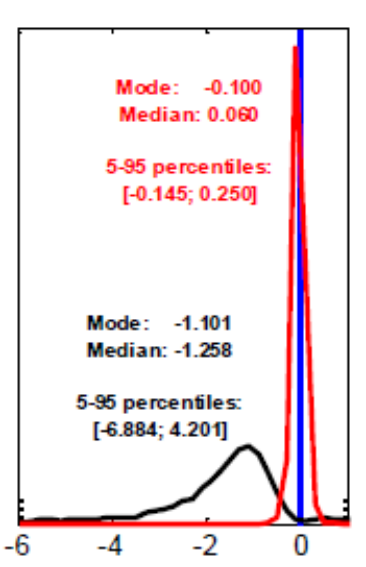

Bootstrapped distributions of the estimated elasticity
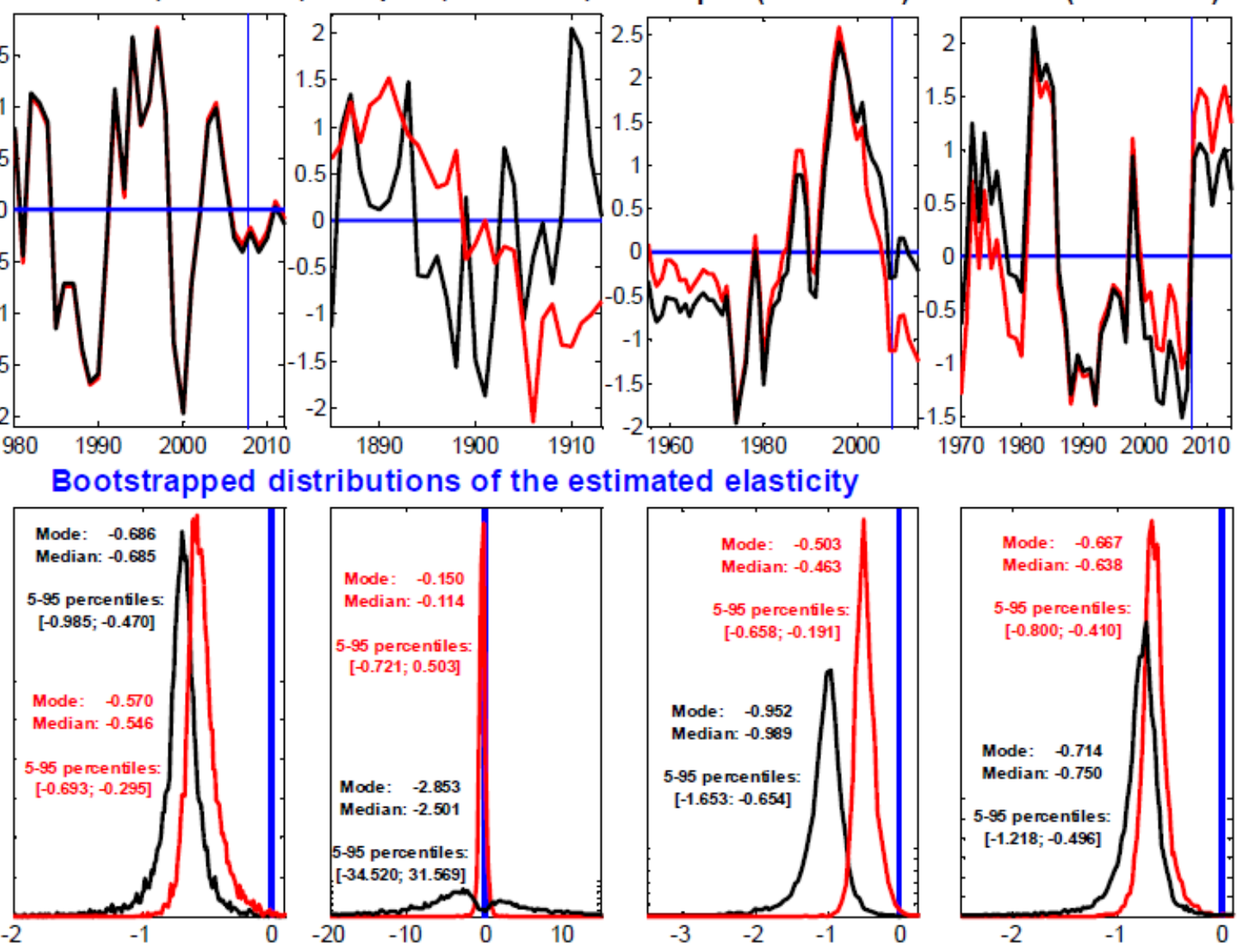

Figure 6 Log-log specification with the $1 \%$ correction to the short rate, imposing unitary income elasticity: cointegration residuals and bootstrapped distributions of the coefficients on the log of the short rate 
Candidate cointegration residuals, de-meaned and standardized Netherlands New Zealand

(1950-1992)

(1934-2004)
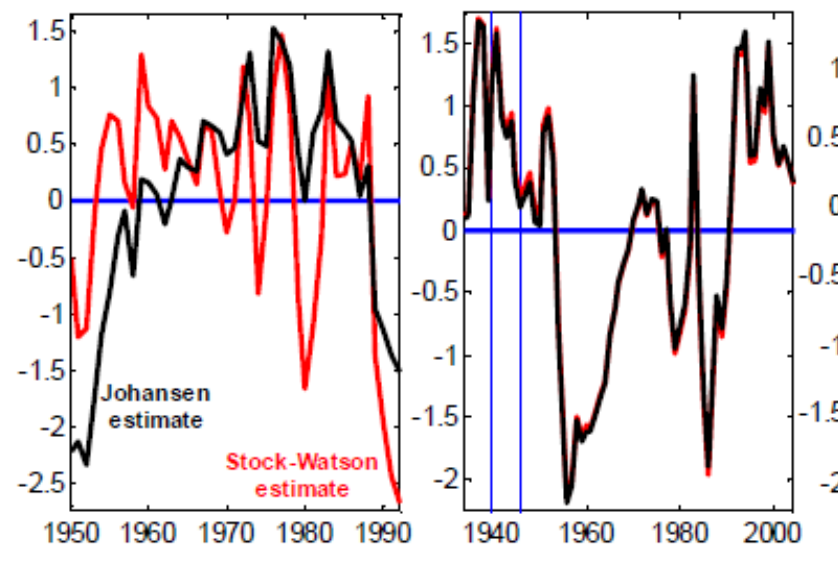

Norway (1946-2013)

Portugal (1914-1965)

Bootstrapped distributions of the estimated elasticity
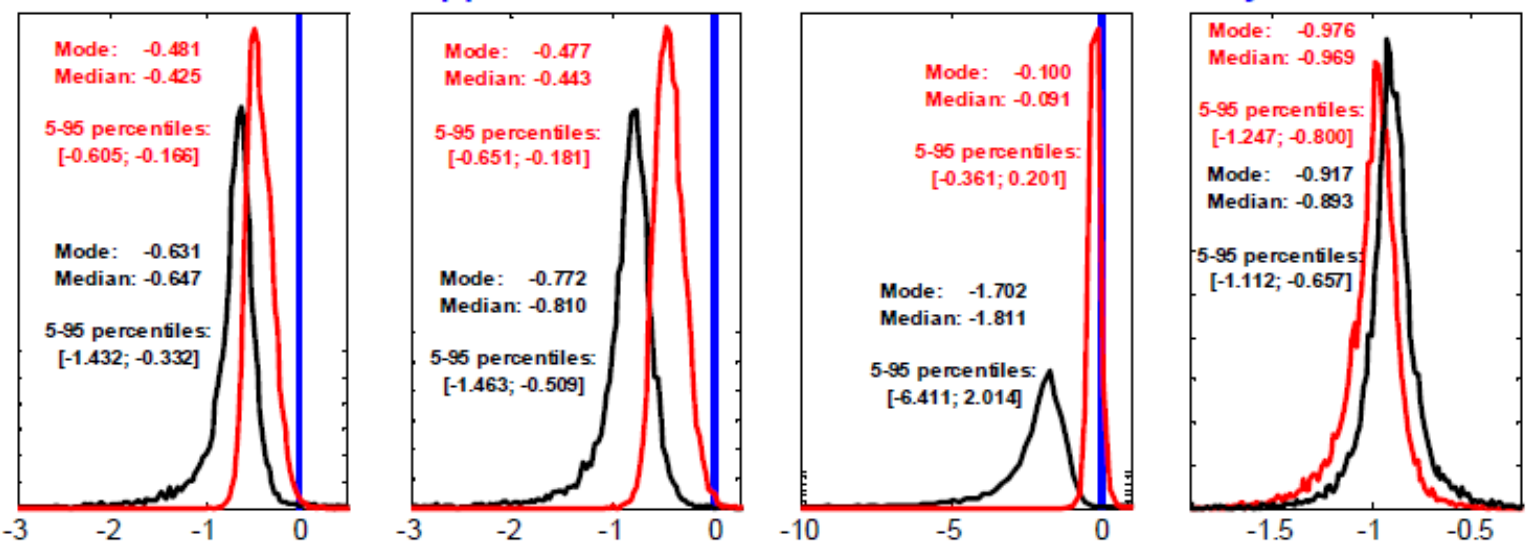

Figure 7 Log-log specification with the $1 \%$ correction to the short rate, imposing unitary income elasticity: cointegration residuals and bootstrapped distributions of the coefficients on the log of the short rate 

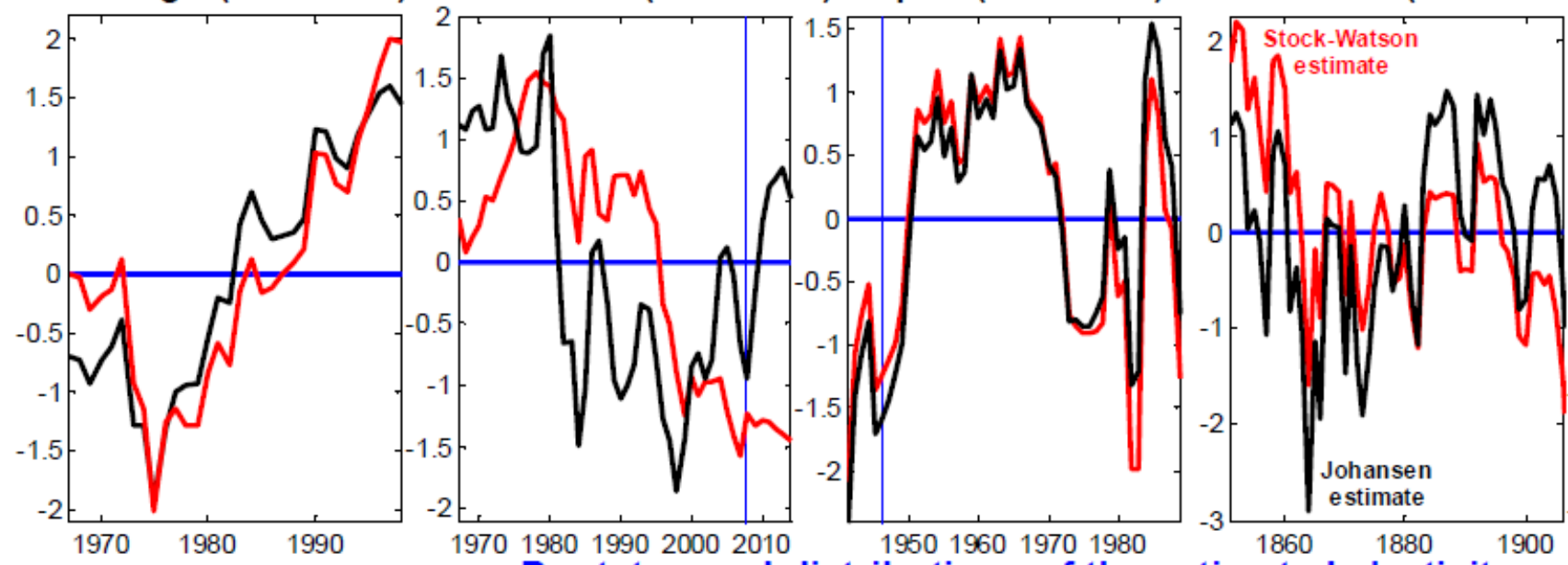

Bootstrapped distributions of the estimated elasticity
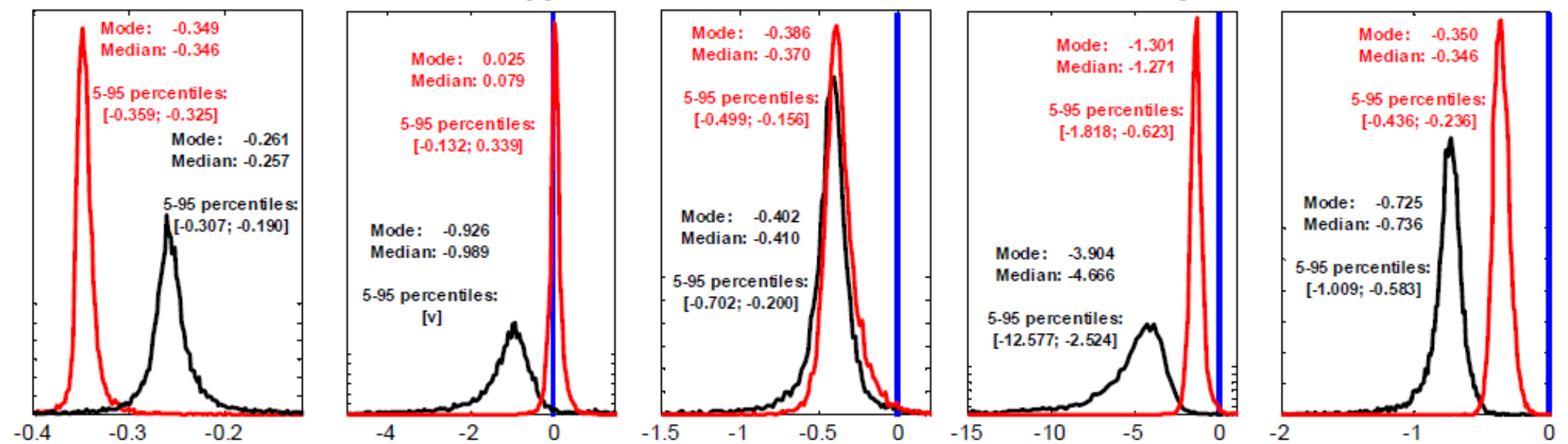

Figure 8 Log-log specification with the 1\% correction to the short rate, imposing unitary income elasticity: cointegration residuals and bootstrapped distributions of the coefficients on the $\log$ of the short rate 


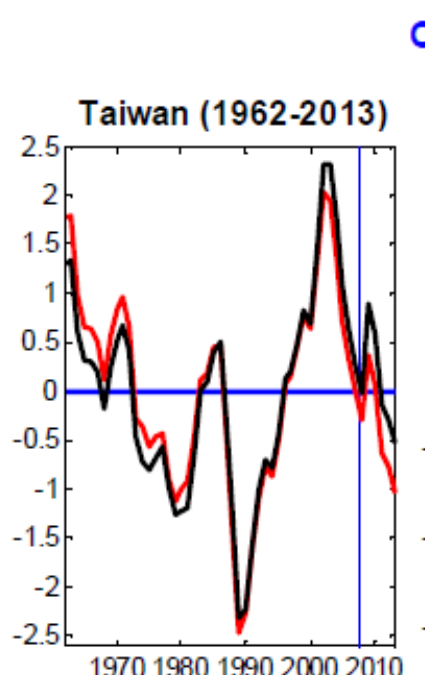

Candidate cointegration residuals, de-meaned and standardized United Kingdom United States Venezuela (1922-2014) $(1915-2014)$ (1962-1999)

West Germany
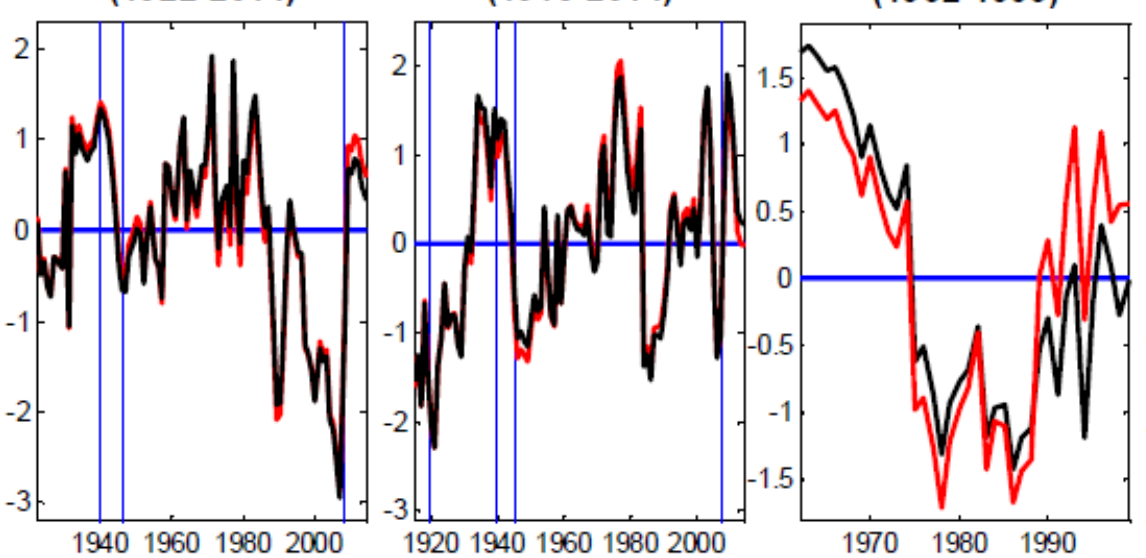
(1960-1989)
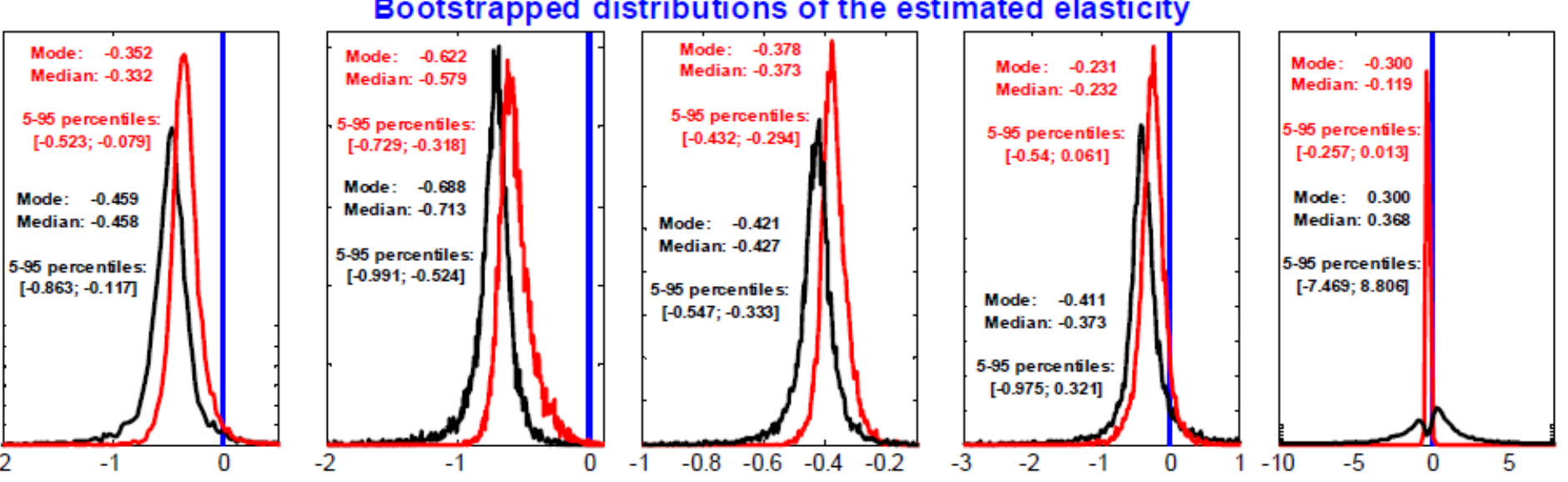

Figure 9 Log-log specification with the $1 \%$ correction to the short rate, imposing unitary income elasticity: cointegration residuals and bootstrapped distributions of the coefficients on the $\log$ of the short rate 
lengths, and on the estimated persistence of the CCRs reported in Table LLCO.1 in the online appendix; and on the CCRs themselves - which are shown in Figures 4 to 9 , and which in several cases appear quite clearly to be stationary (this is the case, in particular, for the United States and the United Kingdom) - our own reading of the overall evidence is that in many cases it is at the very least compatible with the existence of a cointegration relationship between velocity and the short rate.

The Selden-Latané specification Turning to the Selden-Latané specification (Tables $5 a-5 b$ ), evidence of cointegration is, once again, almost uniformly strong for high-inflation countries. As for other countries, it is strong for Australia, Canada, Guatemala, Korea, New Zealand, Norway, Portugal (1914-1965), and the United States based on Lucas and Nicolini's (2015) $M_{1}$ aggregate. $^{37}$

On the other hand, in three cases - Finland, Japan under the Gold Standard, and Portugal (1966-1998) - evidence clearly points towards no cointegration, with Johansen's tests do not rejecting the null of no cointegration, and Shin's tests instead rejecting cointegration.

In several other cases neither Johansen's nor Shin's tests reject the null, thus producing contradictory evidence: This is the case, e.g., of Colombia, Japan (19552013), the Netherlands, Spain, and Switzerland under the Gold Standard. For all of these countries, the same considerations we made in the previous sub-section still apply, so that in these cases the overall evidence is typically compatible with the presence of cointegration between velocity and the short rate. Symmetrically, for Canada (1934-2006), Norway, Switzerland (1948-2005) and the United Kingdom both Johansen's and Shin's tests reject the null. For Canada, Switzerland, and the United Kingdom, our own reading of the overall evidence (not to mention that, as discussed in Section 6, Johansen's procedure is more reliable than Shin's) suggests that it is compatible with cointegration between velocity and the short rate. As for Norway things are less clear-cut: In particular, the CCR shown in Figure 13 does not appear as manifestly stationary.

\subsubsection{Unrestricted tests of the null of no cointegration}

Turning to specifications in which we do not impose unitary income elasticity, Tables SL.4, LL.4, and LLCO.4 in the online appendix report results from Johansen's tests of no cointegration based on unrestricted specifications for the logarithms of GDP and $M_{1}$, and (the logarithm of) the short rate. As we discuss more extensively in Appendix E.3 in the online appendix, based on the log-log specification with the $1 \%$ correction to the short rate, cointegration is detected based on both the trace and the maximum eigenvalue tests for Argentina, Brazil (1974-2012), Canada (19672013), Japan (1955-2013), Korea, Israel, the Netherlands, Norway, Portugal (1914-

\footnotetext{
${ }^{37}$ To be precise: For both Australia and New Zealand the $p$-values for Johansen's trace tests, at 0.116 and 0.106 , are borderline.
} 


\begin{tabular}{|c|c|c|c|}
\hline \multicolumn{4}{|c|}{$\begin{array}{l}\text { Table 5a Results from cointegration tests between } M_{1} \text { velocity and a short- } \\
\text { term rate }{ }^{a} \text { for very high inflation countries }\end{array}$} \\
\hline & \multicolumn{2}{|c|}{ I: Johansen's tests of the null of no cointegration } & \multirow[b]{2}{*}{$\begin{array}{l}\text { II: Shin's tests } \\
\text { of the null of } \\
\text { cointegration }\end{array}$} \\
\hline & $\begin{array}{l}\text { Trace tests of the null of no } \\
\text { cointegration against the } \\
\text { alternative of } 1 \text { or more } \\
\text { cointegrating vectors: }\end{array}$ & $\begin{array}{l}\text { Maximum eigenvalue } \\
\text { tests of } 0 \text { versus } 1 \\
\text { cointegrating vectors: }\end{array}$ & \\
\hline Bolivia, 1980-2013 & $19.339(0.089)$ & $18.519(0.053)$ & $0.090(0.976)$ \\
\hline Brazil, 1974-2012 & $30.987(0.005)$ & $25.024(0.008)$ & $0.640(0.018)$ \\
\hline \multicolumn{4}{|l|}{ Chile } \\
\hline $1940-1995$ & $24.191(0.024)$ & $14.026(0.133)$ & $0.696(0.024)$ \\
\hline 1941-2012 & $23.304(0.020)$ & $18.084(0.035)$ & $0.411(0.307)$ \\
\hline Israel, 1983-2013 & $154.166(0.000)$ & $154.098(0.000)$ & $0.137(0.282)$ \\
\hline Mexico, 1985-2014 & $47.085(3.0 \mathrm{e}-4)$ & $29.609(0.007)$ & $0.110(0.312)$ \\
\hline
\end{tabular}




\begin{tabular}{|c|c|c|c|c|}
\hline \multicolumn{5}{|c|}{ 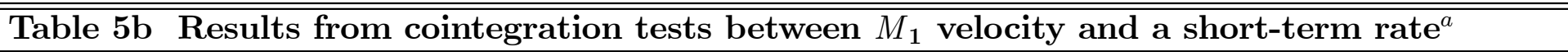 } \\
\hline & & \multicolumn{2}{|c|}{ I: Johansen's tests of the null of no cointegration } & \multirow[b]{2}{*}{$\begin{array}{l}\text { II: Shin's tests } \\
\text { of the null of } \\
\text { cointegration }\end{array}$} \\
\hline & & $\begin{array}{l}\text { Trace tests of the null of no } \\
\text { cointegration against the } \\
\text { alternative of } 1 \text { or more } \\
\text { cointegration vectors: }\end{array}$ & $\begin{array}{l}\text { Maximum eigenvalue } \\
\text { tests of } 0 \text { versus } 1 \\
\text { cointegration vectors: }\end{array}$ & \\
\hline Australia, 1969-2014 & & $16.903(0.116)$ & $15.890(0.063)$ & $0.278(0.227)$ \\
\hline \multirow{2}{*}{ Canada } & $1934-2006$ & $23.157(0.017)$ & $21.380(0.009)$ & $0.545(0.039)$ \\
\hline & $1967-2013$ & $26.139(0.016)$ & $25.195(0.007)$ & $0.090(0.558)$ \\
\hline Colombia, 1959-2011 & & $8.435(0.673)$ & $6.439(0.717)$ & $0.251(0.433)$ \\
\hline Finland, 1914-1985 & & $6.825(0.742)$ & $6.765(0.622)$ & $1.391(0.071)$ \\
\hline Germany, 1876-1913 & & $9.882(0.571)$ & $8.996(0.503)$ & $0.490(0.197)$ \\
\hline Guatemala, 1980-2012 & & $20.282(0.058)$ & $18.014(0.049)$ & $0.053(0.872)$ \\
\hline \multirow{2}{*}{ Japan } & $1885-1913$ & $11.870(0.408)$ & $10.834(0.333)$ & $0.455(0.094)$ \\
\hline & $1955-2013$ & $9.846(0.511)$ & $9.240(0.427)$ & $0.141(0.888)$ \\
\hline Korea, 1970-2014 & & $18.407(0.074)$ & $16.909(0.060)$ & $0.175(0.351)$ \\
\hline Italy, 1949-1996 & & $15.767(0.145)$ & $12.474(0.171)$ & $0.457(0.230)$ \\
\hline
\end{tabular}




\begin{tabular}{|c|c|c|c|}
\hline \multicolumn{4}{|c|}{ 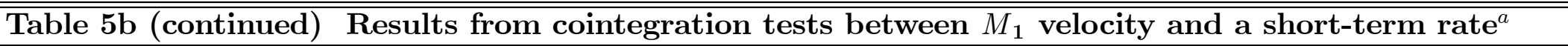 } \\
\hline & I: Johansen's tests of the $\mathrm{n}$ & ll of no cointegration & \multirow[b]{2}{*}{$\begin{array}{l}\text { II: Shin's tests } \\
\text { of the null of } \\
\text { cointegration }\end{array}$} \\
\hline & $\begin{array}{l}\text { Trace tests of the null of no } \\
\text { cointegration against the } \\
\text { alternative of } 1 \text { or more } \\
\text { cointegration vectors: }\end{array}$ & $\begin{array}{l}\text { Maximum eigenvalue } \\
\text { tests of } 0 \text { versus } 1 \\
\text { cointegration vectors: }\end{array}$ & \\
\hline Netherlands, 1950-1992 & $14.491(0.211)$ & $10.052(0.349)$ & $0.253(0.381)$ \\
\hline New Zealand, 1934-2004 & $16.696(0.106)$ & $15.823(0.060)$ & $0.647(0.291)$ \\
\hline Norway, 1946-2013 & $22.770(0.021)$ & $17.992(0.031)$ & $0.932(0.084)$ \\
\hline \multicolumn{4}{|l|}{ Portugal } \\
\hline $1914-1965$ & $26.827(0.012)$ & $25.749(0.004)$ & $0.086(0.495)$ \\
\hline $1966-1998$ & $11.733(0.422)$ & $8.818(0.511)$ & $0.278(0.004)$ \\
\hline South Africa, 1967-2014 & $17.877(0.117)$ & $16.635(0.068)$ & $0.489(0.109)$ \\
\hline Spain, 1941-1989 & $14.260(0.183)$ & $13.569(0.120)$ & $0.272(0.272)$ \\
\hline \multicolumn{4}{|l|}{ Switzerland } \\
\hline $1851-1906$ & $15.883(0.109)$ & $12.625(0.158)$ & $0.635(0.225)$ \\
\hline $1948-2005$ & $38.892(0.000)$ & $35.289(0.000)$ & $0.985(0.033)$ \\
\hline Turkey, 1968-2014 & $6.817(0.814)$ & $4.614(0.896)$ & $0.164(0.523)$ \\
\hline United Kingdom, 1922-2014 & $23.261(0.019)$ & $21.680(0.011)$ & $0.900(0.046)$ \\
\hline \multicolumn{4}{|l|}{ United States, 1915-2014 } \\
\hline based on the standard $M_{1}$ aggregate & $7.152(0.767)$ & $4.822(0.870)$ & $3.507(0.007)$ \\
\hline based on Lucas and Nicolini's 'New $M_{1}$ ' aggregate & $20.769(0.038)$ & $16.557(0.048)$ & $0.554(0.121)$ \\
\hline Venezuela, 1962-1999 & $7.635(0.724)$ & $5.836(0.776)$ & $0.412(0.112)$ \\
\hline
\end{tabular}


Candidate cointegration residuals, de-meaned and standardized

Bolivia, 1980-2013

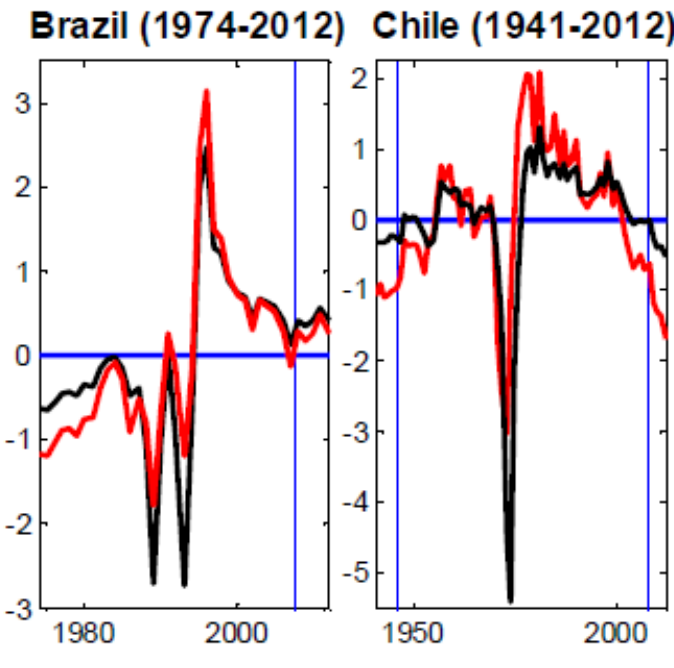

Israel (1983-2013)

Mexico
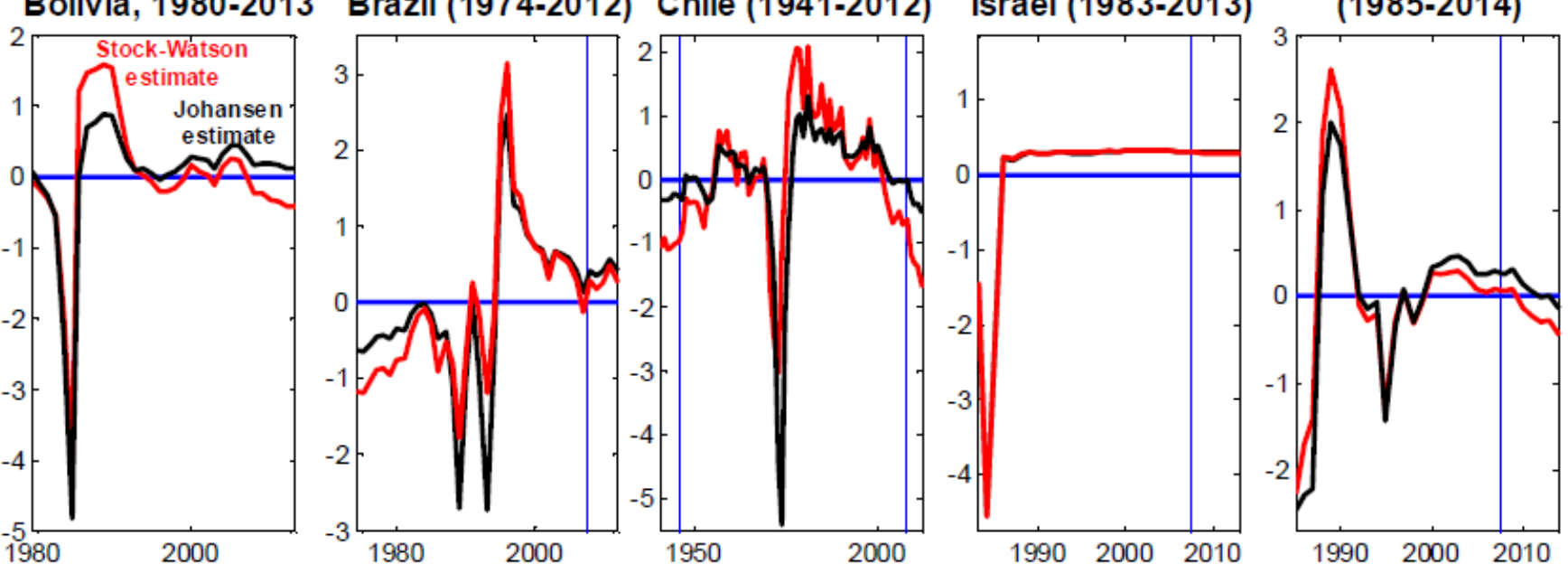

Bootstrapped distributions of the coefficient on the short rate
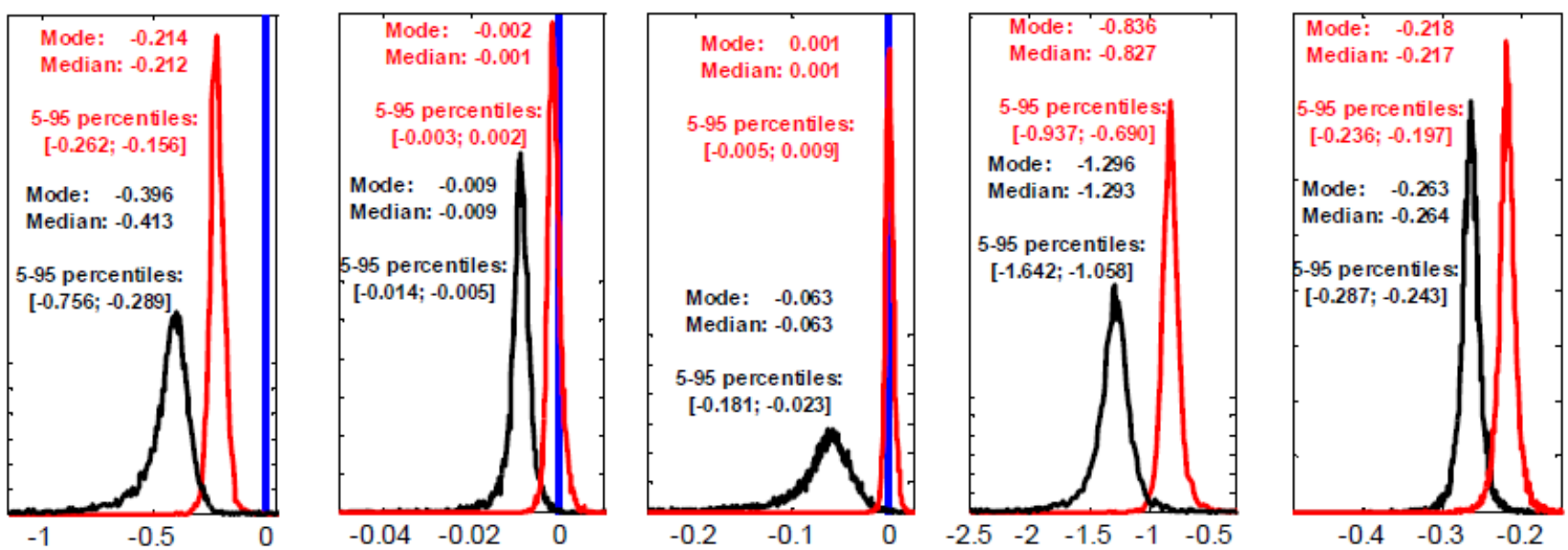

Figure 10 Selden-Latané specification, imposing unitary income elasticity: cointegration residuals and bootstrapped distributions of the coefficients on the short rate 
Candidate cointegration residuals, de-meaned and standardized Australia (1969-2014) Canada (1934-2006) Canada (1967-2013) Colombia (1959-2011)

Finland (1914-1985)
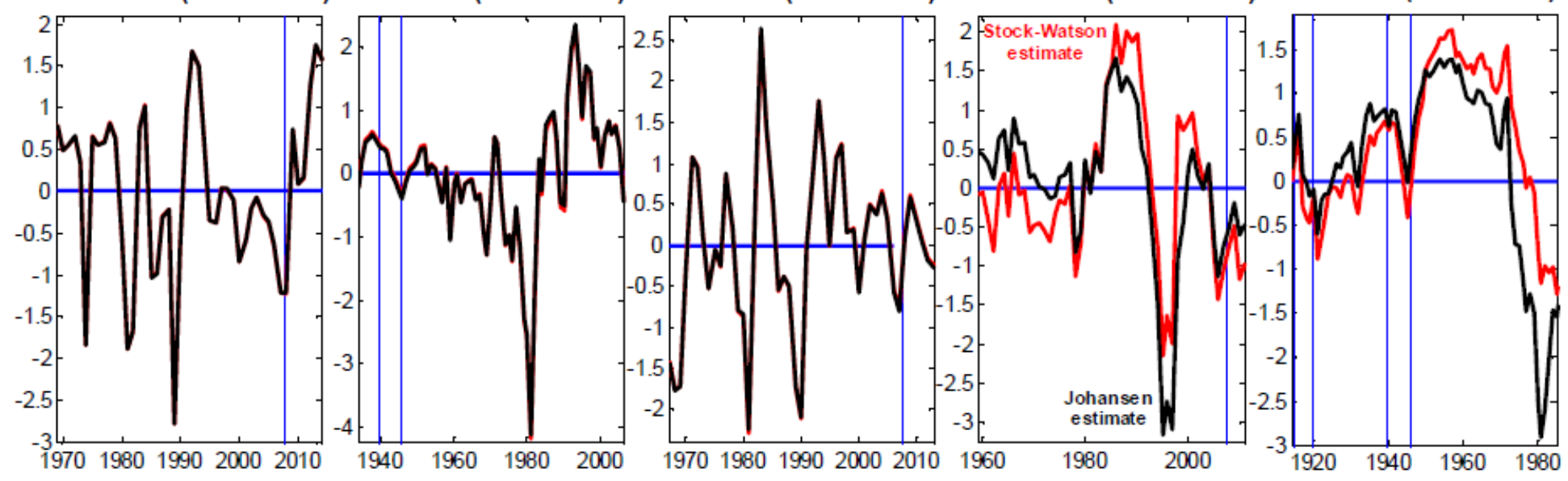

Bootstrapped distributions of the coefficient on the short rate
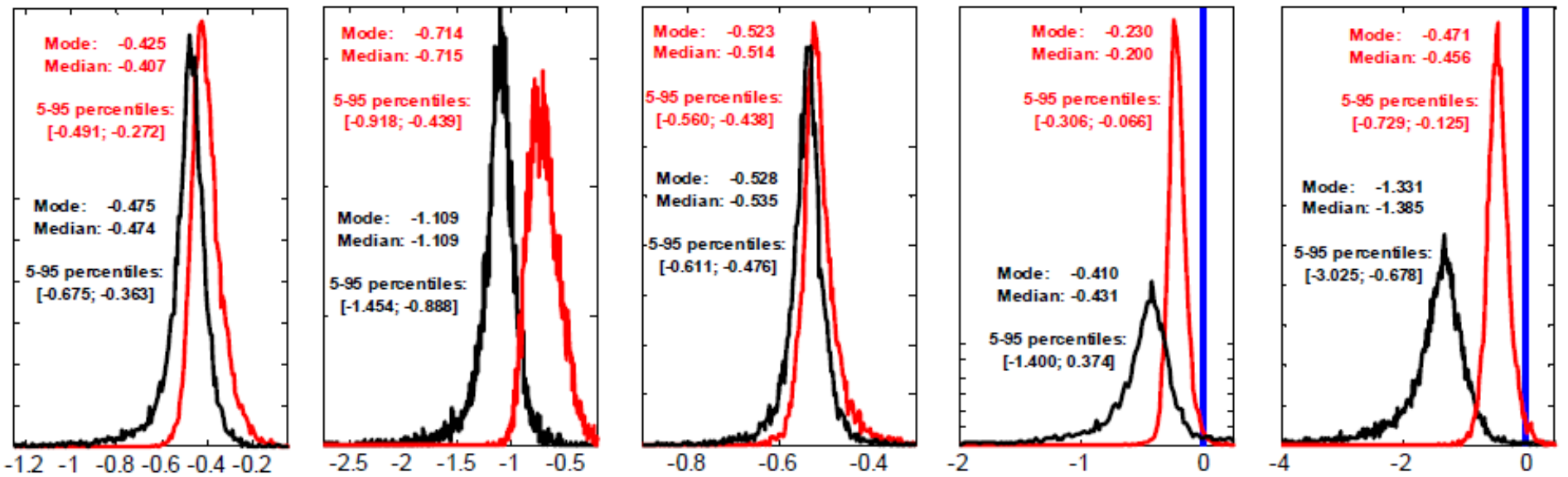

Figure 11 Selden-Latané specification, imposing unitary income elasticity: cointegration residuals and bootstrapped distributions of the coefficients on the short rate 
Candidate cointegration residuals, de-meaned and standardized
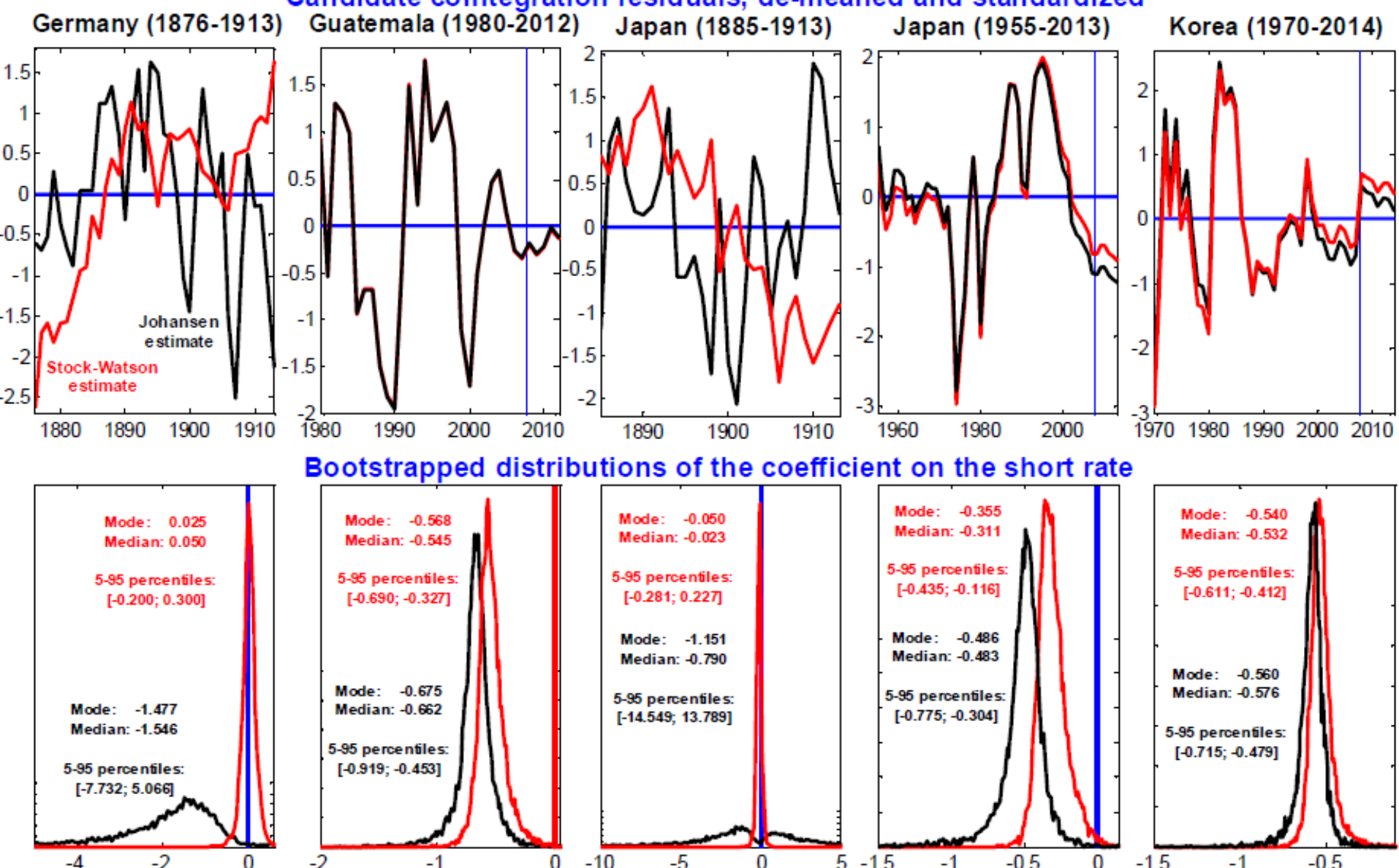

Bootstrapped distributions of the coefficient on the short rate
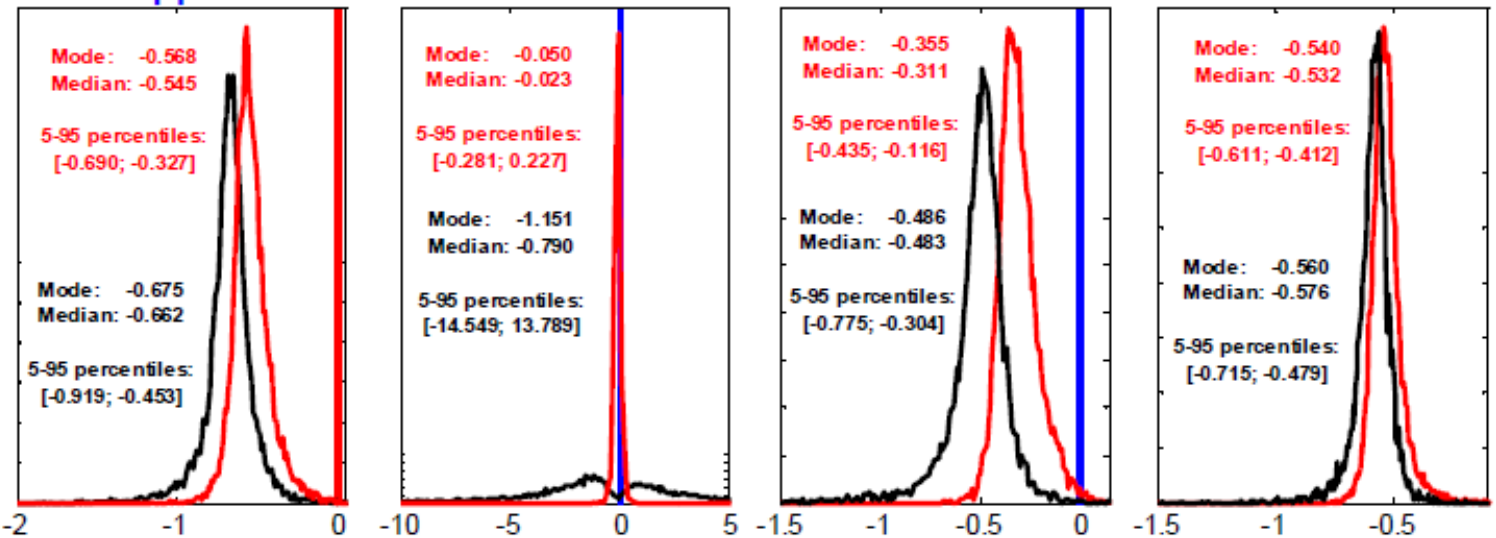

Figure 12 Selden-Latané specification, imposing unitary income elasticity: cointegration residuals and bootstrapped distributions of the coefficients on the short rate 

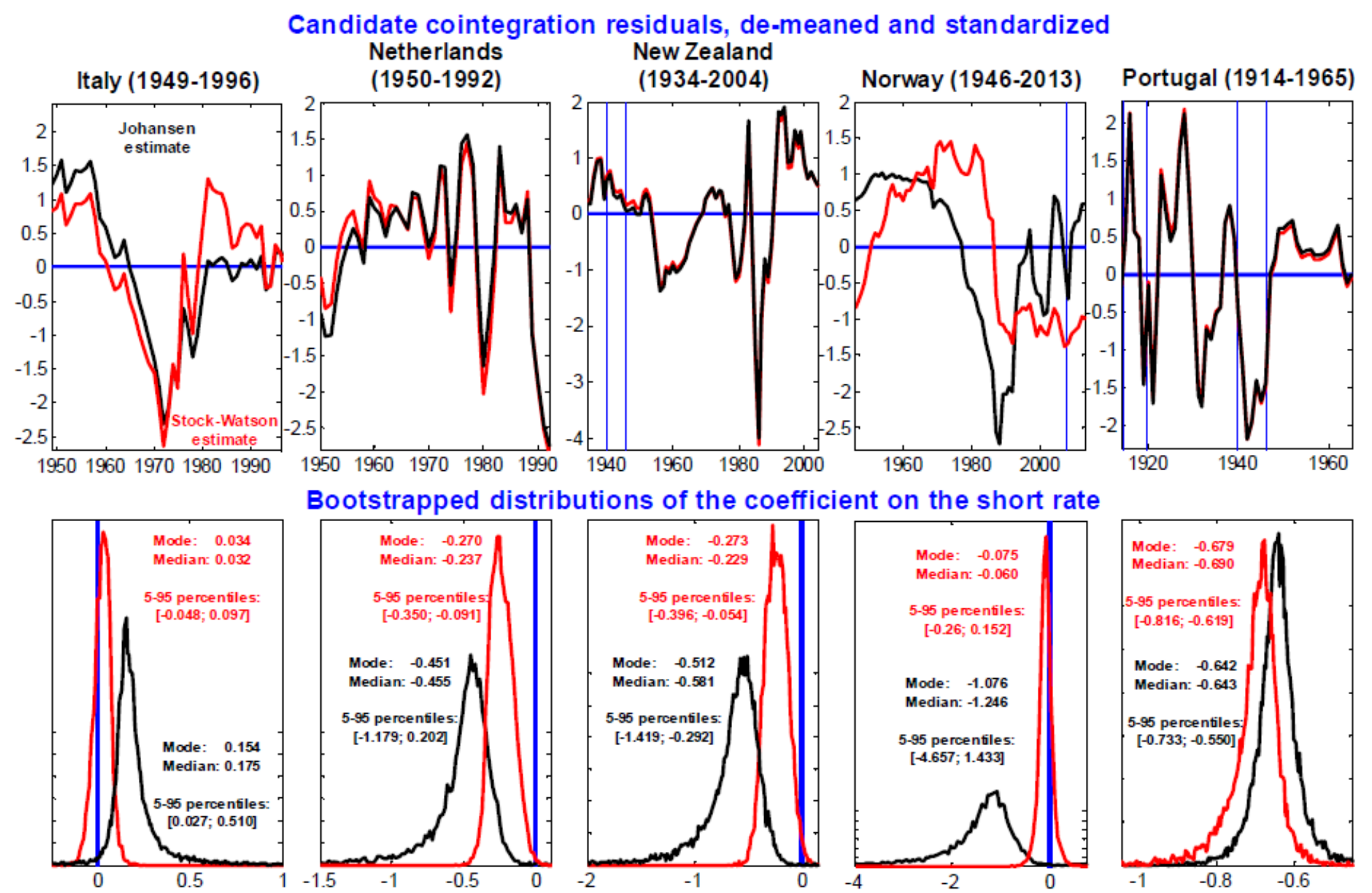

Figure 13 Selden-Latané specification, imposing unitary income elasticity: cointegration residuals and bootstrapped distributions of the coefficients on the short rate 

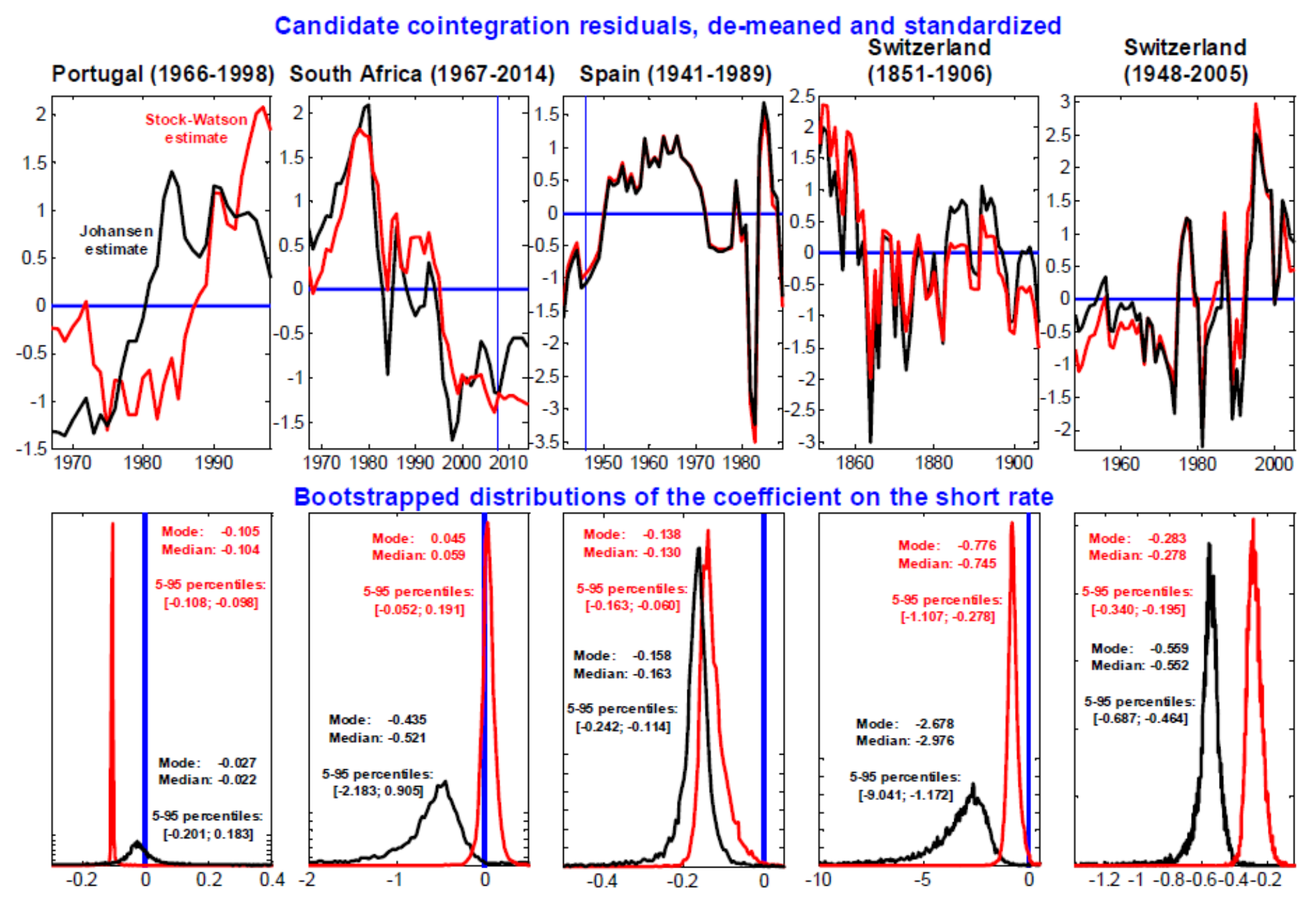

Bootstrapped distributions of the coefficient on the short rate
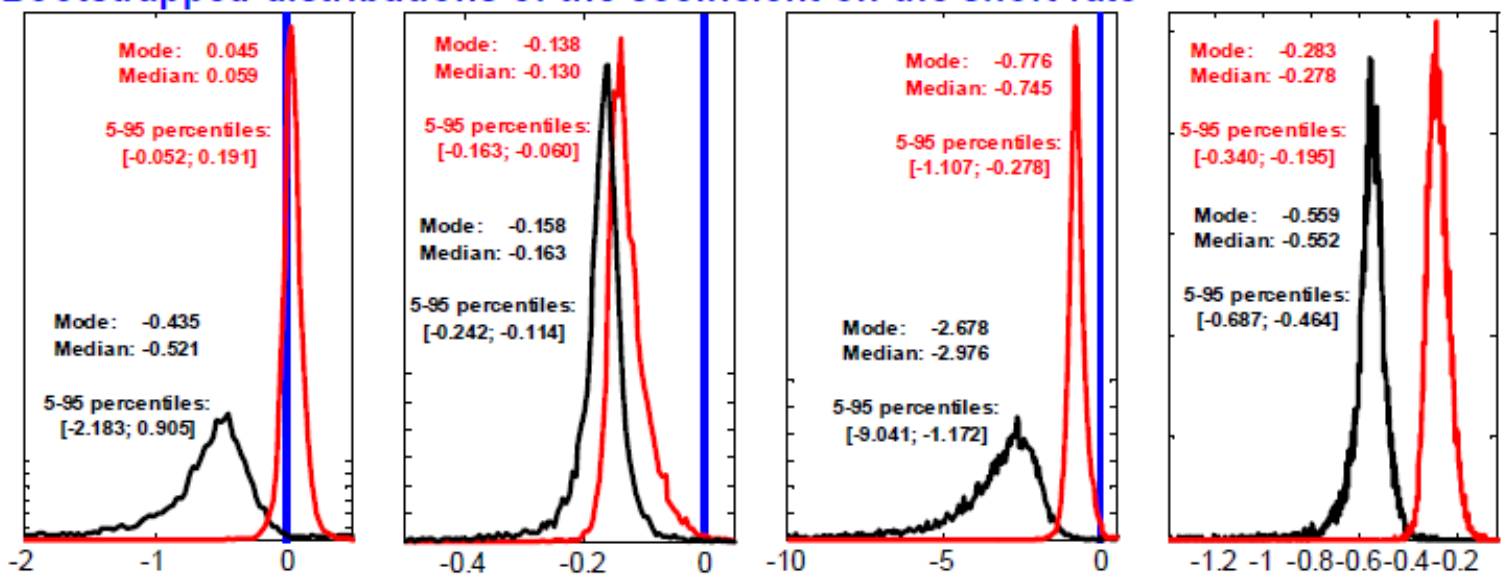

Figure 14 Selden-Latané specification, imposing unitary income elasticity: cointegration residuals and bootstrapped distributions of the coefficients on the short rate 
Candidate cointegration residuals, de-meaned and standardized
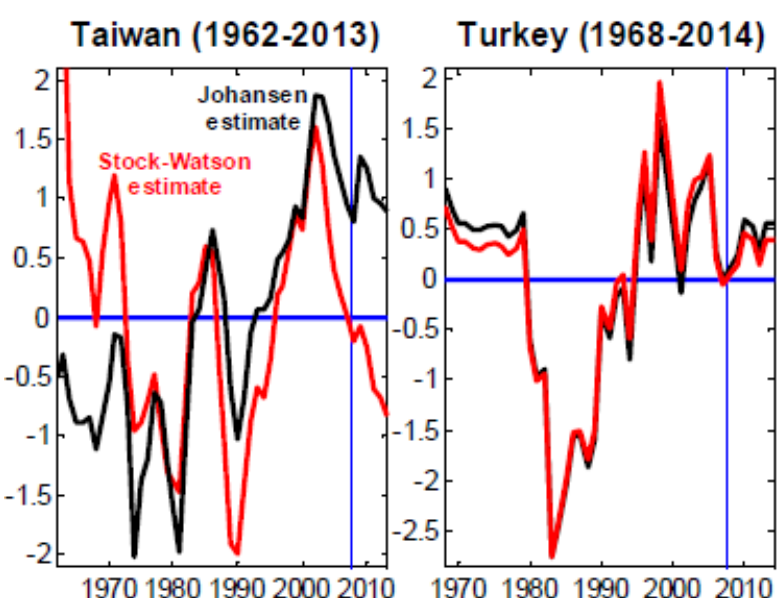

United Kingdom $(1922-2014)$

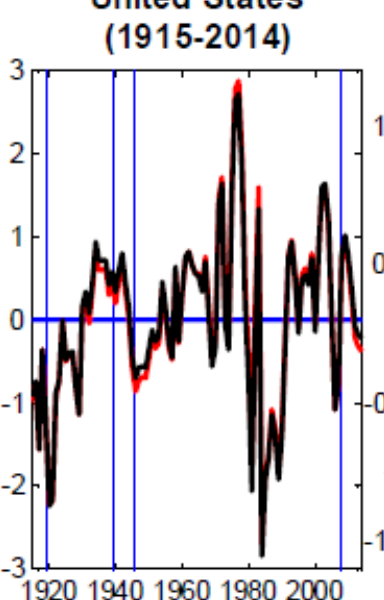

Venezuela (1962-1999)

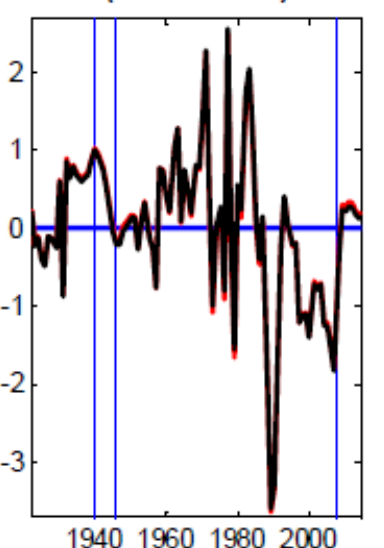
Bootstrapped distributions of the coefficient on the short rate
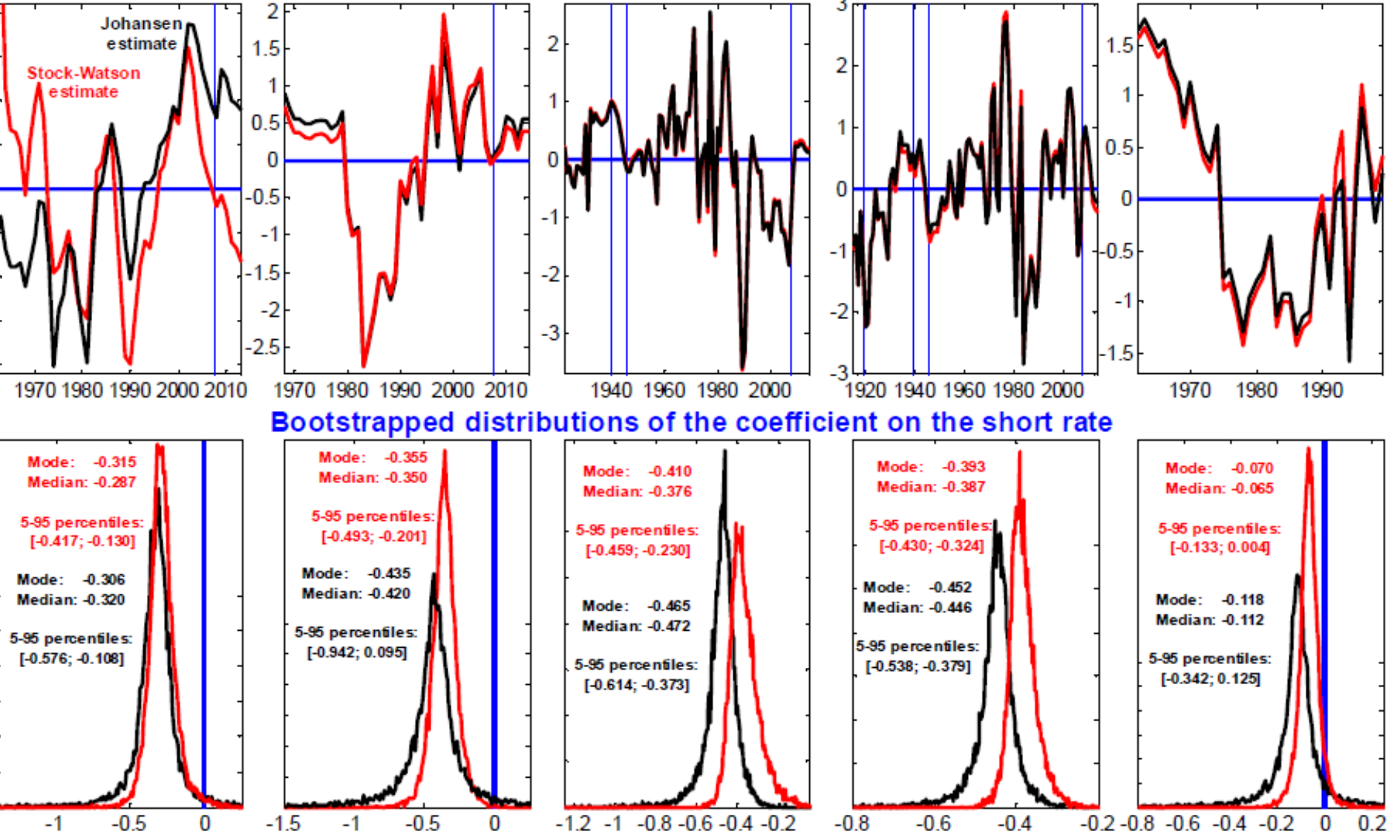

Figure 15 Selden-Latané specification, imposing unitary income elasticity: cointegration residuals and bootstrapped distributions of the coefficients on the short rate 
1965), and Switzerland (1948-2005), whereas the two tests produce opposite results for Bolivia, Germany (1876-2013), New Zealand, and South Africa.

\subsection{The estimated coefficients on the short rate}

We now turn our discussion to the bottom rows of Figures 4 to 9 -showing the estimated interest rate elasticities, which according to the Baumol-Tobin specification ought to be equal to $-1 / 2$ - and to Table LLCO.3 in the online appendix, reporting bootstrapped $p$-values for testing the null hypothesis that the elasticity be equal to $-1 / 2$. Overall results are mixed, with the null being rejected in 17 cases out of 32 based on Johansen's estimator of the cointegration vector, and in 21 cases based on Stock and Watson's estimator.

The bottom rows of Figures 10 to 15 show minus the estimated coefficients on the short rate $^{38}$ based on the Selden-Latané specification, whereas Table SELA.3 in the online appendix reports bootstrapped $p$-values for testing the null hypothesis that the coefficients be equal to -0.4. Since, different from Baumol-Tobin, theory does not provide us with a numerical benchmark which can be used in order to perform statistical tests, we have set such benchmark to -0.4, which is roughly equal to the median or modal estimates we obtain for the United States based on the Lucas-Nicolini aggregate (see Figure 15). (This is why Table SELA.3 does not report results for the United States based on the Lucas-Nicolini aggregate.) The null of -0.4 is rejected in 19 cases out of 33 based on Johansen's estimator of the cointegration vector, and in 25 cases based on Stock and Watson's.

\subsection{Towards a unified framework?}

Is there any way to learn from this exercise which specification-log-log, or SeldenLatané - better fits the data? The econometric approach used herein does not nest the two specifications, and it therefore does not allow us to formally test which of them is better. Visual inspection, however, might favor the log-log specification. To see this, we compare the point estimates of the parameters of both specifications for two sets of countries. Both sets provide good visual evidence and for all countries in both sets there is strong evidence of cointegration in at least one of the specifications. The first set comprises the United States, the United Kingdom, Australia, Canada and New Zealand: All of these countries experienced important variations on their nominal interest rates, but they are low-inflation countries. The second group is composed by Brazil, Bolivia, Chile, and Israel, all high-inflation countries. ${ }^{39}$ In the case of the log-log specification, the estimates are very similar, and around $1 / 2$, as

\footnotetext{
${ }^{38}$ We report minus the coefficient on the short rate in order to make these results as comparable as possible to those based on the log-log and semi-log specifications.

${ }^{39}$ For Argentina, the Selden-Latané specification could not be estimated, since, as explained in the text, the necessary conditions were not fulfilled.
} 
Baumol-Tobin linear technology implies, for most countries: Sometimes they are a bit smaller (as for the U.S., Chile or Brazil), and sometimes a bit higher (as for the U.K., New Zealand or Israel), depending on the specific details of the statistical procedures used, but overall, the sense that 'one size fits all' dominates the estimates.

When considering the Selden-Latané specification, on the other hand, the first set of countries consistently delivers estimates between -0.5 and -0.4 , whereas for some countries belonging to the second group the coefficient on the short rate can get to values such as -0.009 for Brazil, or -0.06 for Chile, and very precisely estimated.

Thus, if we are in search of a unified framework, the Baumol-Tobin specification should be the preferred one. On the other hand, when focusing on the experience of low-inflation countries, such as the United States, the United Kingdom, Canada and Australia, the Selden-Latané specification appears as the preferred one.

One possible interpretation therefore is that the technology that relates number of transactions to total costs exhibits decreasing marginal cost for low values of interest rates, as implied by the Selden-Latane functional form but that it eventually becomes constant, as implied by Baumol-Tobin specification.

\section{Conclusions}

We use a simple model of a transaction demand for money to guide a thorough investigation of the stability of the long run relationship between the ratio of money to output and a short term nominal interest rate. The model we use generalizes the standard Baumol-Tobin model by allowing for general functions relating the total cost of making transactions and the number of portfolio adjustments. We show how alternative assumptions regarding this function delivers alternative empirical specifications that have been used in the literature. We then take these specifications to the data.

Our data set comprises 31 countries for periods that range from 35 to 100 years. The log-log specification, which roughly corresponds to the linear cost function assumed by Baumol and Tobin, with an income elasticity of 1 and an interest rate elasticity close to 0.5 performs remarkably well for all the countries. It is also the case, however, that a specification in which the ratio of money to output is inversely related to a linear function of the short term nominal interest rate is a better description of the data if we focus on countries in which the inflation rate has been in the low range, like the U.S. or the U.K.

Overall, while there are a few countries for which the relationship cannot be detected, we find very strong evidence of a stable long run money demand. 


\section{References}

Alvarez, F., And F. Lippi (2009): "Financial Innovation and the Transaction Demand for Cash," Econometrica, 77(2), 363-402.

BAffigi, A. (2011): "Italian National Accounts: A Project of Banca d'Italia, ISTAT and University of Rome Tor Vergata," Economic History Working Papers, Banca d'Italia, n. 18.

BALL, L. (2001): "Another Look at Long-Run Money Demand," Journal of Monetary Economics, 47, 31-44.

Banca D Italia (2013): "Tavole Storiche, Indicatori Monetari e Finanziari," Dicembre 2013.

Barciela-López, C., A. Carreras, and X. Tafunell (2005): Estadísticas Históricas de España: Siglos XIX-XX, Volume III. Fundacion BBVA.

Barkai, H., and N. Liviatan (2007): The Bank of Israel Volume 1: A Monetary History. Oxford University Press.

BARro, R. (1982): "United States Inflation and the Choice of a Monetary Standard," in Hall, R.E., ed., 'Inflation: Causes and Effects', University of Chicago Press.

Barsky, R. (1987): "The Fisher Hypothesis and the Forecastability and Persistence of Inflation," Journal of Monetary Economics, 19(1), 3-24.

Benati, L. (2008): "Investigating Inflation Persistence Across Monetary Regimes," Quarterly Journal of Economics, 123(3), 1005-1060.

- (2015): "The Long-Run Phillips Curve: A Structural VAR Investigation," Journal of Monetary Economics, 76(November), 15-28.

Bernanke, B., M. Gertler, and M. Watson (1997): "Systematic Monetary Policy and the Effects of Oil Price Shocks," Brookings Papers on Economic Activity, 1997(1), 91-157.

Boeschoten, W. (1992): Hoofdlijnen van de economische geschiedenis van Nederland 1900-1990. Amsterdam: NIBE.

Braun-Llona, J., M. Braun-Llona, I. Briones, J. Diaz, R. Luders, and G. Wagner (1998): "Economia Chilena 1810-1995. Estadisticas Historicas," Pontificia Universidad Catolica de Chile, documento de trabajo.

Bundesbank (1976): Deutsches Geld- und Bankwesen in Zahlen 1876-1975. Deutsche Bundesbank. 
Capie, F., and A. Webber (1985): A Monetary History of the United Kingdom, 1870-1982. London, Allen and Unwin.

Cavaliere, G., A. Rahbek, and R. Taylor (2012): "Bootstrap Determination of the Co-Integration Rank in Vector Autoregressive Models," Econometrica, 80(4), $1721-1740$.

Cavaliere, G., R. Taylor, and C. Trenkler (2015): "Bootstrap Co-Integration Rank Testing: The Effect of Bias-Correcting Parameter Estimates," Oxford Bulletin of Economics and Statistics, forthcoming, -.

DE Jong, A. (1967): "Geschiedenis van de Nederlandsche Bank," Volume 3, pp. $644-645$.

Diebold, F., And C. Chen (1996): "Testing Structural Stability with Endogenous Breakpoint: A Size Comparison of Analytic and Bootstrap Procedures," Journal of Econometrics, 70(1), 221-241.

Elliot, G., T. Rothenberg, and J. H. Stock (1996): "Efficient Tests for an Autoregressive Unit Root," Econometrica, 64(4), 813-836.

Engle, R., And C. Granger (1987): "Cointegration and Error Correction: Representation, Estimation, and Testing," Econometrica, 55, 251-276.

Fratianni, M., and F. Spinelli (1997): A Monetary History of Italy. Cambridge University Press.

Friedman, B. M., And K. N. Kuttner (1992): "Money, Income, Prices, and Interest Rates," American Economic Review, 82(3), 472-492.

Furlong, K. (2001): “The Montreal Gazette Call Loan Rate, 1871-1907," Canadian Journal of Economics, 34(1), 165-173.

Grossman, S., And L. Weiss (1983): "A Transactions-Based Model of the Monetary Transmission Mechanism," American Economic Review, 73(5), 871-80.

Hanvisto, T. (1992): Money and Economic Activity in Finland, 1866-1985. Lund Economic Studies.

Hansen, B. (1999): "The Grid Bootstrap and the Autoregressive Model," Review of Economics and Statistics, 81(4), 594-607.

Hills, S., and R. T. N. Dimsdale (2010): "The UK Recession in Context: What Do Three Centuries of Data Tell Us?," Bank of England Quarterly Bulletin, (2010 Q4), 277-291. 
Homer, S., And R. Sylla (2005): A History of Interest Rates. John Wiley and Sons.

Johansen, S. (2002): "A Small Sample Correction of the Test for Cointegrating Rank in the Vector Autoregressive Model," Econometrica, 70, 1929-1961.

Junguito, R., And H. Rincón (2007): "La política fiscal en el siglo XX en Colombia," in J. Robinson and M. Urrutia (eds.), Economía Colombiana del Siglo XX: Un Análisis Cuantitativo, Banco de la República y Fondo de Cultura Económica, Colombia, pp. - .

Kilian, L. (1998): "Small-Sample Confidence Intervals for Impulse-Response Functions," Review of Economics and Statistics, pp. 218-230.

Klovland, J. T. (2004): "Monetary aggregates in Norway 1819-2003," in Øyvind Eitrheim, Jan T. Klovland and Jan F. Qvigstad, eds., Historical Monetary Statistics for Norway 1819Ü2003, Norges Bank, Occasional Paper N. 35/2004.

Latané, H. A. (1960): "Income Velocity and Interest Rates: A Pragmatic Approach," Review of Economics and Statistics, 42(4), 445-449.

Luchs JR., R. E. (1988): "Money Demand in the United States: A Quantitative Review," Carnegie-Rochester Conference Series on Public Policy, 29, 137-168.

LuCAs JR., R. E., And J.-P. Nicolini (2015): "On the Stability of Money Demand," Journal of Monetary Economics, forthcoming.

Luetkepohl, H. (1991): Introduction to Multiple Time Series Analysis, II edition. Springer-Verlag.

Mata, E., And N. Valerio (2011): The Concise Economic History of Portugal: A Comprehensive Guide.

Meltzer, A. H. (1963): "The Demand for Money: The Evidence from the Time Series," Journal of Political Economy, 71(3), 219-246.

Metcalf, C., A. Redish, and R. Shearer (1996): "New Estimates of the Canadian Money Stock: 1871-1967," University of British Columbia Discussion Paper No. 96-17, July 1996.

Muscatelli, A., And F. Spinelli (2000): "The Long-Run Stability of the Demand for Money: Italy 1861," Journal of Monetary Economics, 45, 717-739.

Officer, L. H., And S. H. Williamson (2015): "The Annual Consumer Price Index for the United States, 1774-2014," available at: http://www.measuringworth.com/uscpi/. 
Rolnick, A. J., And W. Weber (1997): "Money, Inflation, and Output Under Fiat and Commodity Standards," Journal of Political Economy, 105(6), 1308-1321.

RotemberG, J. J. (1984): "A Monetary Equilibrium Model with Transactions Costs," Journal of Political Economy, 92(1), 40-58.

Saint-Marc, M. (1983): Histoire Monetarie de la France, 1880-1980. Paris, Presses Universitaires de la France.

Selden, R. T. (1956): "Monetary Velocity in the United States," in Milton Friedman, editor, ŚStudies in the Quantity Theory of Money $\breve{S}$, University of Chicago Press, pp. 405-454.

Stock, J. H., and M. W. Watson (1993): "A Simple Estimator of Cointegrating Vectors in Higher Order Integrated Systems," Econometrica, 61(4), 783-820.

TAmaki, N. (1995): Japanese Banking: A History (1859-1959). Cambridge University Press. 


\section{A Interest Rate Rules and Money Rules}

Note that (7) and (6) imply

$$
\beta E\left[\frac{V^{\prime}\left(\omega^{\prime}\right)}{\pi\left(s^{\prime}\right)}\right]=\frac{\varepsilon}{R}
$$

and

$$
\delta=\frac{\varepsilon}{n}\left[1-\frac{R^{m}}{R}\right]
$$

Replacing on equation (4) implies

$$
U^{\prime}(x)=\frac{\varepsilon}{R}+\frac{\varepsilon}{n}\left[1-\frac{R^{m}}{R}\right]
$$

or

$$
\begin{aligned}
\varepsilon & =\frac{U^{\prime}(x)}{\left[\frac{1}{n}+\frac{1}{R}\left(1-\frac{1}{n} R^{m}\right)\right]} \\
& =\frac{n U^{\prime}(x)}{\left[1+\frac{1}{R}\left(n-R^{m}\right)\right]}
\end{aligned}
$$

Now, combining (7) and (9) we obtain

$$
\beta E\left[\frac{\varepsilon^{\prime}\left(s^{\prime}\right)}{\pi\left(s^{\prime}\right)}\right] R=\varepsilon
$$

or, using the result above and noting that $x=z(1-\theta(n))$

$$
\beta E\left[\frac{n\left(s^{\prime}\right) U^{\prime}\left[\left(z\left(s^{\prime}\right)\left(1-\theta\left(n\left(s^{\prime}\right)\right)\right)\right]\right.}{\left[1+\frac{1}{R\left(s^{\prime}\right)}\left(n\left(s^{\prime}\right)-R^{m}\left(s^{\prime}\right)\right)\right]} \frac{1}{\pi\left(s^{\prime}\right)}\right] R=\frac{n U^{\prime}(z(1-\theta(n)))}{\left[1+\frac{1}{R}\left(n-R^{m}\right)\right]} .
$$

But, replacing the inflation rate $\pi\left(s^{\prime}\right)=\frac{M\left(s^{\prime}\right) x\left(s^{\prime}\right)}{M x} \frac{n}{n\left(s^{\prime}\right)}$, we obtain

$$
\beta E\left[\frac{U^{\prime}\left[\left(z\left(s^{\prime}\right)\left(1-\theta\left(n\left(s^{\prime}\right)\right)\right)\right]\right.}{\left[1+\frac{1}{R\left(s^{\prime}\right)}\left(n\left(s^{\prime}\right)-R^{m}\left(s^{\prime}\right)\right)\right]} \frac{M}{M\left(s^{\prime}\right)}\right] R=\frac{z(1-\theta(n)) U^{\prime}(z(1-\theta(n)))}{\left[1+\frac{1}{R}\left(n-R^{m}\right)\right]} .
$$

Now, if we let

$$
\Omega=\frac{U^{\prime}(z(1-\theta(n))) z(1-\theta(n))}{\left[1+\frac{1}{R}\left(n-R^{m}\right)\right]}
$$

we can write the expression above as

$$
\beta E\left[\Omega\left(s^{\prime}\right) \frac{M}{M^{\prime}}\right] R=\Omega .
$$


But

$$
M\left(s^{\prime}\right)=M+\mu\left(s^{\prime}\right) P
$$

SO

$$
\frac{M}{M\left(s^{\prime}\right)}=1-\frac{\mu\left(s^{\prime}\right)}{\pi\left(s^{\prime}\right) m\left(s^{\prime}\right)}=\left(1-\frac{\mu\left(s^{\prime}\right) n\left(s^{\prime}\right)}{\pi\left(s^{\prime}\right) z\left(s^{\prime}\right)\left(1-\theta\left(n\left(s^{\prime}\right)\right)\right)}\right)
$$

Replacing above

$$
\beta E\left[\Omega\left(s^{\prime}\right)\left(1-\frac{\mu\left(s^{\prime}\right) n\left(s^{\prime}\right)}{\pi\left(s^{\prime}\right) z\left(s^{\prime}\right)\left(1-\theta\left(n\left(s^{\prime}\right)\right)\right)}\right)\right] R=\Omega .
$$

or

$$
\beta E\left(\frac{\Omega\left(s^{\prime}\right)}{\Omega}\right)-\beta E\left(\frac{\Omega\left(s^{\prime}\right)}{\Omega} \frac{\mu\left(s^{\prime}\right) n\left(s^{\prime}\right)}{\pi\left(s^{\prime}\right) z\left(s^{\prime}\right)\left(1-\theta\left(n\left(s^{\prime}\right)\right)\right)}\right)=\frac{1}{R} .
$$

In general, there are many solutions for the growth rate of money stochastic sequence $\mu\left(s^{\prime}\right)$ that is consistent with a given interest rate. This is so, since the nominal interest rate pins down (weighted) expected inflation, but there are many distributions of future price levels that are consistent with the same expected value of inflation. Notice, however, that there exists a unique growth rate of money that is consistent with the interest rate sequence, and that is predetermined the period before, the solution, $\mu^{*}$, satisfying

$$
E\left(\frac{\beta \Omega\left(s^{\prime}\right)}{\Omega}\right)-\mu^{*} E\left(\frac{\beta \Omega\left(s^{\prime}\right)}{\Omega} \frac{n\left(s^{\prime}\right)}{\pi\left(s^{\prime}\right) z\left(s^{\prime}\right)\left(1-\theta\left(n\left(s^{\prime}\right)\right)\right)}\right)=\frac{1}{R} .
$$

\section{B The Data}

Here follows a detailed description of the dataset. All of the data used in this paper are from original sources. Specifically, they are from either $(i)$ original hard copy (books, or, in the case of West Germany's $M_{1}$, scanned PDFs of the Bundesbank's Monthly Reports, which are available from the Bundesbank's website), in which case we have entered the data manually into Excel; or (ii) central banks' or national statistical agencies websites (these data are typically available in either Excel or simple text format). There are only four exceptions (that is: four series, not four countries) to this, which we discuss below. In those cases we were not able to find the data we were looking for in original documents, and we therefore took them from the International Monetary Fund's International Financial Statistics (henceforth, IMF and IFS, respectively). Some of the data (detailed below) had been previously used by Rolnick and Weber (1997), to which the reader is referred to for specific details about the original sources. The Rolnick-Weber (henceforth, RW) dataset is available at the 'Warren Weber Collection' at the website of the Federal Reserve Bank of Minneapolis. 


\section{B.1 Argentina}

With the single exception of an $M_{2}$ series available for the period 1884-1994, which is from the RW dataset, all other series are from the Banco Central de la República Argentina (the central bank, henceforth, Banco Central). Specifically, two series for $M_{1}$ and $M_{3}$, available for the periods 1900-2004 and 1863-2004, respectively, are from Banco Central's Table 7.1.4 ('Agregados Monetarios'). A series for a short-term nominal interest rate, available for the period 1821-2004, is from Banco Central's Table 7.1.4 ('Tasas activas'). Interestingly, among all of the countries we consider in this paper, Argentina is the only one which directly provides an estimate of the (inverse of) the velocity of circulation of monetary aggregates. Specifically, Banco Central's Table 7.1.4 provides the ratios between either $M_{1}$ and $M_{3}$ and nominal GDP (' $M_{1} \%$ PBI' and ' $M_{3} \%$ PBI', respectively; 'PBI' is the Spanish acronym for GDP). The two sample periods are the same as for $M_{1}$ and $M_{3}$, respectively. Based on the ratio between $M_{1}$ and GDP, and the series for $M_{1}$, we then reconstructed a nominal GDP series.

\section{B.2 Australia}

An $M_{1}$ series for the period 1900-2014 has been constructed in the following way. An annual series for the period 1900-1973 has been kindly provided by Cathie Close of the Reserve Bank of Australia (henceforth, $R B A$ ). A monthly seasonally unadjusted series, available since 1975 , is from the $R B A$ 's website (' $M_{1}, \$$ billion, RBA, 42216'; the series' acronym is DMAM1N), and it has been converted to the annual frequency by taking annual averages (since for the year 1975 the series is available from February, the average for that year has been computed for the period FebruaryDecember). The missing observation for 1974 has been interpolated as in Bernanke, Gertler, and Watson (1997), using as interpolator series the IMF's IFS series labelled as 'Money', which, over the periods of overlapping, closely co-moves with both $M_{1}$ series. A 90-day nominal interest rate for bank accepted bills and negotiable certificates of deposit is from the $R B A$ 's website ('90-day BABs/NCDs, Bank Accepted Bills/Negotiable Certificates of Deposit-90 days, Monthly, Original, Per cent, AFMA, 42156, FIRMMBAB90'). It is available since 1969. A series for nominal GDP, available since 1960, is from the Australian Bureau of Statistics ('Gross domestic product: Current prices; A2304617J; \$ Millions').

\section{B.3 Bolivia}

Series for nominal GDP, the GDP deflator, the monetary base, $M_{0}, M_{1}$, and a shortterm nominal interest rate, all available for the period 1980-2013, are from the Unidad de Analisis de Politicas Sociales y Economicas (Bolivia's national statistical agency, known as $U D A P E$ for short). 


\section{B.4 Brazil}

Series for nominal GDP, $M_{0}, M_{1}$, and GDP deflator inflation, all available for the period 1901-2000, are from IBGE's (the Brazilian Institute of Geography and Statistics) Estatisticas do Seculo $X X$ (Statistics of the XX Century). The internet link is: http://seculoxx.ibge.gov.br/economicas. A series for nominal GDP for the period 2000-2012 is also from IBGE. Series for $M_{0}$ and $M_{1}$ for the period 2000-2012 are from the Banco Central do Brasil (Brazil's central bank). A series for a short-term nominal interest rate for the period 1974-2012 is from the Banco Central do Brasil. Two series for a nominal Government bond yield (period: 1901-1913 and 1929-1959) and the Banco Central do Brasil's Discount rate (period: 1948-1989) are both from Homer and Sylla (2005)'s Table 81, pages 629-631.

\section{B.5 Canada}

An annual series for nominal GDP, available since 1870, has been constructed by linking the Urquhart series (available from Statistics Canada, which is Canada's national statistical agency), for the period 1870-1924; series 0380-0515, v96392559 (1.1) from Statistics Canada, for the period 1925-1980; and series 0384-0038, v62787311 (1.2.38) from Statistics Canada, for the period 1981-2013. A series for the GDP deflator available since 1870 is from Statistics Canada (the series' code is 3830027 , v55080518 (1.11)). An annual series for the CPI starting in 1870 is from the RW dataset until 1914, and from Statistics Canada after that. A short-term interest rate for the period 1871-1907 (specifically: the 'Montreal call loan rate') is from Furlong (2001). As for the later period, we use a series for the 3-month Treasury bill rate which has been constructed by linking the series from the Historical Statistics of Canada, available for the period 1934-1935, to the series 'Treasury Bill Auction - Average Yields - 3 Month, Per cent / en pourcentage' from the Bank of Canada (Canada's central bank). Monthly series for $M_{0}, M_{1}$, and $M_{2}$ starting in January 1872 are from Metcalf, Redish, and Shearer (1996), and they have been extended as follows. As for $M_{0}$, we use the series from Metcalf et al. (1996) until December 1954. Then, starting from January 1955, we use the series labelled as 'Monetary base (notes and coins in circulation, chartered bank and other Canadian Payments Association members' deposits with the Bank of Canada) (x 1,000,000)' from Statistics Canada. As for $M_{2}$, we use the series from Metcalf et al. (1996) until December 1967. Then, starting from January 1968, we use the series labelled as 'M2 (net) (currency outside banks, chartered bank demand and notice deposits, chartered bank personal term deposits, adjustments to M2 (net), v37198' from Statistics Canada. Finally, as for $M_{1}$, we use the series from Metcalf et al. (1996) until December 1952; after that, we link it via splicing to the series labelled as 'Currency and demand deposits, $M_{1}$ (x 1,000,000), v37213' until November 1981 from Statistics Canada; finally, from December 1981 until December 2006, we use the series from Statistics Canada labelled as ' $M_{1}$ (net) (currency outside banks, chartered bank demand deposits, adjustments to $M_{1}$ (continuity adjustments 
and inter-bank demand deposits) (x 1,000,000), v37200'. An important point to stress is that over the periods of overlapping, the three series are near-identical (up to a scale factor), which justifies their linking. On the other hand, for the period after December 2006 we were not able to find an $M_{1}$ series which could be reliably linked to the one we use for the period December 1981-December 2006 (over the last several decades, Canada's monetary aggregates have undergone a number of redefinitions, which complicates the task of constructing consistent long-run series for either of them). As a result, for the most recent period we have decided to consider another series which we consider in isolation (that is: without linking it to any other $M_{1}$ aggregate). The series is 'M1B (gross) (currency outside banks, chartered bank chequable deposits, less inter-bank chequable deposits) (x 1,000,000), v41552787', which is available since January 1967 from Statistics Canada. Finally, we convert the monthly series to the annual frequency by taking simple annual averages.

\section{B.6 Chile}

Annual series for nominal GDP, the GDP deflator, $M_{1}$, and $M_{2}$ are from Braun-Llona, Braun-Llona, Briones, Diaz, Luders, and Wagner (1998) for the period 1940-1995. As for the period 1996-2012 they are from the Banco Central de Chile, Chile's central bank (specifically, nominal GDP and the GDP deflator are from the Banco Central's Anuarios de Cuentas Nacionales, whereas $M_{1}$ and $M_{2}$ are from Banco Central's Base Monetaria y Agregados Monetarios Privados. A short-term nominal interest rate ('1-day interbank interest rate, financial system average (annual percentage)') from the Banco Central de Chile is available for the period 1940-1995. In order to extend our analysis to the present as much as possible, we therefore also consider, as an alternative measure of the opportunity cost of money, GDP deflator inflation.

\section{B.7 Colombia}

Data for Colombia have been kindly provided by David Perez Reyna. Annual series for nominal GDP, the monetary base, and a short term nominal interest rate for the period 1905-2003 are from Junguito and Rincón (2007). As for the period 2004-2012, they are from Colombia's Ministerio de Hacienda y Credito Publico. Annual series for the monetary base, $M_{1}$, and $M_{3}$ for the period 1905-2012 are from the Banco de la Republica, Colombia's central bank.

\section{B.8 Denmark}

Long-run data for Denmark have been kindly provided by Kim Abildgren of Danmarks Nationalbank (the Danish Central Bank, henceforth, DNB). A series for nominal GDP (million kroner, current prices) is available for the period 1856-2012. A series for the $D N B$ 's lending rate (per cent per annum) is available for the period 1819-2012. A 
quarterly series for $M_{2}$ is available for the period 1923Q1-2011Q4, and it has been converted to the annual frequency by taking annual averages. An annual series for $M_{1}$ for the period 1875-2012 has been constructed as follows. From the financial balance sheets of the central bank, of the central government, and of private commercial and savings banks (all available for the period 1875-2005), we have extracted three series for central bank currency, Treasury currency, and deposits at private commercial and savings banks. The $M_{1}$ aggregate has been constructed as the simple sum of the three series. It is to be noticed that the series for deposits at private commercial and savings banks also includes long-term deposits, and may therefore not be exactly comparable to the other $M_{1}$ series we use in this paper. Unfortunately, there is no way to eliminate this problem, because the financial balance sheets of private commercial and savings banks do not possess an extent of disaggregation sufficient to allow us to uniquely focus on short-term deposits. We have performed two checks on the reliability of the $M_{1}$ aggregate we have constructed. First, we have compared it to the $M_{1}$ series from the OECD's Main Economic Indicators, which is available since 1970. Over the period of overlapping, the evolution of the two $M_{1}$ aggregates is very similar. Second, we have compared it to the annual $M_{1}$ series we constructed by taking annual averages of the monthly $M_{1}$ series from the $D N B$ 's website ('DNM1KOR'), which is available for the period January 1991-October 2013. Once again, over the period of overlapping the evolution of the two $M_{1}$ aggregates is very similar, which provides some reassurance on the reliability of our long-run reconstructed series. Finally, we have linked the long-run reconstructed series to the $D N B$ 's one (available since 1991) by splicing.

\section{B.9 Finland}

Long-run monthly data for $M_{1}$ for the period January 1866-December 1985 have been generously provided by Tarmo Haavisto. The data come from his Ph.D. dissertation (see Haavisto (1992)), and have been converted to the annual frequency by taking simple annual averages. A series for Bank of Finland's monetary policy rate (labelled as the 'Base rate'), available since January 1867, is from Suomen Pankki Finlands Bank, i.e., Finland's central bank (henceforth, Suomen Pankki). To be precise, Suomen Pankki does not provides the actual time series for the base rate, but rather the dates at which the rate had been changed (starting from January $1^{\text {st }}, 1867$ ), together with the new value of the base rate prevailing starting from that date. Based on this information, we constructed a daily series for the base rate starting on January $1^{\text {st }}, 1867$ via a straightforward MATLAB program, and we then converted the series to the annual frequency ba taking annual averages. Finally, annual series for nominal GDP, real GDP, and the GDP deflator, available since 1860, are from Finland's Historical Statistics, which are available from the web page of Statistics Finland, which is Finland's national statistical agency. (To be precise, from the homepage of Statistics Finland, look at Home $>$ Statistics $>$ National Accounts $>$ Annual national accounts 
$>$ Tables.) Specifically, the nominal GDP series is B1GMHT ('Gross domestic product at current prices, 1860-1960, million. mk').

\section{B.10 France}

Annual series for nominal GDP, nominal $M_{1}$, and the short rate are all from SaintMarc (1983). Specifically, the series for nominal GDP is the Toutain Index from Annexe I: Revenu national, Produit Interieur Brut, pages 99-100 of Saint Marc (1983), and it is available for the period 1815-1913. The series for $M_{1}$ is from the table 'VitesseRevenu, Vy, et taux de liquidite, TL', pages 74-75 of Saint Marc (1983), and it is available for the period 1807-1913. The series for the short rate is from Section 7, 'Evaluation des taux de l'interet', pages 93-96, of Saint Marc (1983), and it is available for the period 1807-1913. In our analysis, however, we focus on the period 1851-1913 because for the entire period 1820-1851 the short rate had been fixed at 4 per cent.

\section{B.11 Germany}

\section{B.11.1 Germany under the Gold Standard}

An annual series for nominal GDP for the period 1876-1913 is from the RW dataset. An annual series for $M_{1}$ for the period 1876-1923 has been reconstructed based on the disaggregated monetary data reported in the Bundesbank publication Bundesbank (1976), which has been kindly provided by Martin Mandler of the Bundesbank. An annual series for the central bank's monetary policy rate is from the NBER Historical Database. Specifically, the series is the 'Official Bank Discount Rate for Germany' (acronym is M13015DEM156NNBR).

\section{B.11.2 West Germany}

Although data for post-WWII Germany are available, in principle, for the entire period 1950-1998, in the empirical work we have decided to only use data for West Germany for the period 1960-1989. The reason is that we are skeptical about the possibility of meaningfully linking the various series for nominal GDP in order to create a single series for the period 1950-1998, because $(i)$ before 1960, GDP data did not include West Berlin and the Saarland, which, in 1960, jointly accounted for about $6 \%$ of overall GDP; and $(i i)$ the reunification of 1990 created discontinuities in both GDP and $M_{1}$ (we thought the problem could be side-stepped by focusing on $M_{1}$ velocity, but in fact this series also seems to exhibit a discontinuity around the time of reunification). Entering into details, an annual series for the Bundesbank's monetary policy rate for the period 1949-1998 has been constructed by taking annual averages of the monthly series 'BBK01.SU0112, Diskontsatz der Deutschen Bundesbank / Stand am Monatsende, \% p.a.', which is available from the Bundesbank's website. As for nominal GDP, the original annual series are from Germany's Federal Statistical 
Office, and they are available for the period 1950-1960 ('Gross domestic product at current prices, Former Territory of the Federal Republic excluding Berlin-West and Saarland'); 1960-1970 ('Gross domestic product at current prices, Former Territory of the Federal Republic'); and 1970-1991 ('Gross domestic product at current prices, Former Territory of the Federal Republic, (results of the revision 2005)'). There is also a fourth series available for reunified Germany, but, as we already mentioned, it cannot be meaningfully linked to the series for the period 1970-1991 because of the discontinuity induced by the 1990 reunification. The second and third series can be linked because the difference between them is uniquely due to changes in the accounting system, rather than to territorial redefinitions. Linking the first and second series, on the other hand, is problematic because, as previously mentioned, before 1960 GDP data did not include West Berlin and the Saarland. Our decision has been to ignore the first GDP series, and therefore to start the sample in 1960, for the following two reasons. First, the dimension of West Berlin and the Saarland was not negligible. The value taken by nominal GDP in 1960 according to the first and second series was equal to 146.04 and 154.77, respectively, a difference equal to 6 per cent. Second, this problem might be ignored if we had good reasons to assume that, during those years, West Berlin and the Saarland's nominal GDP was growing exactly at the same rate as in the rest of Germany. This, however, is pretty much a heroic assumptionespecially for West Berlin. As a result, in the end we just decided to ignore the first series. Finally, turning to $M_{1}$, this turned out to be the single most excruciating piece of data collection in the entire enterprise (it took about one day and a half). German $M_{1}$ data, which are available at the monthly frequency since 1948, can only be recovered from the Bundesbank's original Monthly Reports, which are available in scanned form at the Bundesbank's website. So what we did is the following. We downloaded the scanned PDFs of the Monthly Reports, and we manually inputted the data in Excel, one 'chunk' (that is: one Monthly Report) at a time. An important point to notice is that as it is in (e.g.) the U.S., German monetary aggregates are not revised, so that it is indeed possible to link the figures coming from successive issues of the Monthly Report. With a few exceptions in the 1940 and early 1950s, each report contains about one year-one year and a half of data. There are a few discontinuities in the series, but other than that, the overlapping portions coming from successive issues are identical (over the entire sample we noticed about 4-5 exceptions, which means that those months were revised, and in those cases we took the values coming from the most recent Monthly Report). The discontinuities were just level shifts: we checked the log-differences of the two series pertaining to each discontinuity, and they were near-identical. So in the end we linked the various pieces coming from the different issues of the Monthly Report, thus obtaining a single monthly series for the period up to December 1998. Finally, we converted the series to the annual frequency by taking annual averages. 


\section{B.12 Guatemala}

All of the data are from the Banco de Guatemala's website. A series for nominal GDP is available for the period 1950-2012. A series for $M_{1}$ ('M1 Medio CirculanteMillones de quetzales') is available for the period 1980-2014. A series for a nominal short rate ('Interest rate $1 /$ Domestic currency, passive') is available for the period 1980-2013.

\section{B.13 Hong Kong}

An annual series for nominal GDP for the period 1961-2012 is from the Hong Kong Monetary Authority's (henceforth, HKMA) website (the series is labelled as 'Nominal GDP, HK\$ million, Table031: GDP and its main expenditure components at current market prices'). An annual series for $M_{1}$ for the period 1985-2014 is from the HKMA's website (the series is labelled as ' $M_{1}$, Total,l HK\$'). An annual series for the $M_{1}$ for the period 1982-2014 is from the HKMA's website (the series is labelled as 'Overnight rate, Table 6.3 : Hong Kong Interbank Offered Rates').

\section{B.14 Japan}

Sources for Japanese data are as follows. A monthly series for the Bank of Japan's (henceforth, BoJ) discount rate, available since January 1883, is from the BoJ's longrun historical statistics, which are available at its website (the series is labelled as: 'BJ'MADR1M: The Basic Discount Rate and Basic Loan Rate'). Annual series for nominal GNP and $M_{1}$ for the period 1885-1940 are from Table 48 of Tamaki (1995). As for the period since 1955 , data for nominal GDP and $M_{1}$ are as follows. Series for nominal and real GDP, and the GDP deflator, are from the Economic and Social Research Institute (henceforth, ESRI), Cabinet Office, Government of Japan. (The key internet links are: http://www.stat.go.jp/english/data/chouki/03.htm and http://www.stat.go.jp/english/data/nenkan/1431-03.htm) An important point to stress here is the following. For the period before 1970, ESRI only provides tables for gross domestic expenditure, rather than gross domestic product. However, over the period of overlapping (that is: 1970-1998), the relevant series coming from Table 3-1 ('Gross Domestic Expenditure (At Current Prices, At Constant Prices, Deflators) 68SNA, Benchmark year = 1990 (C.Y.1955-1998, F.Y.1955-1998), Value in billions of yen') and Table 3-3b ('3-3-b Gross Domestic Product Classified by Economic Activities (Medium Industry Group), (At Current Prices, At Constant Prices, Deflators) - 68SNA, Benchmark year = 1990 (1970-1998), Value in billions of yen') are either numerically identical (in the case of nominal GDP), or numerically identical up to a scale factor (for the other two series). This means that - as it should be expected based on just simple economic logic - the series which in Table 3-1 is labelled as 'Gross Domestic Expenditure' (Column Y in the Excel spreadsheet 03-01.xls) is, in fact, nominal gross domestic product, and the same holds for its real counterpart and 
the deflator. As for $M_{1}$, a monthly series for the period January 1955-December 2014 was constructed by linking, via splicing, the following thre series from the BoJ's website: MA'MAMS1EN01 ('(discontinued)_M1/Amounts Outstanding at End of Period/(Reference) Money Stock (Based on excluding Foreign Banks in Japan, etc., through March 1999)'); MA'MAMS3EN01 ('(discontinued)_M1/Amounts Outstanding at End of Period /(Reference) Money Stock (from April 1998 to March 2008)'); and MA'MAM1NEM3M1MO ('M1/Amounts Outstanding at End of Period/Money Stock'). An important point to stress is that, over the periods of overlapping, the series are essentially identical (up to a scale factor), which justifies their linking. Finally, the resulting monthly $M_{1}$ series was converted to the annual frequency by taking annual averages.

\section{B.15 Korea}

A series for $M_{1}$ (' $M_{1}$, Narrow Money, Average, Bil.Won') is available since 1970 from the website of the Central Bank of Korea (henceforth, BOK). A series for nominal GDP ('Gross domestic product, current prices, Bil.Won') is available since 1953, again from the $B O K$ 's website. A series for the central bank's discount rate ('Republic of Korea, Interest Rates, Discount Rate, Percent per Annum') is available since 1948 from the IMF's IFS.

\section{B.16 Israel}

Series for nominal and real GDP, available for the period 1950-2013, are from Israel's Central Bureau of Statistics (henceforth, $C B S$; special thanks to Svetlana Amuchvari of the $C B S$ for help with the data). Specifically, starting from 1995, the data are from Table 17 of the 'National Accounts, 1995-2013'. For the period 1950-1994, they are from the $C B S$ 's Statistical Abstract of Israel (see columns D and J of Table 6.1, 'National Income and Expenditure: Resources and Uses of Resources'). The GDP deflator has been computed as the ratio between the two series. An annual CPI inflation series ('Change in Level of Price Indices, Percentages, Annual, average'), available since 1971, is from the $C B S$ ' website (specifically, the series is from Table 13.1 of Statistical Abstract of Israel). For the period 1966-1975 the series for $M_{1}$ is from Table 4.6, page 120, of Barkai and Liviatan (2007). For the period since April 1981, a monthly $M_{1}$ series is from the Bank of Israel's website (special thanks to Aviel Shpitalnik of the Bank of Israel for help with the data). The series is M1.M ('M1 = Money supply, Monthly (M), NIS, million, Current prices'), and it has been converted to the annual frequency ba taking annual averages. A short-term interest rate for the period 1966-1974 is the 'Nominal rate of return on MAKAM (3-month bills)' from Table 4.9, page 129, of Barkai and Liviatan (2007). Since 1989 it is the Bank of Israel's 'Actual effective rate of interest', from the Bank of Israel's website. For the period 1983-1988 we use the 'Discount Rate' from the IMF's IFS. Over the 
period of overlapping (i.e., since 1989) the Bank of Israel's actual effective rate of interest and the discount rate from the $I M F$ are virtually identical, which justifies their linking.

\section{B.17 Italy}

Series for nominal GDP at current market prices, real GDP in chained 2005 Euros, and the implied GDP deflator, all available for the period 1861-2010, are from the sheet 'Tab_03' in the Excel spreadsheet 'Data_Na150-1.1.xls', which is available at the Banca d'Italia's website at: http://www.bancaditalia.it/statistiche/tematiche/statstoriche/index.html. The spreadsheet contains the estimates of the Italian National Accounts' aggregates which are extensively discussed in Baffigi (2011). A series for $M_{0}$, available for the period 1947-1993, respectively, is from the Rolnick-Weber dataset. A series for $M_{1}$, available for the period 1861-1991, is from the Data Appendix, pp. 49-52 of Fratianni and Spinelli (1997). Series for $M_{1}$ and $M_{2}$, available for the period 1948-1998 are from the table 'Componenti della moneta dal 1948 al 1998' of BancadItalia (2013). In our analysis we use the $M_{1}$ series from Fratianni and Spinelli (1997) for the Gold Standard period, and the one from Banca d'Italia for the post-WWII period (over the period of overlapping, however, the two series are very similar, so that in practice this choice does not entail material implications). Shortand long-term interest rates for the period 1861-1996 are from Muscatelli and Spinelli (2000). A series for the 'Tasso Ufficiale di Sconto' - that is: Banca d'Italia's official discount rate - is from the tables 'Tassi d'interesse delle principali operazioni della banca centrale' and 'Variazione dei tassi ufficiali della Banca d'Italia, 1936-2003' of BancadItalia (2013).

\section{B.18 Mexico}

A monthly interest rates series for the period January 1978-present is from the Banco de Mexico's 'Indicadores de tasas de interes de Valores Publicos' (Banco de Mexico, henceforth $B d M$, is Mexico's central bank). It has been converted to the annual frequency by taking annual averages. Two annual interest rates series ('Interest Rate (\%) Commercial loans' and 'Interest Rate (\%), Official discount rate', respectively) are from Table 83, pages 639-640, of Homer and Sylla (2005). The first series is available for the periods 1942-1963 and 1978-1989. The second is available for the period 1936-1978. Annual series for $M_{0}, M_{1}$, and $M_{2}$ for the period 1925-2014 are from the Instituto Nacional de Estadistica y Geografia (Mexico's national statistical agency, henceforth INEGI), 'Estadisticas Historicas de Mexico, 2014', whereas for the period 1985-2014 they are from the $B d M$ 's website. The series from the $B d M$ are available at the monthly frequency, and we converted them to the annual frequency by taking annual averages. Annual series for nominal GDP are from INEGI, 'Estadisticas Historicas de Mexico 2014', for the period 1925-1970; from the IMF's IFS for the period 
1970-1988; from $B d M$ for the period 1988-2004; and from INEGI for the period 20042013. The four series have been linked via splicing. An annual CPI inflation series available since 1949 is from the IMF's IFS ('Mexico, Consumer Prices, All items, Percent Change over Corresponding Period of Previous Year').

\section{B.19 Morocco}

A monthly seasonally unadjusted series for $M_{1}$, available since January 1985 , is from the website of Bank Al-Maghrib (the Central Bank of Morocco, henceforth, BAM). The annual series has been computed by taking simple annual averages of the original monthly data. An annual series for nominal GDP, available for the period 19802010, is from the 'Comptes Nationaux' (National Accounts) from the website of the High Commission for Planning of Morocco. A series for the minimum rate applied to notebook accounts, available since January 1983, is from the website of $B A M$. BAM sets the interest rate two times a year, on January 1, and on July 1 . The table at the central bank's website reports the values for the interest rate which have been set every January 1 and July 1 starting from 1983. From this information we computed the annual average rates by taking a simple average within the year.

\section{B.20 Netherlands}

A series for the discount rate of De Nederlandsche Bank (the Dutch central bank, henceforth, $D N B$ ) for the period 1900-1992 is from Table 65 of Homer and Sylla (2005) until 1989, and from DNB's website after that. Series for nominal and real Net National Income (NNI), and for the NNI deflator, for the period 1900-1992 are from Table 1, pages 94-95 of Boeschoten (1992). A series for $M_{2}$, available for the period 1900-1992, is from the Rolnick-Weber dataset. A series for $M_{1}$, available since 1864, has been constructed by linking the series from deJong (1967) and one from $D N B$.

\section{B.21 New Zealand}

A series for $M_{1}$, available since 1934, is from the Reserve Bank of New Zealand (henceforth, RBNZ). A series for nominal GDP in millions of Australian dollars is from Statistics New Zealand. A series for a short-term nominal interest rate starting in 1934 has been constructed in the following way. Homer and Sylla's (2005) Table 79 contains a series for the RBNZ's official discount rate for the period 1934-1989. Since 1999 , the $R B N Z$ has been using, as its monetary policy rate, the 'Official Cash Rate', which is available from the $R B N Z$ 's website. Since these two short-term rates have been used by the $R B N Z$ as its official monetary policy rate for the periods 19341989 and 1999-present, respectively, they are in fact conceptually the same, and can therefore be linked. For the period in-between (1990-1998), for which no monetary 
policy rate is available, we have used the 'Overnight Interbank Cash Rate' from the $R B N Z$. The rationale for doing so is that since 1999 , this rate has been very close to the Official Cash Rate, which justifies the linking of the two series.

\section{B.22 Norway}

A series for $M_{1}$, available since 1919, and two series for $M_{0}$ and $M_{2}$, available since 1819, are from the Historical Statistics of Norges Bank (Norway's central bank), which are available at its website. Specifically, all historical statistics for Norway's monetary aggregates are from Klovland (2004). Series for nominal GDP and the GDP deflator; and for real GDP, real private consumption expenditures, and real gross investments (in millions of 2005 NOKs), all available since 1830, are from Norges Bank's Historical Statistics (for all series the period 1940-1945 is missing). As for the short-term nominal interest rate, ideally we would have liked to use Norges Bank's discount rate. The problem with this is that, although the discount rate is available (from Norges Bank's website) since 1819, it has missing observations for the period 1987-1990. As a result, we have resorted to using the Average Deposit Rate (again, from Norges Bank's website), which is available since 1822, it has no missing observations, and over the period which is analyzed herein has been quite close to the discount rate.

\section{B.23 Portugal}

An annual series for $M_{1}$ for the period 1854-1998 is from Table 5 of Mata and Valerio (2011). Annual series for real and nominal GDP for the period 1868-2008 are from Table 4 of Mata and Valerio (2011). A series for the official discount rate of the Banco de Portugal (the Portuguese central bank), available for the period 1930-1989, is from Table 74 of Homer and Sylla (2005). Series for the consumer price index, $M_{0}$, and $M_{2}$ for the period 1932-1989 are from the Rolnick-Weber dataset.

\section{B.24 South Africa}

All of the data for South Africa are from the website of its central bank, the South African Reserve Bank (SARB). Specifically, a series for the 'Bank rate' ('Lowest rediscount rate at $S A R B$ '; code is $\mathrm{KBP} 1401 \mathrm{M}$ ) is available since 1923 . A series for $M_{1}$ ('Monetary aggregates / Money supply: M1, R millions'; code is KBP1371J) is available since 1967. A series for nominal GDP ('Gross domestic product at market prices, R millions'; code is KBP6006J) is available since 1946.

\section{B.25 Spain}

Annual series for $M_{0}$ and $M_{2}$ for the period 1874-1980 are from the RW dataset (the years 1936-1940 are missing). An annual series for $M_{1}$ for the period $1865-1998$ is 
from Cuadro 9.16 'Agregados Monetarios, 1865-1998' of Barciela-López, Carreras, and Tafunell (2005), pp. 697-699 (the series is labelled as 'M1, datos a fin de ano, en millones de pesetas'; the years 1936-1940 are missing). An annual series for nominal GDP for the period 1850-2000 is from Cuadro 17.7 of Barciela-López, Carreras, and Tafunell (2005), pp. 1338-1340 (the series is labelled as 'El PIB a precios corrientes, 1850-2000, millones de pesetas'; PIB is the Spanish acronym of GDP). An annual series for the 'Descuento comercial' of the Banco de Espana (Spain's central bank, henceforth, $B d E$ ) is from Cuadro 9.17 of Barciela-López, Carreras, and Tafunell (2005), pp. 699-701. The series is available for the periods 1874-1914, 1920-1935, and 1942-1985. An annual series for the official discount rate of the $B d E$, available for the period 1930-1989, is from Table 74, pp. 541-542, of Homer and Sylla (2005). A monthly series for the 3-month Treasury bill rate available since March 1988 ('Tipo de interese hasta 3 meses. Conjunto del mercado. Op. simples al contado. Letras del Tesoro.'), is from the BdE's website, and it has been converted to the annual frequency by taking annual averages (the data for 1988 have been ignored, since the series starts in March of that year).

\section{B.26 Switzerland}

Annual series for the consumer price index, $M_{0}, M_{1}$ (based on the 1995 definition), $M_{3}$ (based on the 1995 definition), and the Swiss National Bank's (henceforth, SNB) official discount rate, all available at least since 1929, are from the $S N B$ 's website. Specifically, the series for $M_{0}, M_{1}$, and $M_{3}$ from the $S N B$ 's Historical Statistics, which are available up until 2006, have been extended up to 2014 by applying the annual growth rates of the corresponding monetary aggregate from the SNB's Monthly Statistical Bulletin of July 2015 (see section 'Monetary base and liquidity, B2 Monetary aggregates M1, M2 and M3, Level (annually)'. The series for the discount rate is available up until 2007. An annual series for nominal GDP available for the period 1948-2005 is from the website of the project Economic history of Switzerland during the 20th century - see at: http://www.fsw.uzh.ch/histstat/main.php. (Q.16b Gross domestic product (expenditure approach) in real 1990 prices and nominal, 1948-2005 in Million Swiss Francs).

\section{B.27 Taiwan}

All of the data are from the Central Bank of the Republic of China (Taiwan), i.e., Taiwan's central bank (henceforth $C B R C T$ ). An annual series for nominal GDP ('GDP by expenditures at current prices') is available for the period 1951-2013. An annual series for the $C B R C T$ 's discount rate is available for the period 1962-2014. Two annual series for $M_{1}$ ('M1A (End of Period), M1A = Currency in circulation(currency held by the public)+Checking accounts and passbook deposits of enterprises, individuals and non-profit organizations held in banks and community financial institutions' 
and 'M1B (End of Period), M1B = M1A + Passbook savings deposits of Individuals and non-profit organizations in banks and community financial institutions') are both available for the period 1962-2014. In order to be sure that the series we use in this paper does not include components which go beyond a transaction purpose, we used the first one, M1A.

\section{B.28 Turkey}

A monthly series for $M_{1}$, available since January 1964, is from the website of the Turkey's central bank, Turkiye Cumhuriyet Merkez Bankasi (henceforth, TCMB). The annual series used in the paper has been constructed by taking simple annual averages of the original monthly data. A series for the central bank's discount rate is from Homer and Sylla's (2005) Table 74, pages 541-542, until 1990. After that, it is from $T C M B$. Specifically, TCMB's website reports the dates in which the discount rate was changed, together with the new values taken by the discount rate at each date. Based on this information, for each year since 1990 we have calculated the number of days in the year for which each value of the discount rate has been in effect, and based on this we have computed, for every year, a simple weighted average of the individual values of the discount rate. A series for the Gross Domestic Product in current prices, available since 1967, is from the website of TurkStat (Turkey's statistical office).

\section{B.29 United Kingdom}

All of the U.K. data are from version 2.2 of the Bank of England's dataset of longrun historical statistics, which is available from the Bank of England's website. The Excel spreadsheet, called threecenturies_v2.2.xlsx (henceforth, TC), was dowloaded on August 5, 2015. The first version of the dataset was discussed in detail in Hills and Dimsdale (2010). A series for $M_{0}$ for the period 1870-present is from column $\mathrm{N}$ of sheet 12 of TC. A series for $M_{3}$ for the period 1870-1969 is from column $\mathrm{S}$ of sheet 12 of TC (the series is originally from Capie and Webber (1985)). A series for $M_{4}$ for the period 1963-present is from column $\mathrm{Z}$ of sheet 12 of TC. A series for $M_{1}$ for the period 1922-present has been constructed in the following way. For the period 1922-1969, we take annual averages of Capie and Webber's (1985) monthly $M_{1}$ series, which is in column G of sheet 29 of TC. As for the period 1969-present, we take annual averages of the quarterly aggregate 'Non-interest bearing $M_{1}$ ' from column $\mathrm{F}$ of sheet 30 of TC. Finally, we link the resulting two annual series by splicing. A series for the Bank of England's monetary policy rate (known as the 'Bank Rate') available since 1694 is from column B of sheet 15 of TC. A series for a long-term interest rate (the 'Consol yield') is from sheet 15 of TC. A series for real GDP ('Chained composite measure of GDP at market prices. Chained volume measure £mn, reference year $2011^{\prime}$ ) available since 1700 is from column D of sheet 2 of TC, whereas the corresponding series for 
nominal GDP ('Composite estimate of UK nominal GDP at market prices £mn') is from from column D of sheet 3. A series for real consumption ('Real consumption, Chained Volume measure, £mn, 2011 prices') is from sheet 2 of TC.

\section{B.30 United States}

The series for the 3-month Treasury Bill rate, nominal GDP, and both the 'standard' $M_{1}$ aggregate and the 'New $M_{1}$ ' one, all available for the period 1915-2008, are from Lucas and Nicolini (2015). All series have been updated based on either series' updated original data sources. The original source for the 3-month Treasury Bill rate is the Economic Report of the President (henceforth, ERP), whereas the ones for nominal GDP are Kuznets and Kendrick's Table Ca184-191 before 1929, and Table 1.1.5 of the National Income and Product Accounts (henceforth, NIPA) after that. The series for the St. Louis adjusted monetary base (the acronym is $A M B S L$ ), available since 1918, is from FRED II, at the St. Louis FED's website. A series for $M_{2}$, and a discontinued series for $M_{3}$, available since 1959, and for the period 19592005, respectively, are from FRED II (acronyms are M2SL and M3SL, respectively). A series for $M_{2}$ available for the period 1878-2003 is from the RW dataset. Annual series for nominal GDP at current prices, real GDP in millions of 2009 dollars, and the GDP deflator (Index: 2009=100) are from Officer and Williamson (2015).

\section{B.31 Venezuela}

Annual data for nominal GDP ('Producto Interno Bruto, Millones de Bolívares a Precios Corrientes'), $M_{1}$ ('Circulante, (M1), I.1, Circulante, Liquidez Monetaria y Liquidez Ampliada, Saldos al final de cada período en millones de bolívares'), and a short-term rate ('Tasas de Interes Activas Anuales Nominales Promedio, Ponderadas de los Bancos Comerciales y Universales, Porcentajes') are from the Banco Central de Venezuela. GDP is available for the period 1957-2007. $M_{1}$ is available for the period 1940-2014. The interest rate is available for the period 1962-1999. An alternative monthly interest series, available since July 1997 ('Tasa de Interés Aplicable al Cálculo de los Intereses Sobre Prestaciones Sociales (Porcentajes)') has been converted to the annual frequency by taking averages within the year. It has been used for the scatterplot in Figure 1, but it cannot be linked to the other interest rate series as, over the period of overlapping, the two series are different. 